\title{
One-Pot Synthesis of Chiral, Spirocyclic 4-Hydantoin-Proline Derivatives for Incorporation into Spiroligomer-Based Macromolecules
}

\author{
JD Northrup, Claire R. Purcell, Christian E. Schafmeister* \\ Department of Chemistry, Temple University, Philadelphia, Pennsylvania 19122, \\ United States \\ *meister@temple.edu
}

\begin{tabular}{|c|c|c|}
\hline $1-4$ & Table of contents & \\
\hline 5 & Chemdraw for compounds $2 a-17 a, 11 b-16 b$ & \\
\hline 6 & Chemdraw for compounds $18 a-31 a, 17 b-29 b$ & \\
\hline 7 & ${ }^{1} \mathrm{H}$ NMR for compound & $2 a$ \\
\hline 8 & ${ }^{13} \mathrm{C}$ NMR for compound & $2 a$ \\
\hline 9 & HPLC Chromatogram for compound & 2b \\
\hline 10 & ${ }^{1} \mathrm{H}$ NMR for compound & $2 b$ \\
\hline 11 & ${ }^{13} \mathrm{C}$ NMR for compound & $2 b$ \\
\hline 12 & ${ }^{1} \mathrm{H}$ NMR (RT) for compound & $3 a$ \\
\hline 13 & ${ }^{1} \mathrm{H}$ NMR $\left(65^{\circ} \mathrm{C}\right)$ for compound & $\mathbf{3 a}$ \\
\hline 14 & ${ }^{13} \mathrm{C}$ NMR for compound & $3 a$ \\
\hline 15 & HPLC Chromatogram for compound & $3 b$ \\
\hline 16 & ${ }^{1} \mathrm{H}$ NMR for compound & $3 b$ \\
\hline 17 & ${ }^{13} \mathrm{C}$ NMR for compound & $3 b$ \\
\hline 18 & ${ }^{1} \mathrm{H}$ NMR for compound & $4 a$ \\
\hline 19 & ${ }^{13} \mathrm{C}$ NMR for compound & 4a \\
\hline 20 & HPLC Chromatogram for compound & $4 b$ \\
\hline 21 & ${ }^{1} \mathrm{H}$ NMR for compound & $4 b$ \\
\hline 22 & ${ }^{13} \mathrm{C}$ NMR for compound & $4 b$ \\
\hline 23 & ${ }^{1} \mathrm{H}$ NMR for compound & $5 a$ \\
\hline 24 & ${ }^{13} \mathrm{C}$ NMR for compound & $5 a$ \\
\hline 25 & HPLC Chromatogram for compound & $5 b$ \\
\hline 26 & ${ }^{1} \mathrm{H}$ NMR for compound & $5 b$ \\
\hline 27 & ${ }^{13} \mathrm{C}$ NMR for compound & $5 b$ \\
\hline 28 & ${ }^{1} \mathrm{H}$ NMR for compound & $6 a$ \\
\hline 29 & ${ }^{13} \mathrm{C}$ NMR for compound & 6a \\
\hline 30 & HPLC Chromatogram for compound & 6b \\
\hline 31 & ${ }^{1} \mathrm{H}$ NMR for compound & 6b \\
\hline 32 & ${ }^{13} \mathrm{C}$ NMR for compound & 6b \\
\hline
\end{tabular}


${ }^{1} \mathrm{H}$ NMR for compound $7 \mathrm{a}$

${ }^{13} \mathrm{C}$ NMR for compound $\mathbf{7 a}$

HPLC Chromatogram for compound $\mathbf{7 b}$

${ }^{1} \mathrm{H}$ NMR for compound $\mathbf{7 b}$

${ }^{13} \mathrm{C}$ NMR for compound $\mathbf{7 b}$

${ }^{1} \mathrm{H}$ NMR for compound $\mathbf{8 a}$

${ }^{13} \mathrm{C}$ NMR for compound $\mathbf{8 a}$

HPLC Chromatogram for compound $\mathbf{8 b}$

${ }^{1} \mathrm{H}$ NMR for compound $\mathbf{8 b}$

${ }^{13} \mathrm{C}$ NMR for compound $\mathbf{8 b}$

${ }^{1} \mathrm{H}$ NMR for compound $9 \mathbf{9 a}$

${ }^{13} \mathrm{C}$ NMR for compound $9 \mathrm{a}$

HPLC Chromatogram for compound $\mathbf{9 b}$

${ }^{1} \mathrm{H}$ NMR for compound $9 \mathrm{~b}$

${ }^{13} \mathrm{C}$ NMR for compound $9 \mathrm{~b}$

${ }^{1} \mathrm{H}$ NMR for compound $\mathbf{1 0 a}$

${ }^{13} \mathrm{C}$ NMR for compound $10 \mathrm{a}$

HPLC Chromatogram for compound 10b

${ }^{1} \mathrm{H}$ NMR for compound $10 \mathrm{~b}$

${ }^{13} \mathrm{C}$ NMR for compound $\mathbf{1 0 b}$

${ }^{1} \mathrm{H}$ NMR for compound $11 \mathrm{a}$

${ }^{13} \mathrm{C}$ NMR for compound 11a

${ }^{1} \mathrm{H}$ NMR for compound $\mathbf{1 1 b}$

${ }^{13} \mathrm{C}$ NMR for compound $\mathbf{1 1 b}$

${ }^{1} \mathrm{H}$ NMR for compound $12 \mathrm{a}$

${ }^{13} \mathrm{C}$ NMR for compound $\mathbf{1 2 a}$

${ }^{1} \mathrm{H}$ NMR for compound $\mathbf{1 2 b}$

${ }^{13} \mathrm{C}$ NMR for compound $\mathbf{1 2 b}$

${ }^{1} \mathrm{H}$ NMR for compound $\mathbf{1 3 a}$

${ }^{13} \mathrm{C}$ NMR for compound $13 \mathbf{a}$

${ }^{1} \mathrm{H}$ NMR for compound $\mathbf{1 3 b}$

${ }^{13} \mathrm{C}$ NMR for compound $\mathbf{1 3 b}$

${ }^{1} \mathrm{H}$ NMR for compound $14 \mathrm{a}$

${ }^{13} \mathrm{C}$ NMR for compound $\mathbf{1 4 a}$

${ }^{1} \mathrm{H}$ NMR for compound $15 \mathbf{a}$

${ }^{13} \mathrm{C}$ NMR for compound $15 \mathrm{a}$ 
69

70

71

72

73

74

75

76

77

78

79

80

81

82

83

84

85

86

87

88

89

90

91

92

93

94

95

96

97

98

99

100

101

102

103

104
${ }^{1} \mathrm{H}$ NMR for compound $15 \mathrm{~b}$

${ }^{13} \mathrm{C}$ NMR for compound $\mathbf{1 5 b}$

${ }^{1} \mathrm{H}$ NMR for compound $16 \mathbf{a}$

${ }^{13} \mathrm{C}$ NMR for compound $\mathbf{1 6 a}$

${ }^{1} \mathrm{H}$ NMR for compound $\mathbf{1 6 b}$

${ }^{13} \mathrm{C}$ NMR for compound $\mathbf{1 6 b}$

${ }^{1} \mathrm{H}$ NMR for compound $17 \mathrm{a}$

${ }^{13} \mathrm{C}$ NMR for compound $\mathbf{1 7 a}$

${ }^{1} \mathrm{H}$ NMR for compound $\mathbf{1 7 b}$

${ }^{13} \mathrm{C}$ NMR for compound $17 \mathrm{~b}$

${ }^{1} \mathrm{H}$ NMR for compound $18 \mathrm{a}$

${ }^{13} \mathrm{C}$ NMR for compound $\mathbf{1 8 a}$

${ }^{1} \mathrm{H}$ NMR for compound $\mathbf{1 8 b}$

${ }^{13} \mathrm{C}$ NMR for compound $\mathbf{1 8 b}$

${ }^{1} \mathrm{H}$ NMR for compound $19 \mathrm{a}$

${ }^{13} \mathrm{C}$ NMR for compound $19 a$

${ }^{1} \mathrm{H}$ NMR for compound $20 \mathrm{a}$

${ }^{13} \mathrm{C}$ NMR for compound $20 \mathrm{a}$

${ }^{1} \mathrm{H}$ NMR for compound $\mathbf{2 1 a}$

${ }^{13} \mathrm{C}$ NMR for compound 21a

${ }^{1} \mathrm{H}$ NMR for compound $\mathbf{2 2 a}$

${ }^{13} \mathrm{C}$ NMR for compound 22a

${ }^{1} \mathrm{H}$ NMR for compound 23a

${ }^{13} \mathrm{C}$ NMR for compound $23 \mathbf{a}$

${ }^{1} \mathrm{H}$ NMR for compound $\mathbf{2 3 b}$

${ }^{13} \mathrm{C}$ NMR for compound $\mathbf{2 3 b}$

${ }^{1} \mathrm{H}$ NMR for compound $\mathbf{2 4 a}$

${ }^{13} \mathrm{C}$ NMR for compound $\mathbf{2 4 a}$

${ }^{1} \mathrm{H}$ NMR for compound 24b

${ }^{13} \mathrm{C}$ NMR for compound 24b

${ }^{1} \mathrm{H}$ NMR for compound $25 \mathrm{a}$

${ }^{13} \mathrm{C}$ NMR for compound $25 \mathrm{a}$

${ }^{1} \mathrm{H}$ NMR for compound $\mathbf{2 5 b}$

${ }^{13} \mathrm{C}$ NMR for compound $25 \mathrm{~b}$

${ }^{1} \mathrm{H}$ NMR for compound $\mathbf{2 6 a}$

${ }^{13} \mathrm{C}$ NMR for compound $\mathbf{2 6 a}$ 
105

106

107

108

109

110

111

112

113

114

115

116

117

118

119

120

121

122

123

124

125

126

127
${ }^{1} \mathrm{H}$ NMR for compound $\mathbf{2 6 b}$

${ }^{13} \mathrm{C}$ NMR for compound $\mathbf{2 6 b}$

${ }^{1} \mathrm{H}$ NMR for compound $27 \mathrm{a}$

${ }^{13} \mathrm{C}$ NMR for compound $27 \mathrm{a}$

${ }^{1} \mathrm{H}$ NMR for compound $\mathbf{2 8 a}$

${ }^{13} \mathrm{C}$ NMR for compound $\mathbf{2 8 a}$

${ }^{1} \mathrm{H}$ NMR for compound $\mathbf{2 8 b}$

${ }^{13} \mathrm{C}$ NMR for compound $\mathbf{2 8 b}$

${ }^{1} \mathrm{H}$ NMR for compound $29 \mathrm{a}$

${ }^{13} \mathrm{C}$ NMR for compound $29 \mathrm{a}$

${ }^{1} \mathrm{H}$ NMR for compound $29 \mathrm{~b}$

${ }^{13} \mathrm{C}$ NMR for compound $29 \mathrm{~b}$

${ }^{1} \mathrm{H}$ NMR for compound $\mathbf{3 0 a}$

${ }^{13} \mathrm{C}$ NMR for compound $\mathbf{3 0 a}$

${ }^{1} \mathrm{H}$ NMR for compound $\mathbf{3 1 a}$

${ }^{13} \mathrm{C}$ NMR for compound $31 \mathrm{a}$

Scheme SI 1 for Compounds 32-35

LCMS Chromatogram for compound 32

${ }^{1} \mathrm{H}$ NMR for compound 32

${ }^{13} \mathrm{C}$ NMR for compound $\mathbf{3 2}$

LCMS Chromatogram for compound 33

${ }^{1} \mathrm{H}$ NMR for compound $\mathbf{3 3}$

${ }^{13} \mathrm{C}$ NMR for compound $\mathbf{3 3}$ 
Page 5 of 127

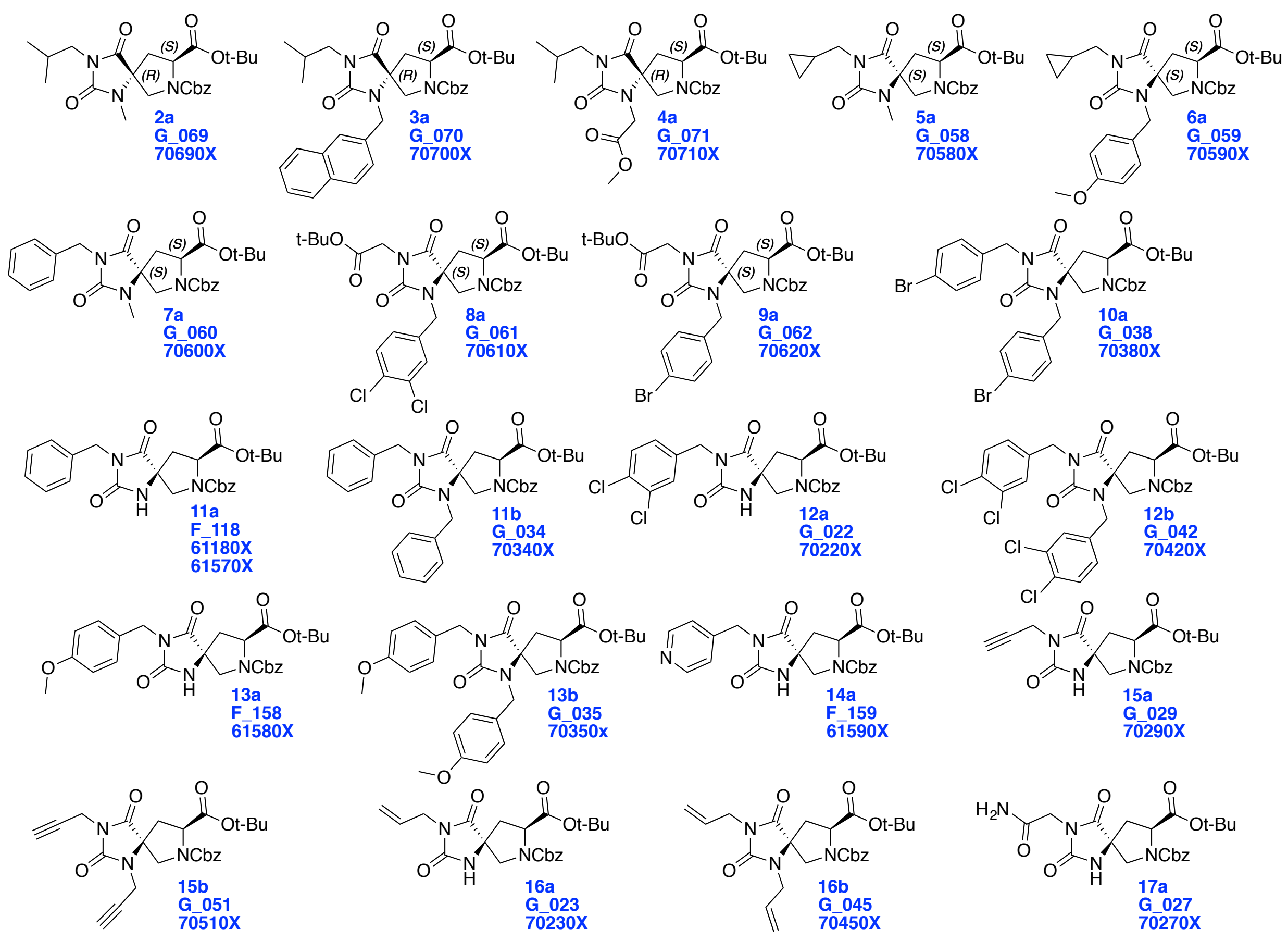


Page 6 of 127
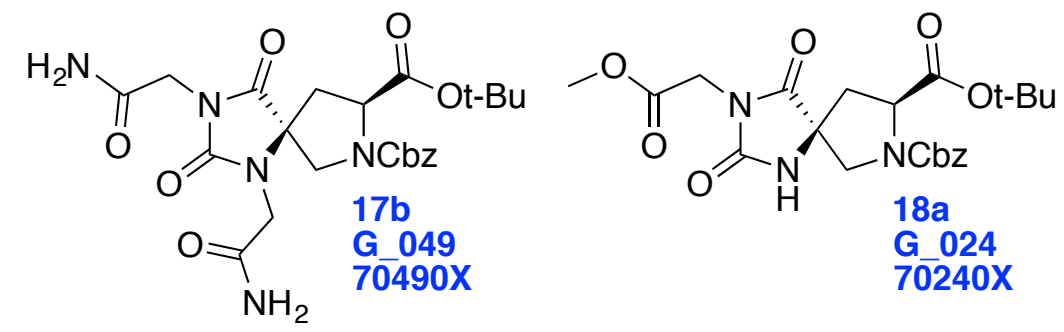

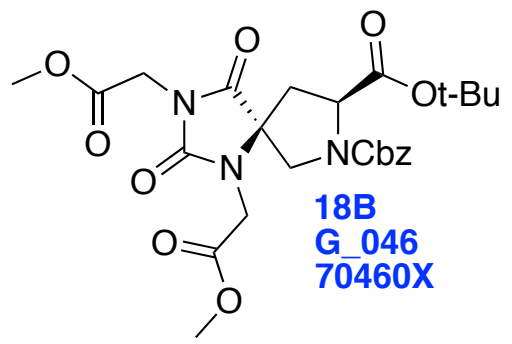<smiles>[R20][R9]([Y])([H])[O-]</smiles><smiles>[R]OC(=O)[C@@H]1C[C@@]2(CN1C(=O)OCCCC)NC(=O)N(Cc1ccc(Br)cc1)C2=O</smiles>

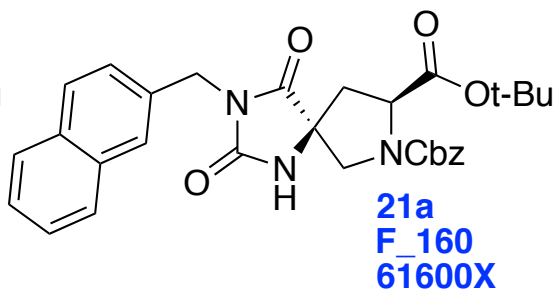

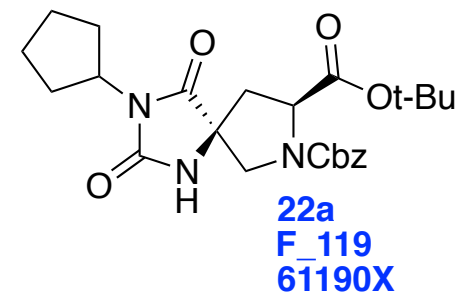

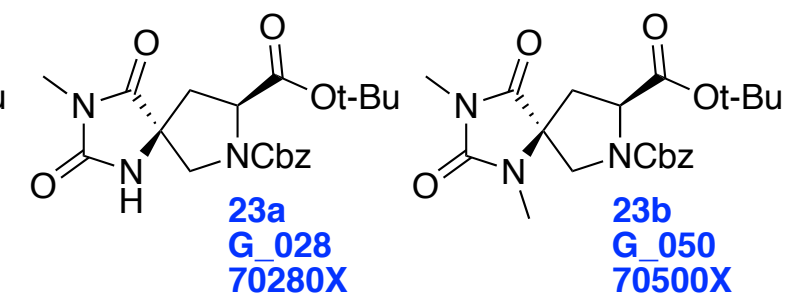<smiles>[R][R10]([Y2])([R20])F</smiles><smiles>[R20]O[R16]([Y])([R5])[H]</smiles><smiles>[R16]OC(=O)CN1C(=O)N[C@]2(C[C@H](C(=O)OCC)C(=O)N2)C1=O</smiles>

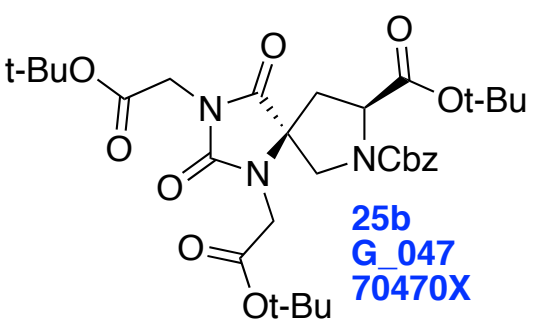<smiles>[R6]O[R6]([R20])([Y])[R6]</smiles>

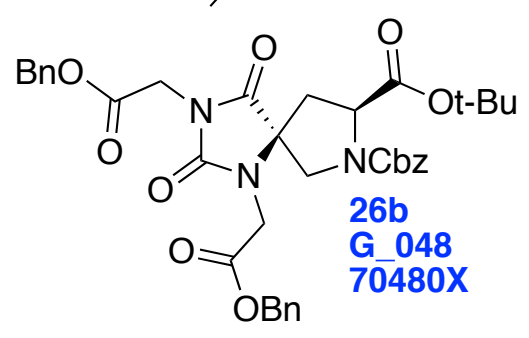

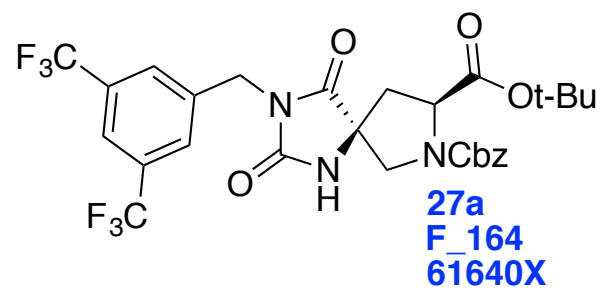<smiles>[R20][R6]([R6])([R6])F</smiles>
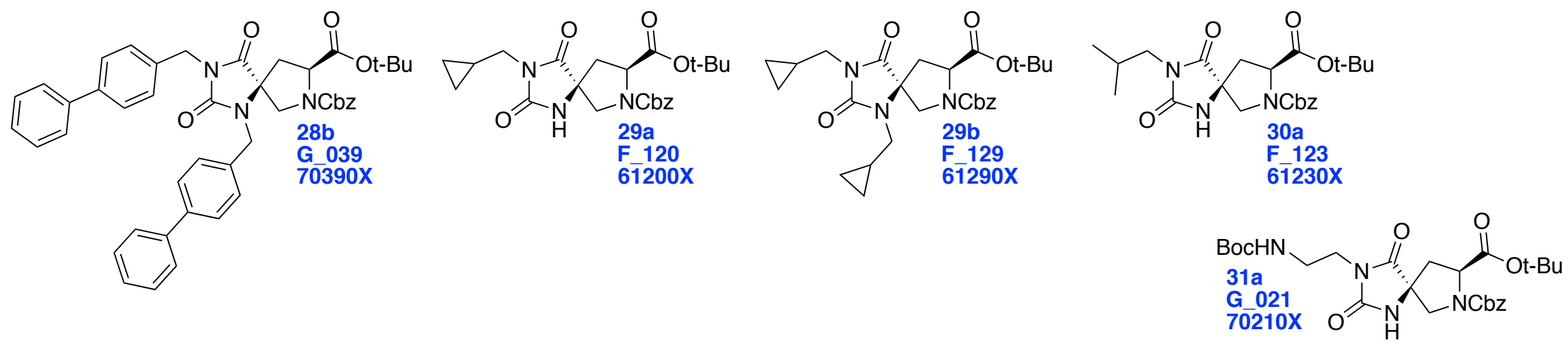
Page 7 of 127

This report was created by ACD/NMR Processor Academic Edition. For more information go to www.acdlabs.com/nmrproc/

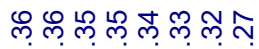

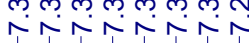

유유

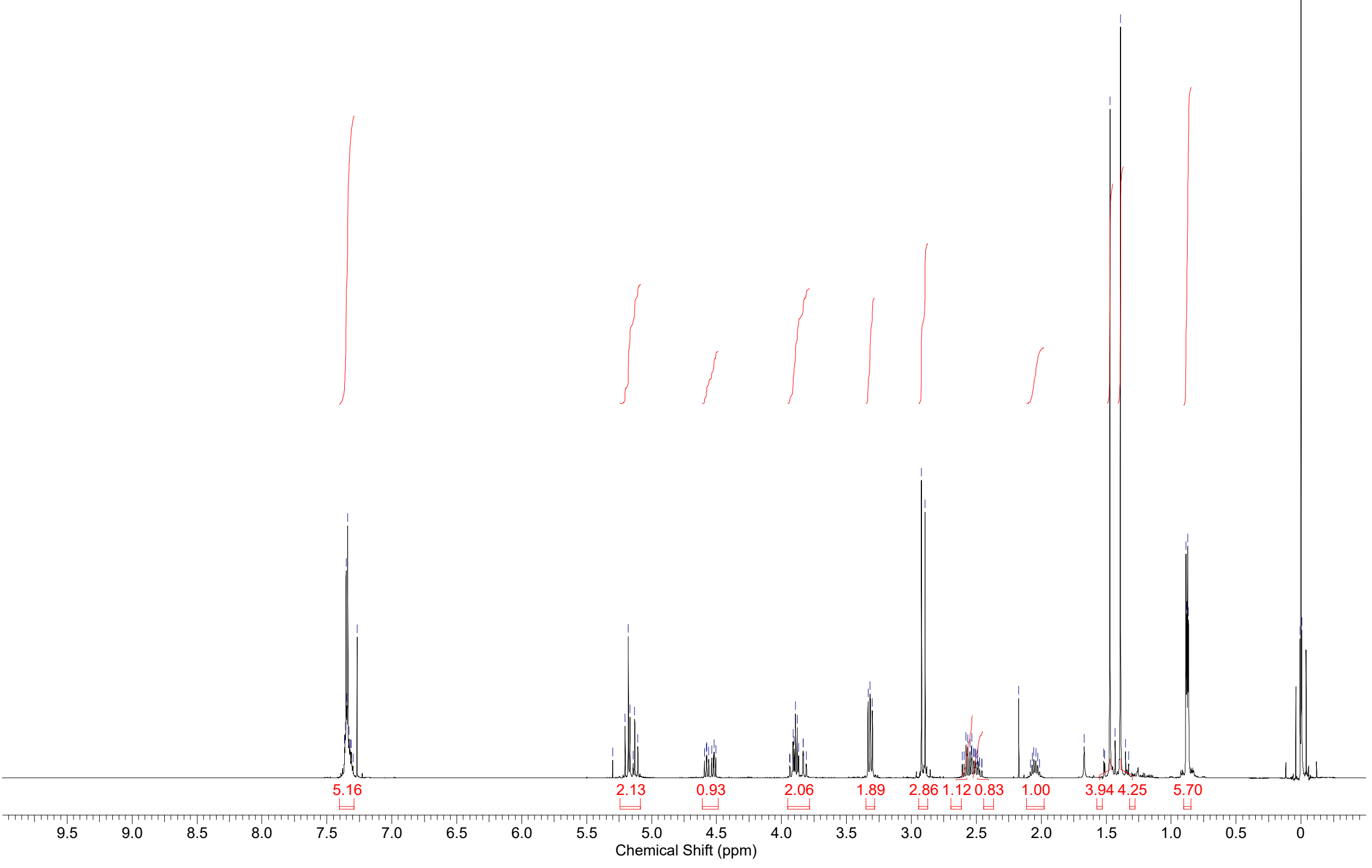


This report was created by ACD/NMR Processor Academic Edition. For more information go to www.acdlabs.com/nmrproc/

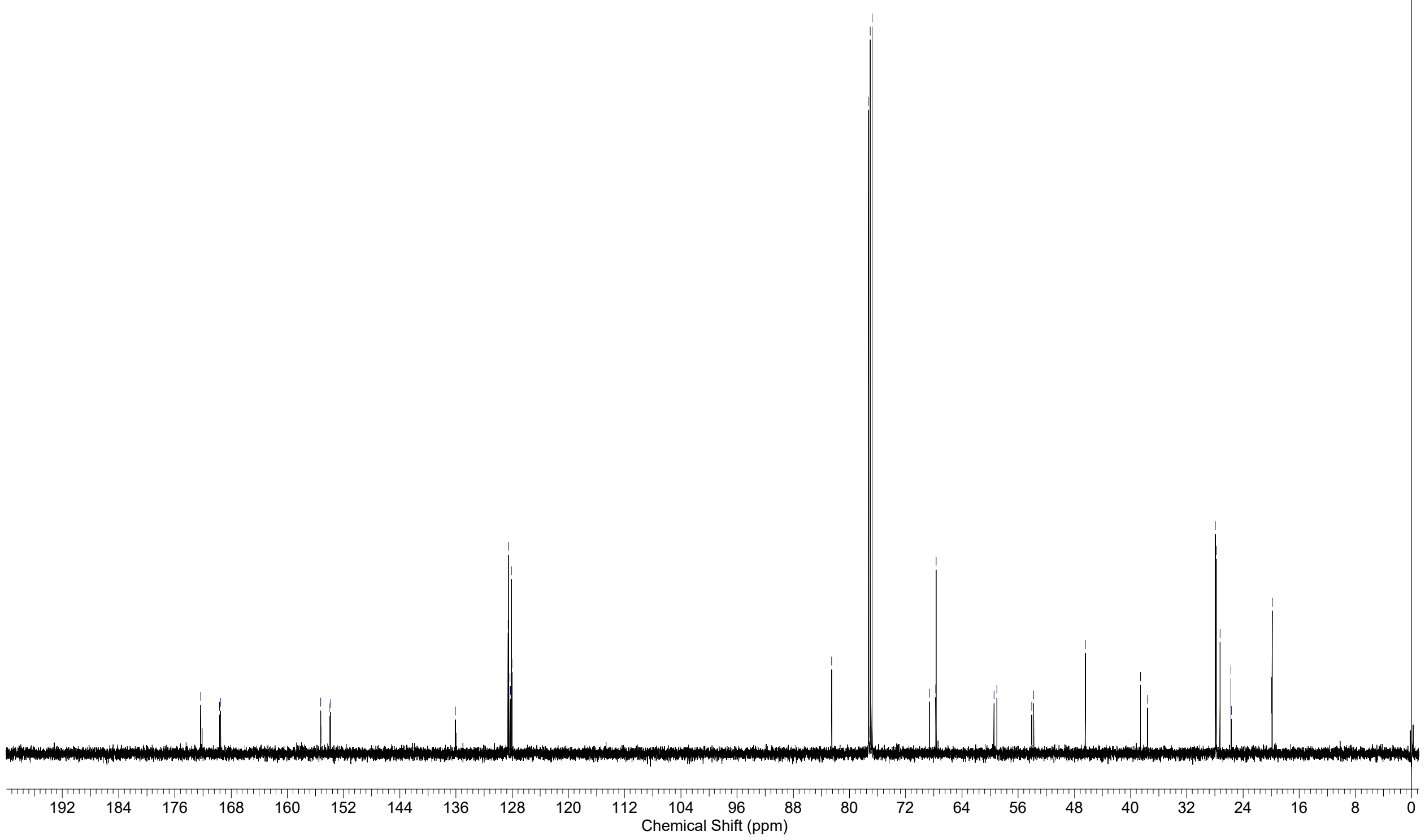


Page 9 of 127

2 - HPLC@ 254 nm
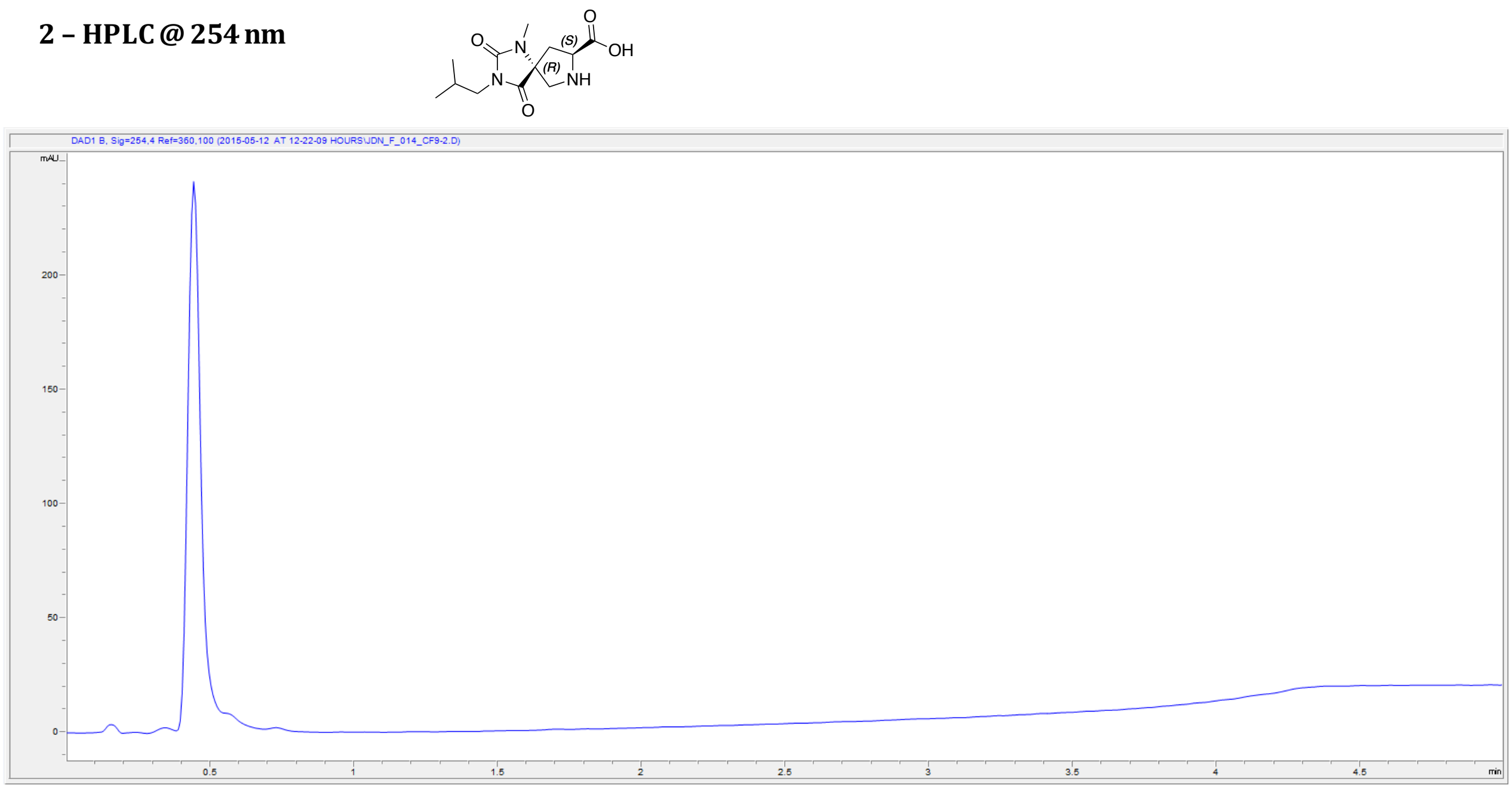
Page 10 of 127

This report was created by ACD/NMR Processor Academic Edition. For more information go to www.acdlabs.com/nmrproc/

F014 1H DMSO proton.atm

601401.esp

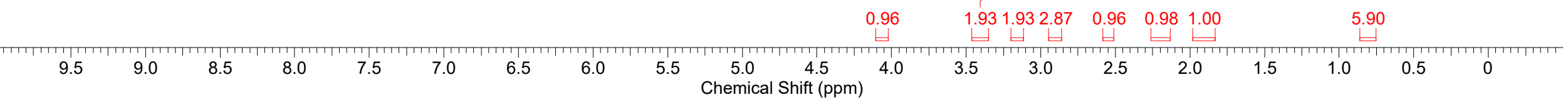


Page 11 of 127

This report was created by ACD/NMR Processor Academic Edition. For more information go to www.acdlabs.com/nmrproc/

F014 13C DMSO carbon10MIN.atm

601402.esp

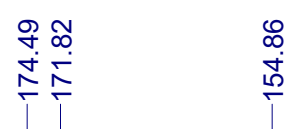

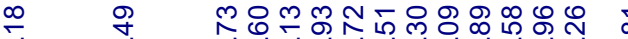

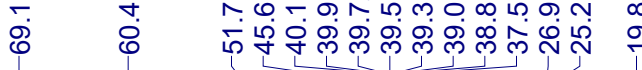

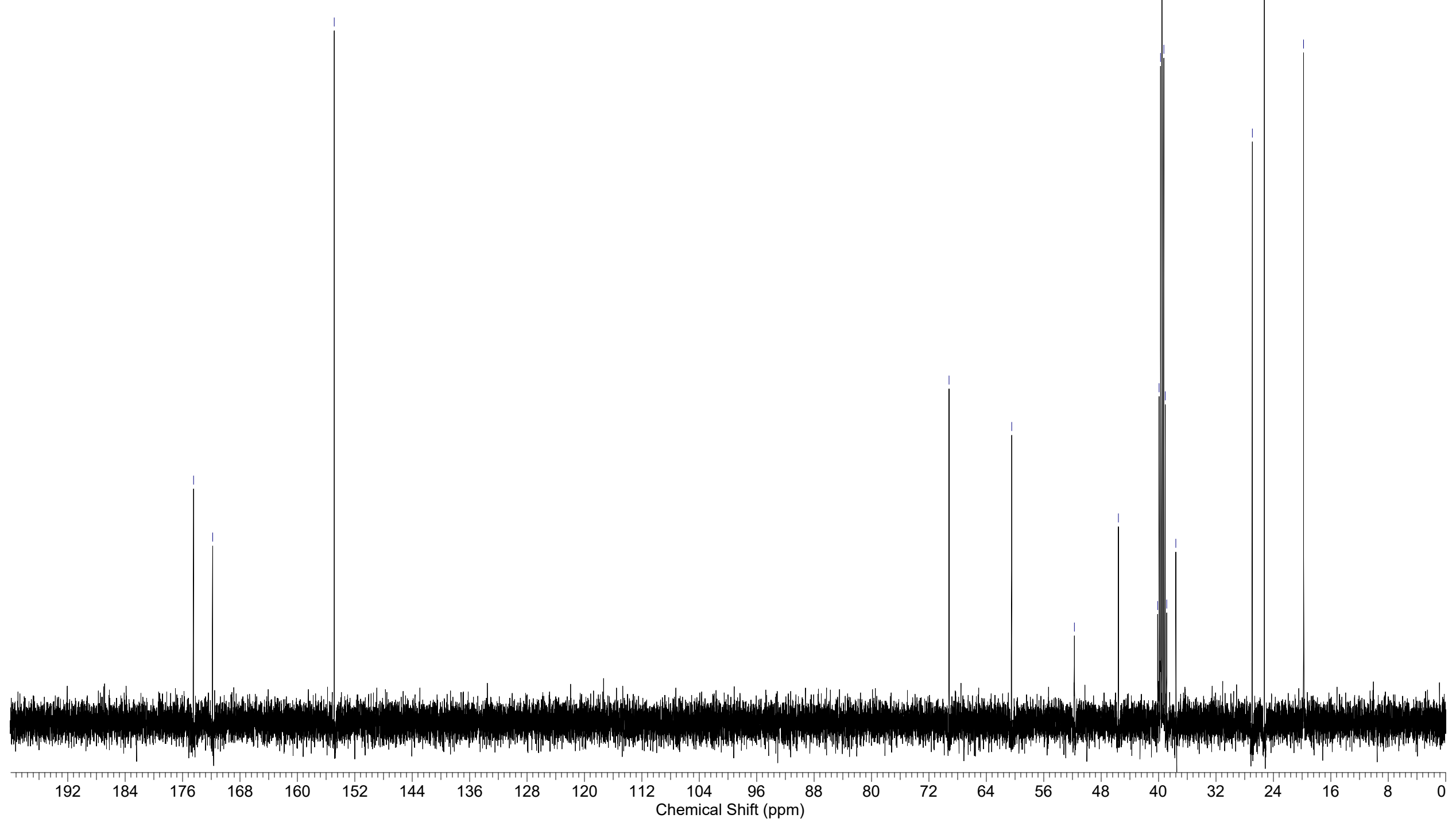


Page 12 of 127

This report was created by ACD/NMR Processor Academic Edition. For more information go to www.acdlabs.com/nmrproc/

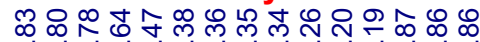

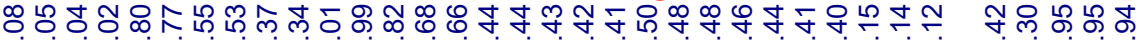

2.070 .590 .990 .600 .420 .600 .440 .430 .592 .40 
Page 13 of 127

This report was created by ACD/NMR Processor Academic Edition. For more information go to www.acdlabs.com/nmrproc/

707003.esp

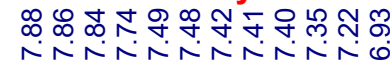

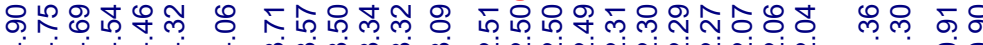

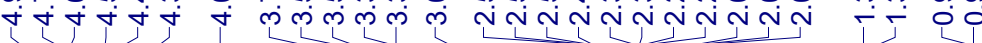

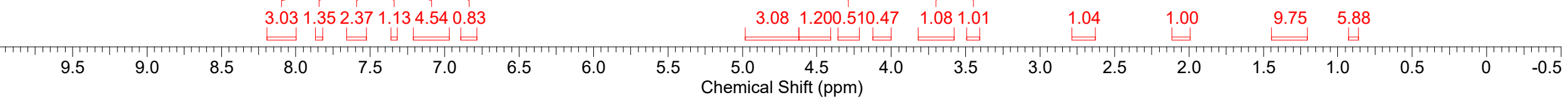


Page 14 of 127

This report was created by ACD/NMR Processor Academic Edition. For more information go to www.acdlabs.com/nmrproc/

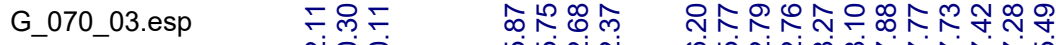

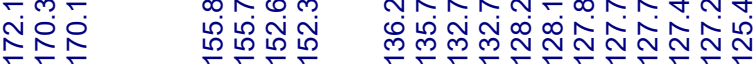

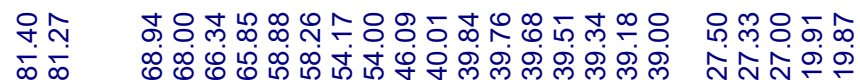

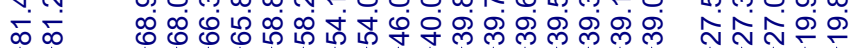

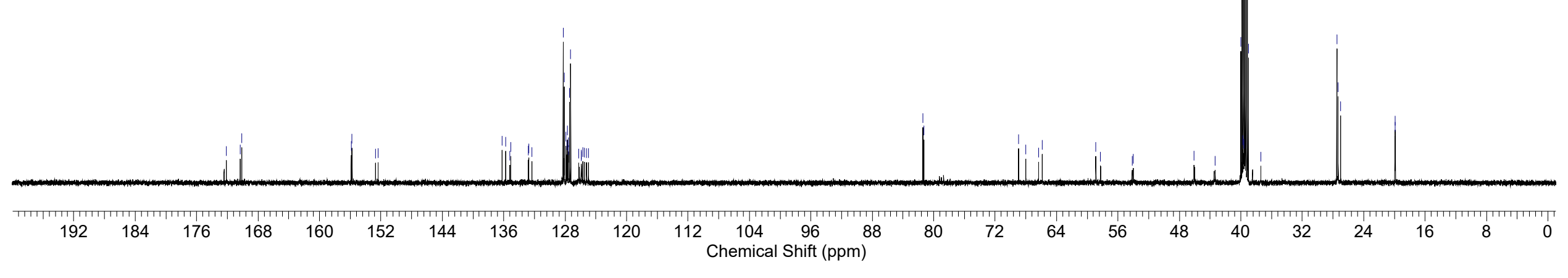


Page 15 of 127

3 - HPLC@ 274 nm
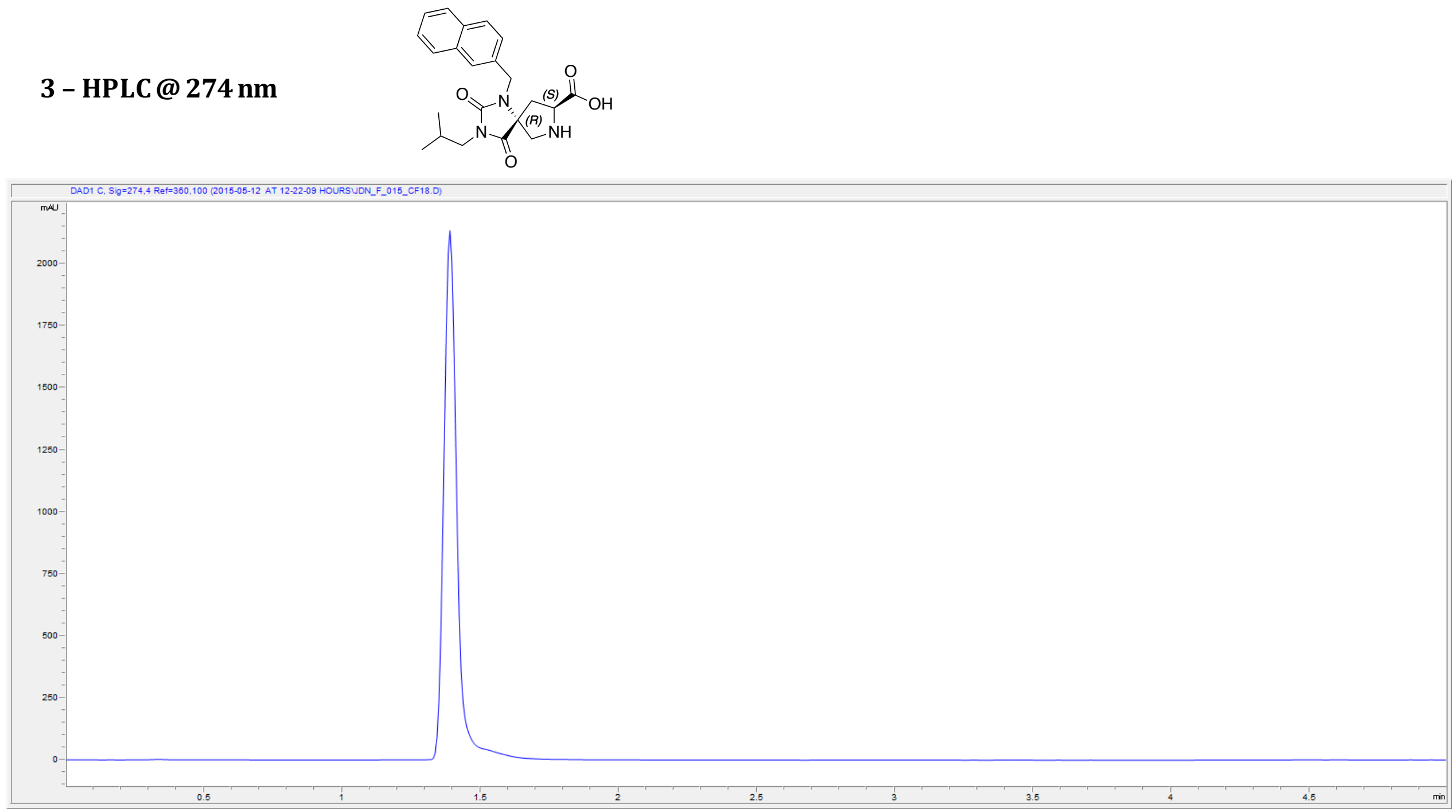
Page 16 of 127

This report was created by ACD/NMR Processor Academic Edition. For more information go to www.acdlabs.com/nmrproc/

F015 1H DMSO proton.atm

601501.esp

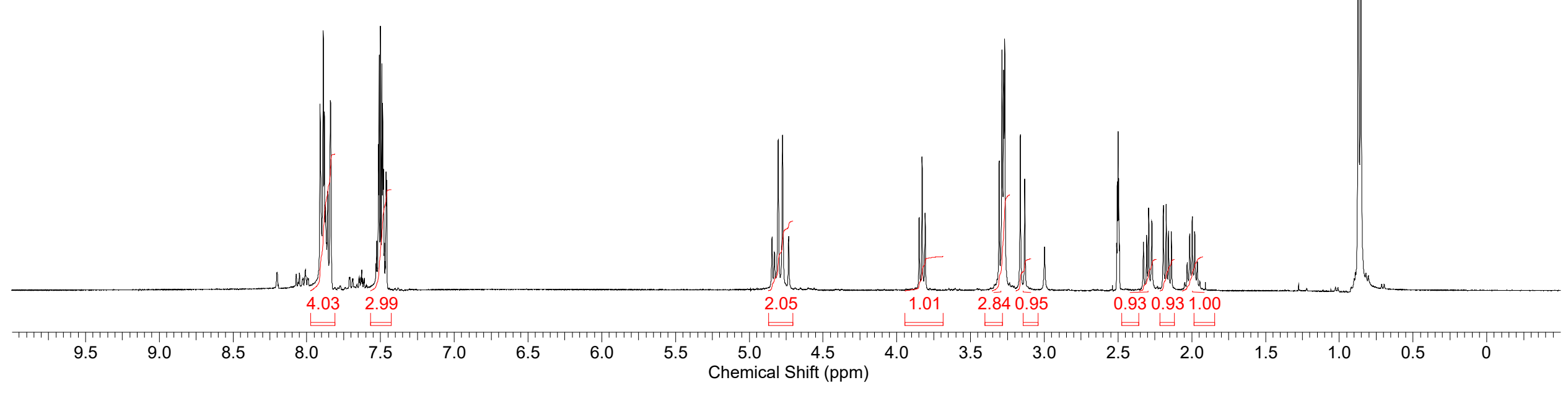


Page 17 of 127

This report was created by ACD/NMR Processor Academic Edition. For more information go to www.acdlabs.com/nmrproc/

F015 13C DMSO carbon30MIN.atm

601502.esp

\begin{tabular}{|c|c|c|}
\hline 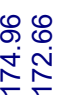 & $\begin{array}{l}\infty \\
\stackrel{\infty}{\infty} \\
\stackrel{1}{\tau}\end{array}$ & 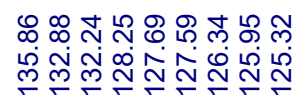 \\
\hline
\end{tabular}

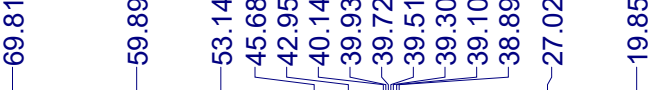

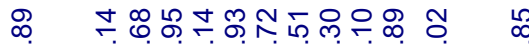

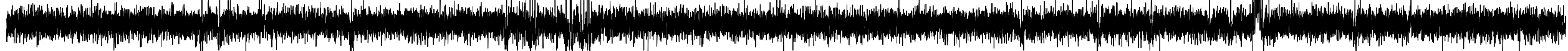


Page 18 of 127

G_071_01.esp
This report was created by $A C D / N$

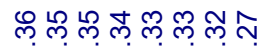

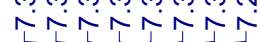

Academic Edition. For more information go to www.acdlabs.com $/ \mathrm{nmrproc} /$

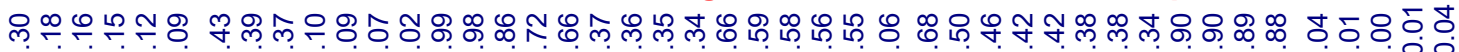
फिंம்

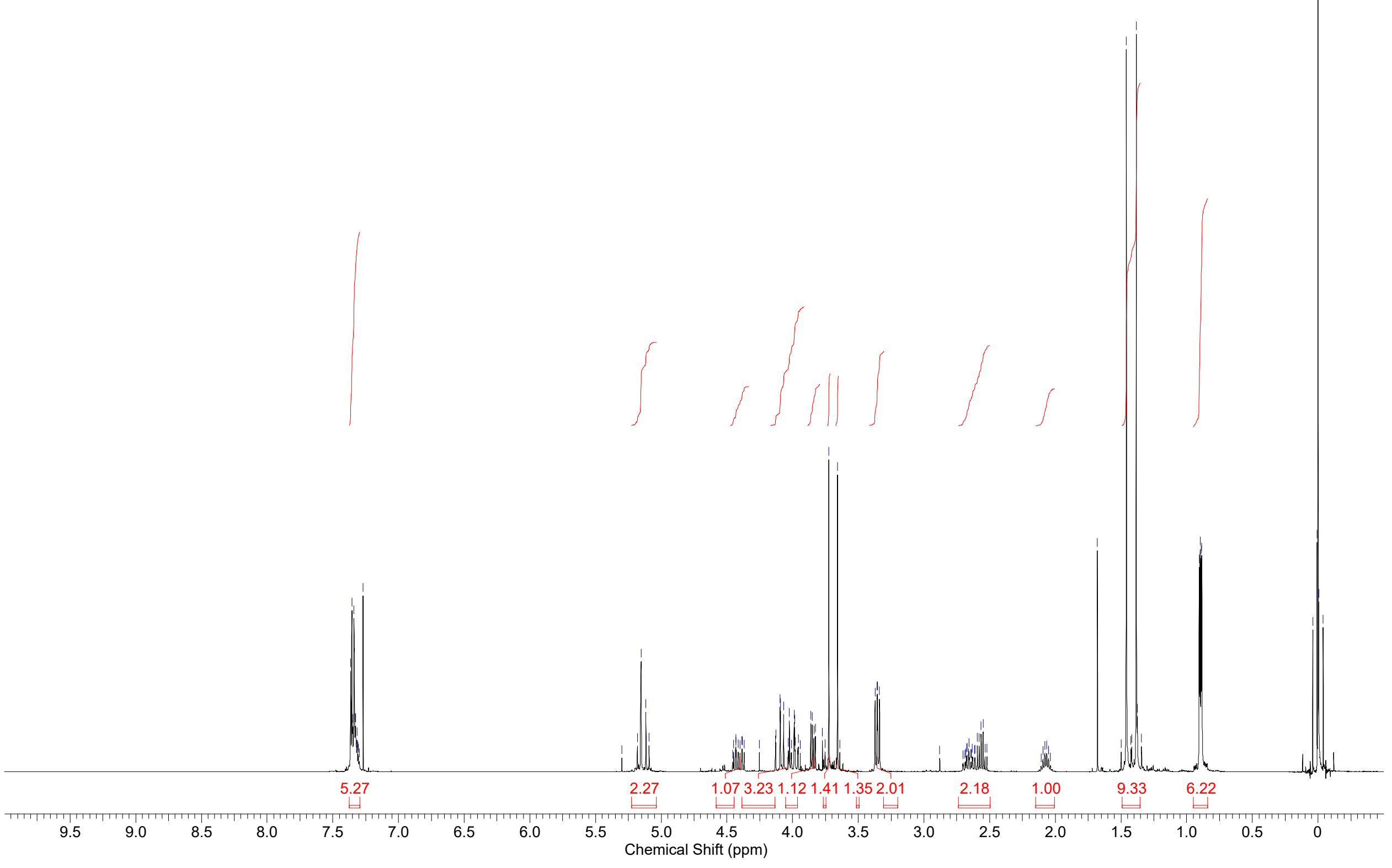


Page 19 of 127

This report was created by ACD/NMR Processor Academic Edition. For more information go to www.acdlabs.com/nmrproc/
G_071_02.esp

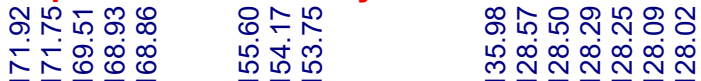

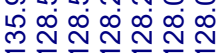

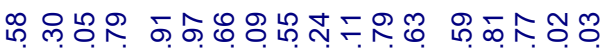

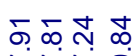

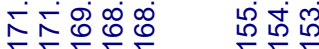

赫

ลิกลกั

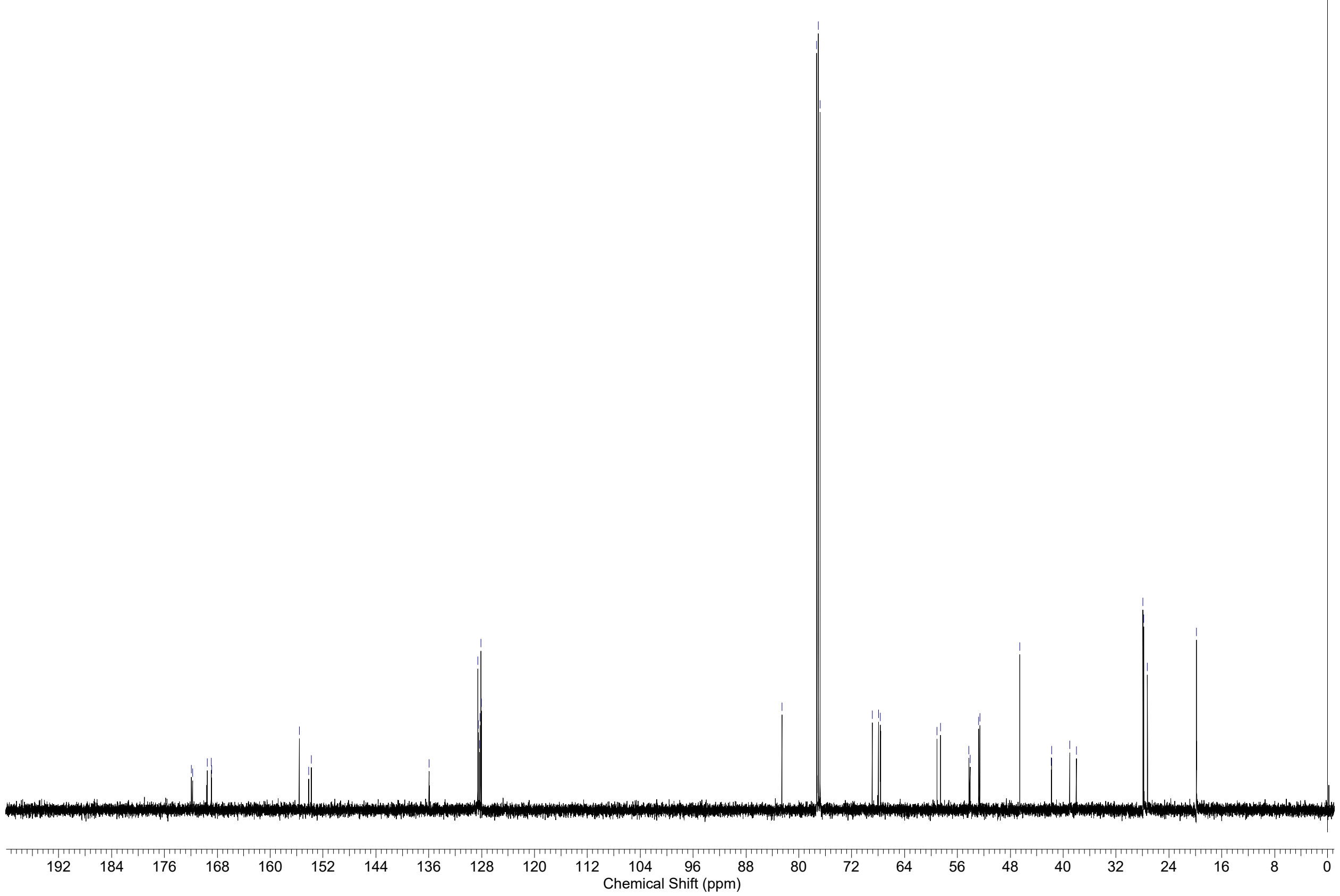


Page 20 of 127

4 - HPLC@ 220 nm
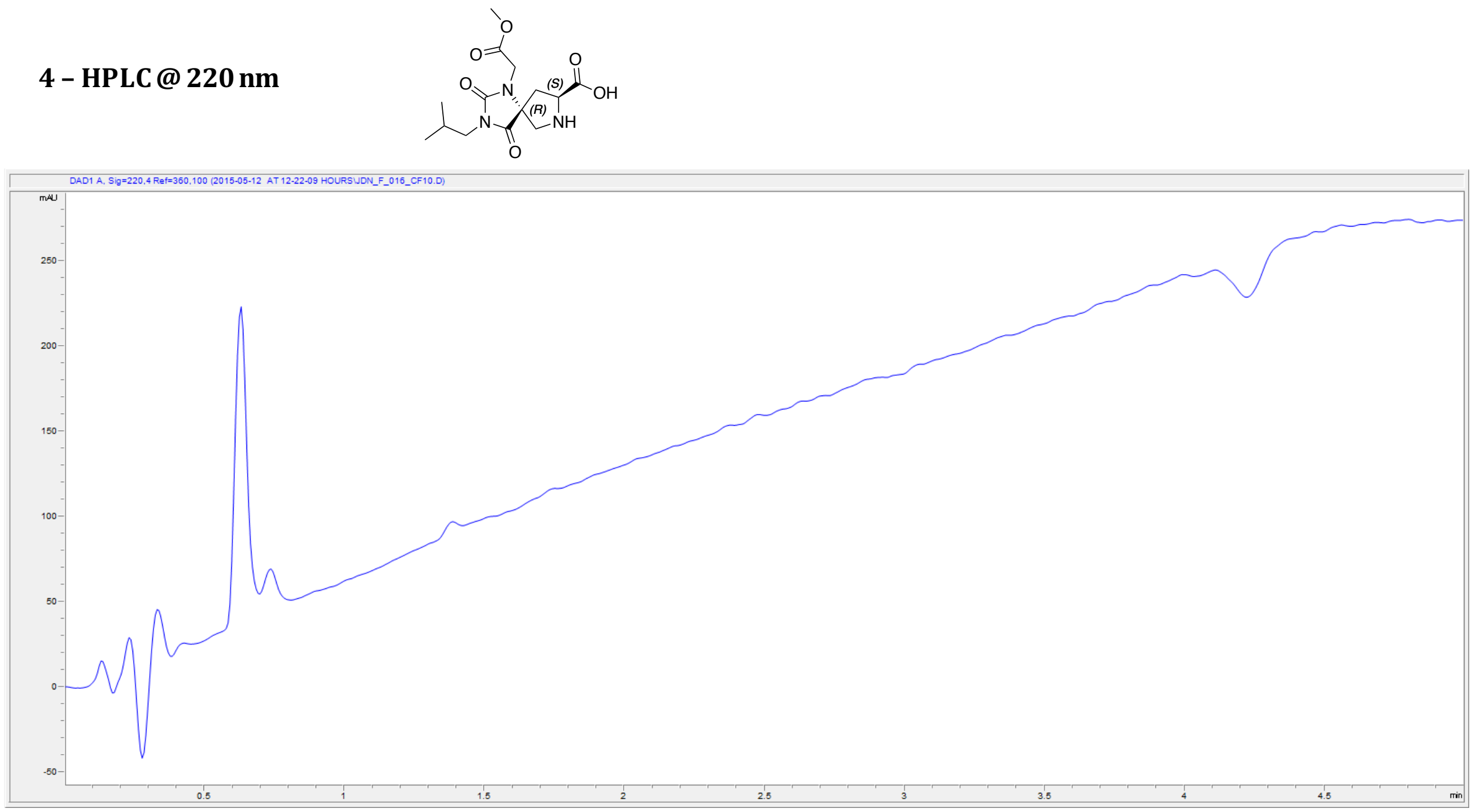
This report was created by ACD/NMR Processor Academic Edition. For more information go to www.acdlabs.com/nmrproc/

601601.esp

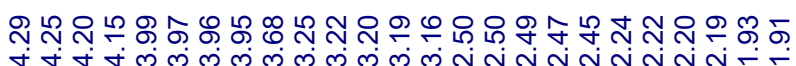

F016 1H DMSO proton.atm

我

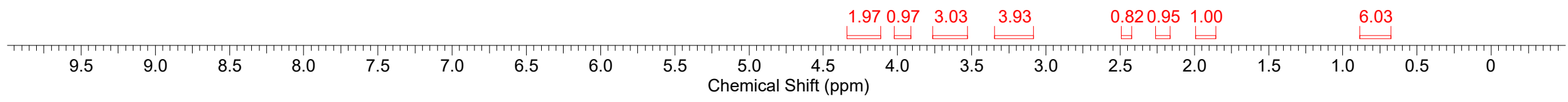


Page 22 of 127

This report was created by ACD/NMR Processor Academic Edition. For more information go to www.acdlabs.com/nmrproc/

F016 13C DMSO carbon30MIN.atm

\begin{tabular}{|c|c|}
\hline 601602.esp & 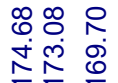 \\
\hline
\end{tabular}

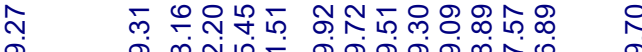

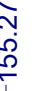

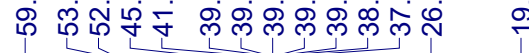

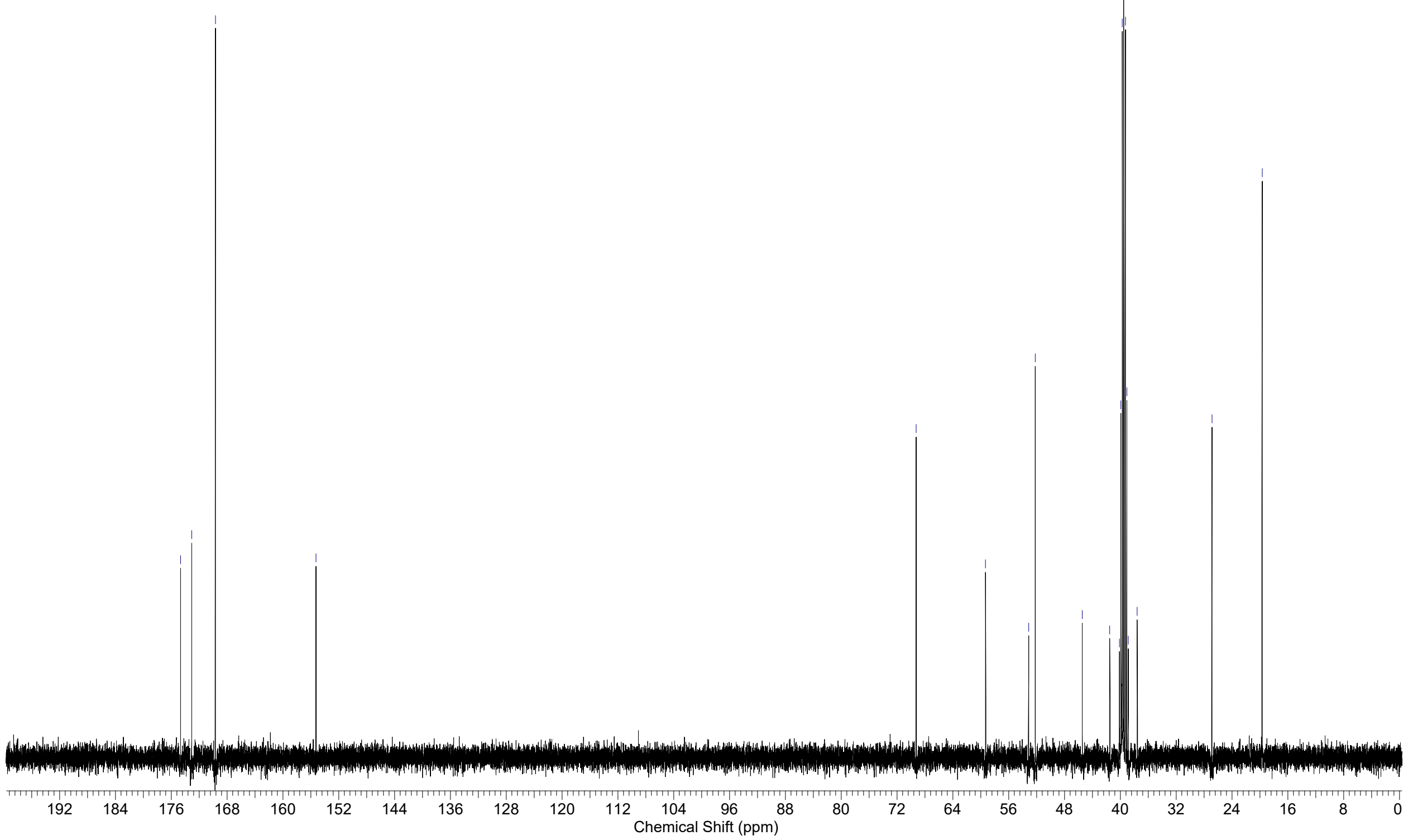


Page 23 of 127

This report was created by ACD/NMR Processor Academic Edition. For more information go to www.acdlabs.com/nmrproc/

705801.esp

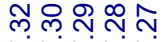

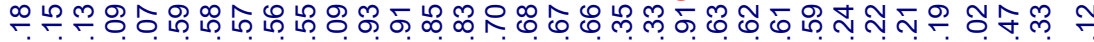

ம் மூ ம்

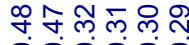

ベNヘ

000000

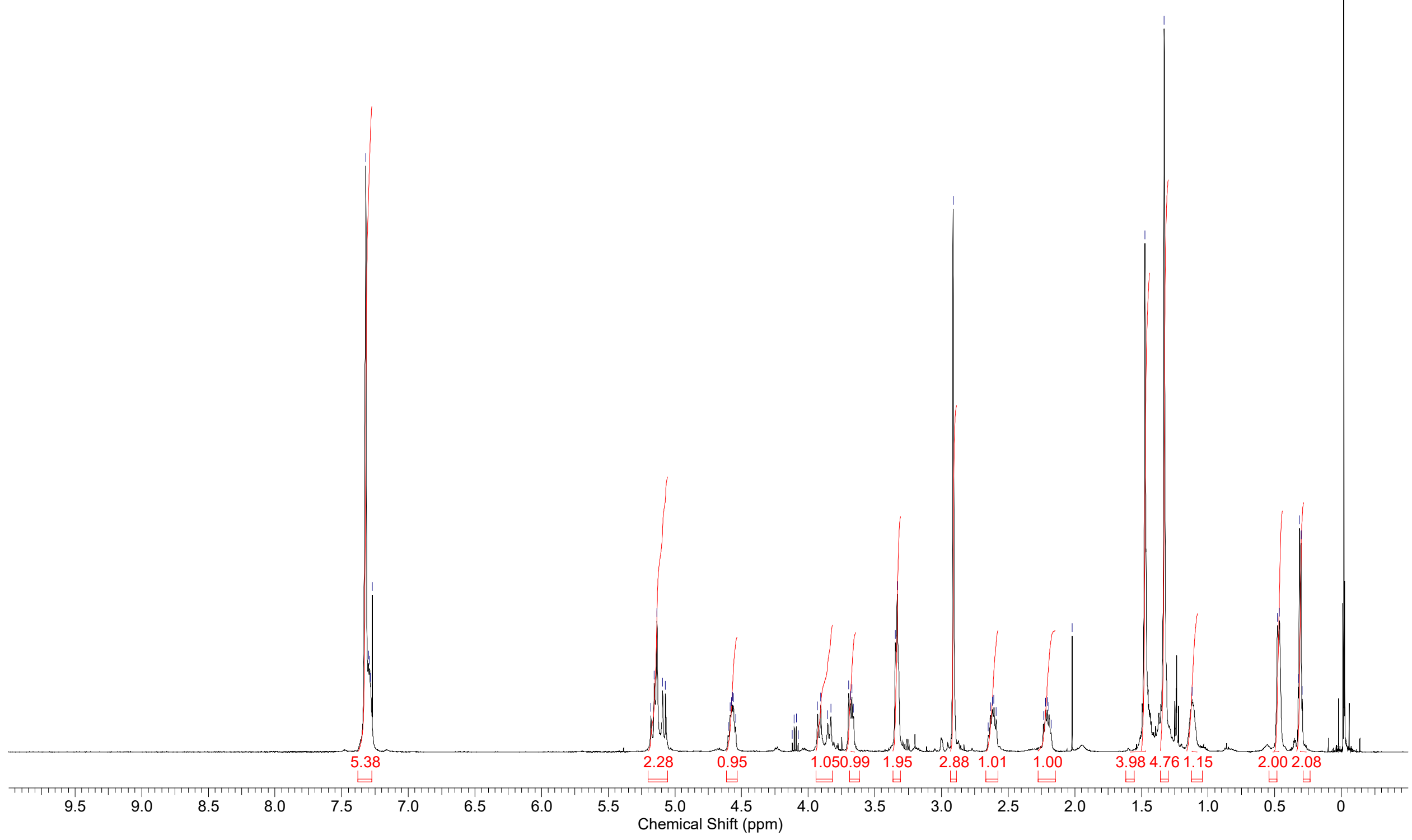


Page 24 of 127

This report was created by ACD/NMR Processor Academic Edition. For more information go to www.acdlabs.com/nmrproc/

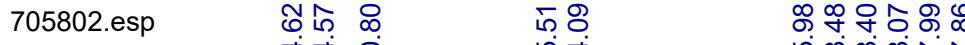

采点点

त̄is

웅유웅

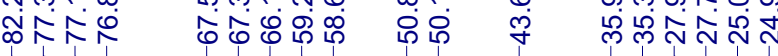

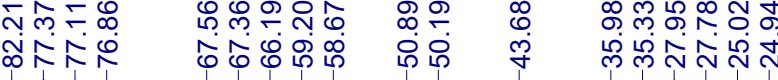

๙

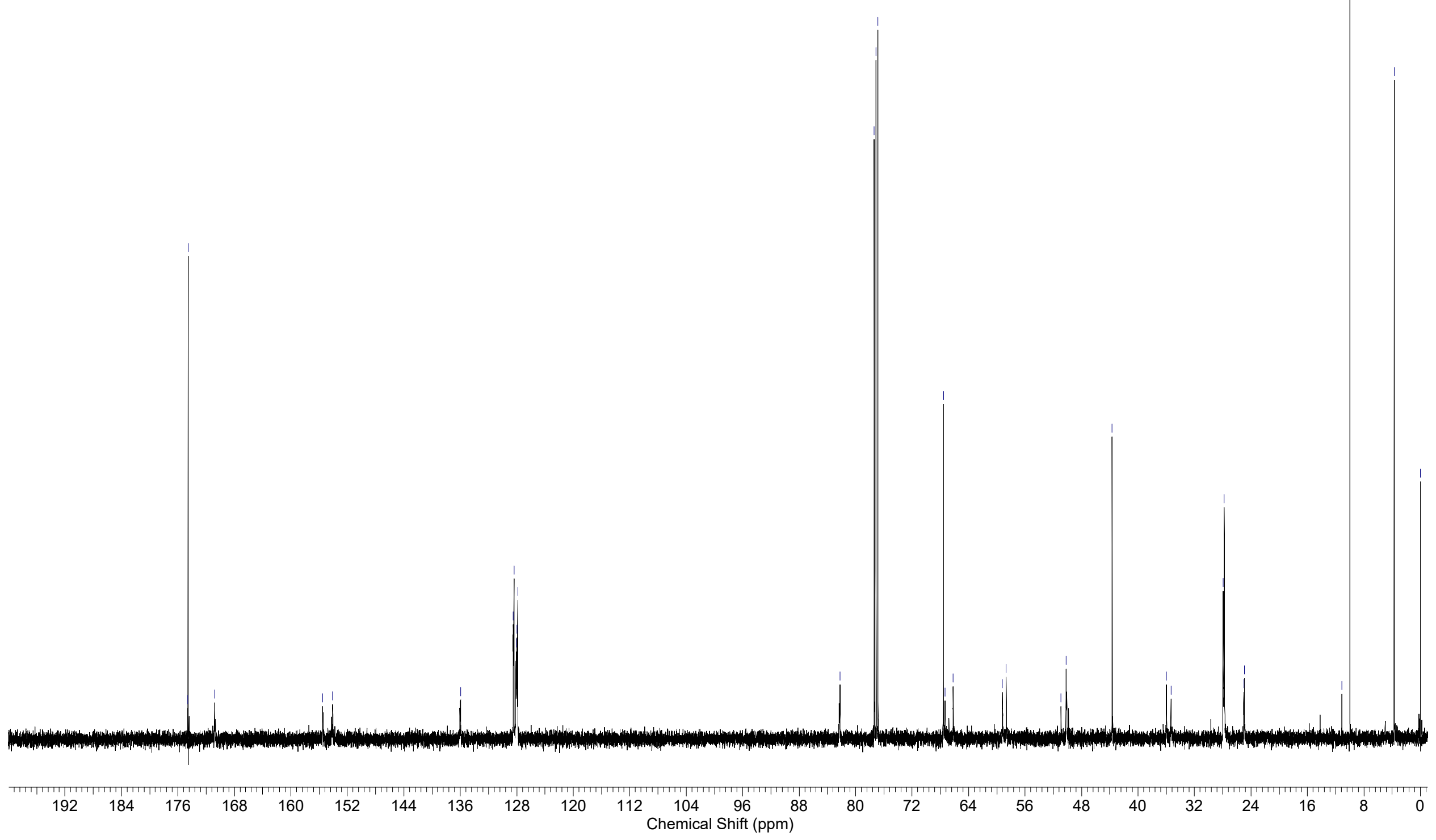




\section{5 - HPLC@ 254 nm}
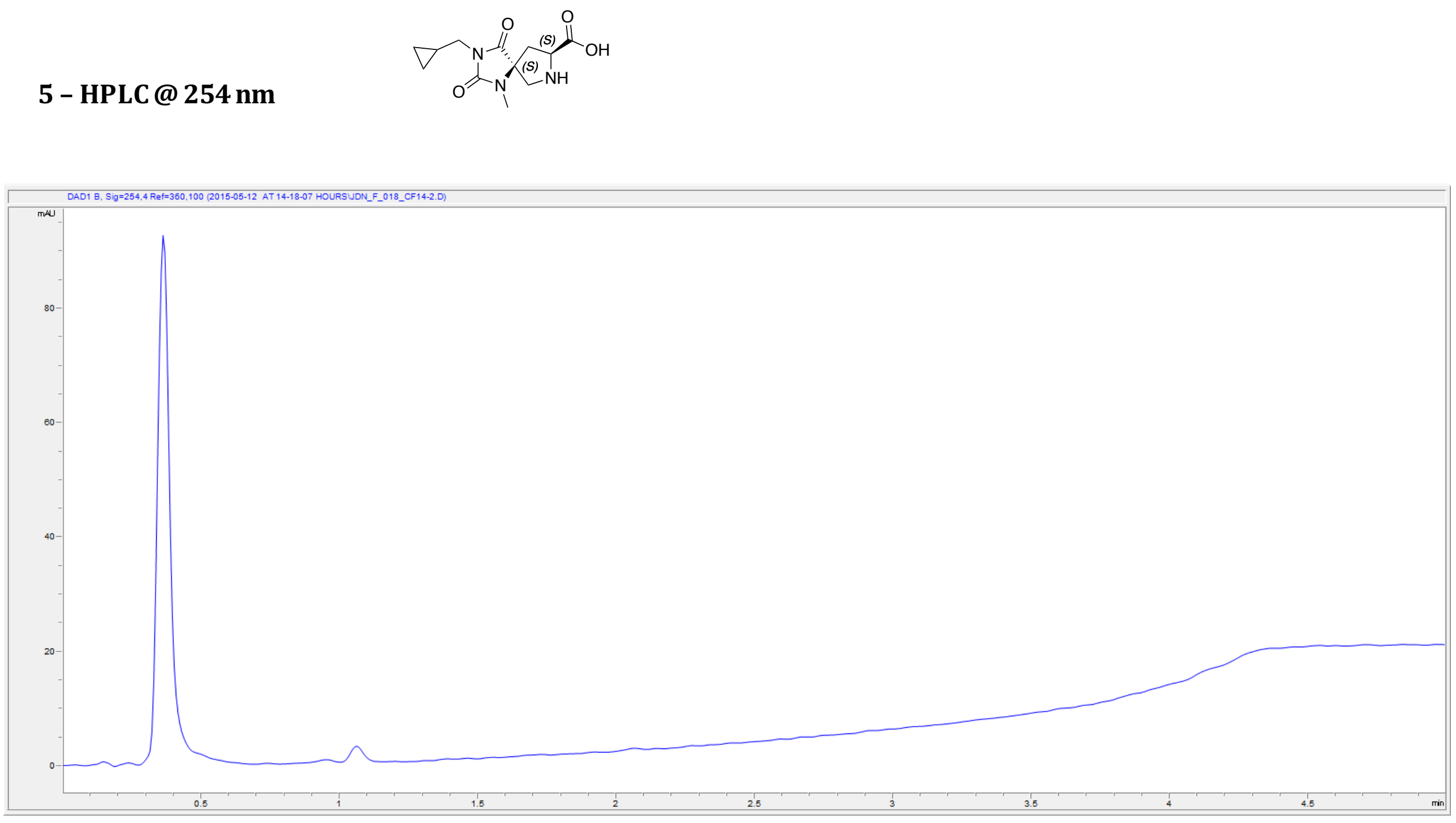
Page 26 of 127

This report was created by ACD/NMR Processor Academic Edition. For more information go to www.acdlabs.com/nmrproc/

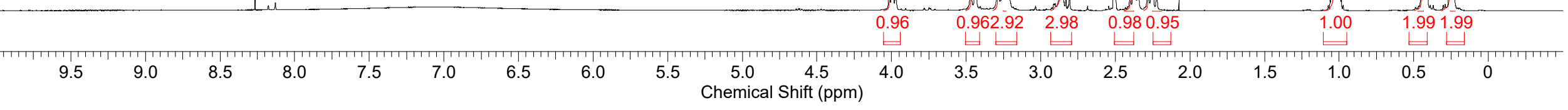


Page 27 of 127

This report was created by ACD/NMR Processor Academic Edition. For more information go to www.acdlabs.com/nmrproc/

601802.esp

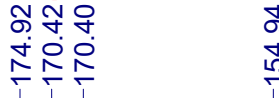

家

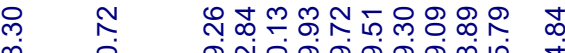

@i

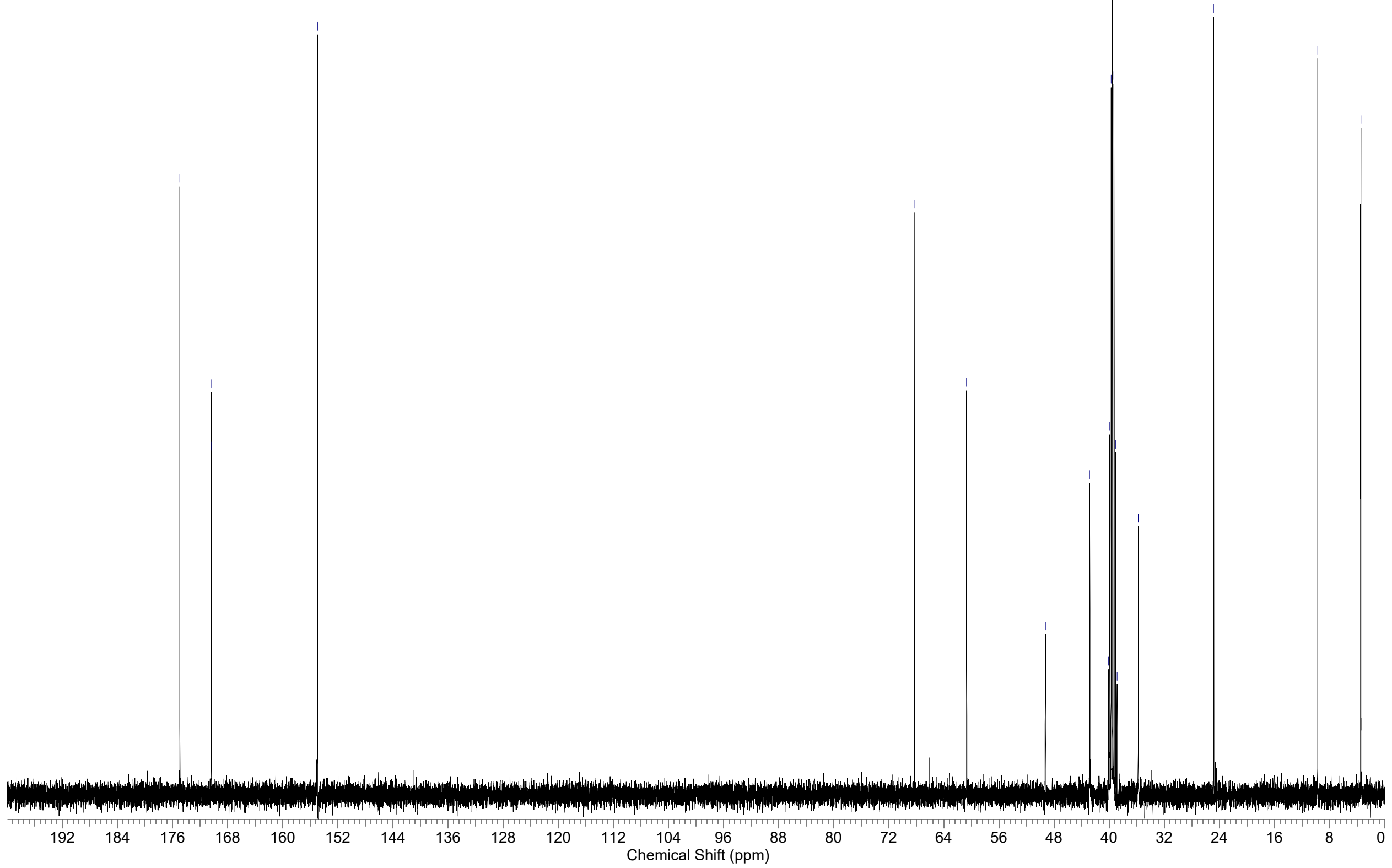


Page 28 of 127

This report was created by ACD/NMR Processor Academic Edition. For more information go to www.acdlabs.com/nmrproc/

705901.esp

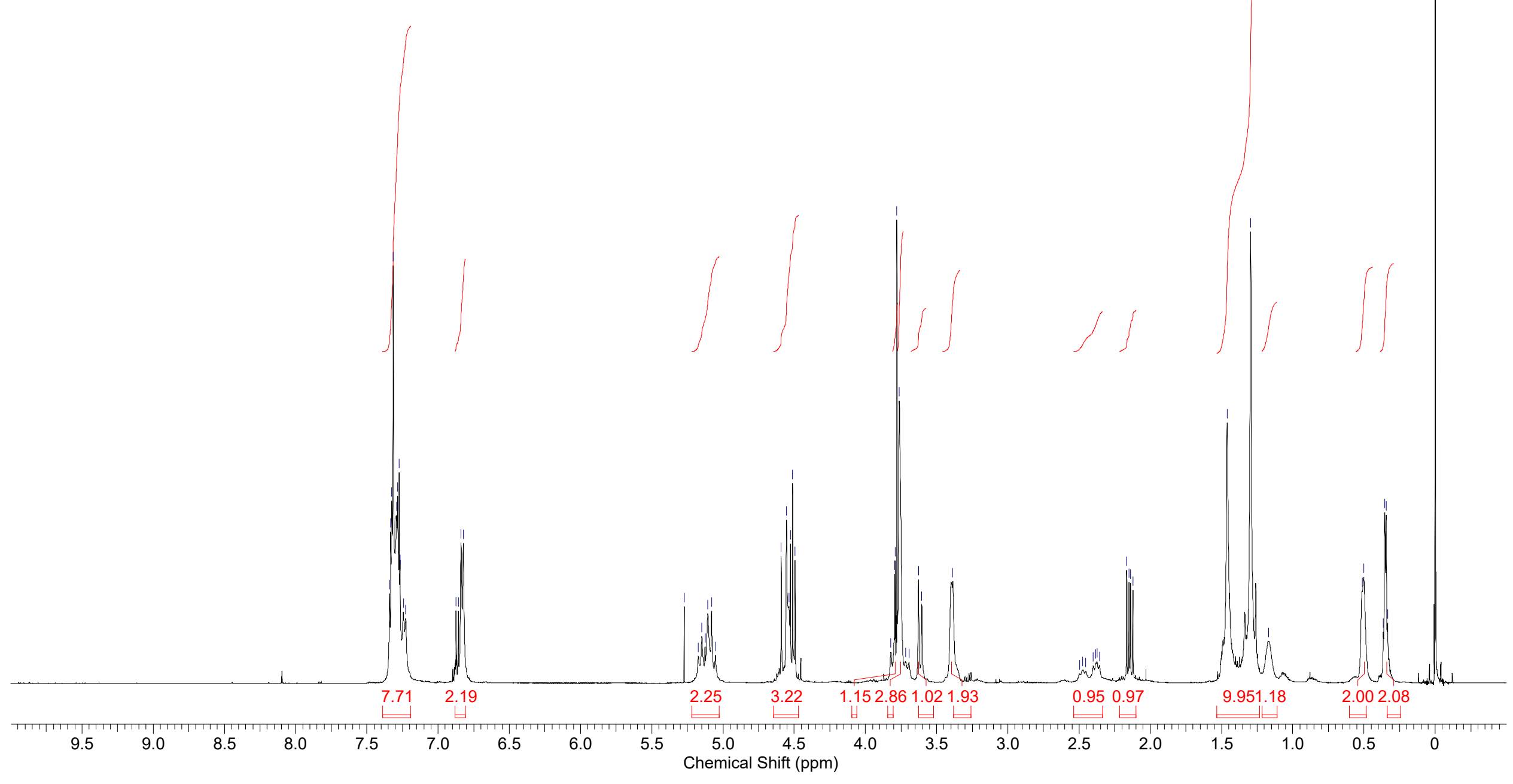


Page 29 of 127

This report was created by ACD/NMR Processor Academic Edition. For more information go to www.acdlabs.com/nmrproc/

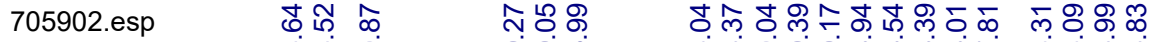

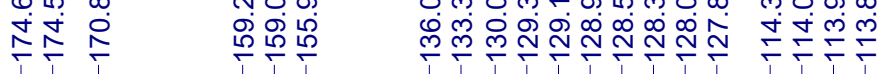

等

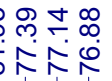

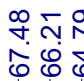

ஸे ก
$\infty$
$\infty$
$\infty$

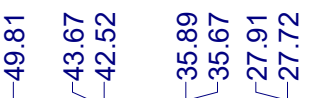

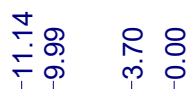

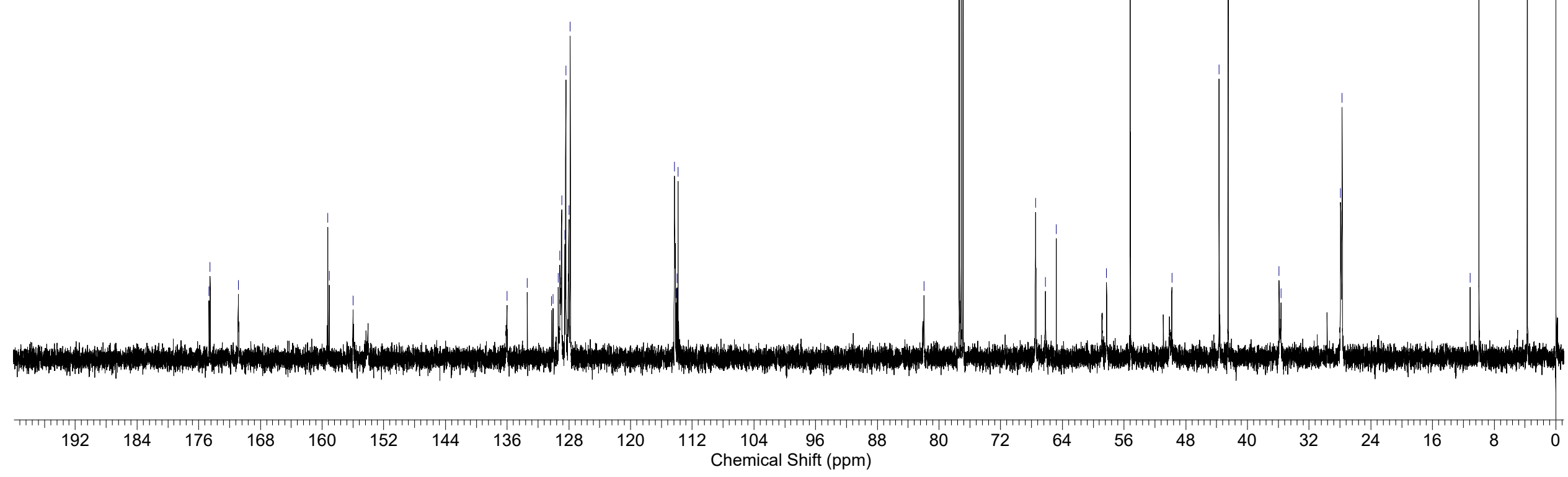


Page 30 of 127

6 - HPLC@ 254 nm
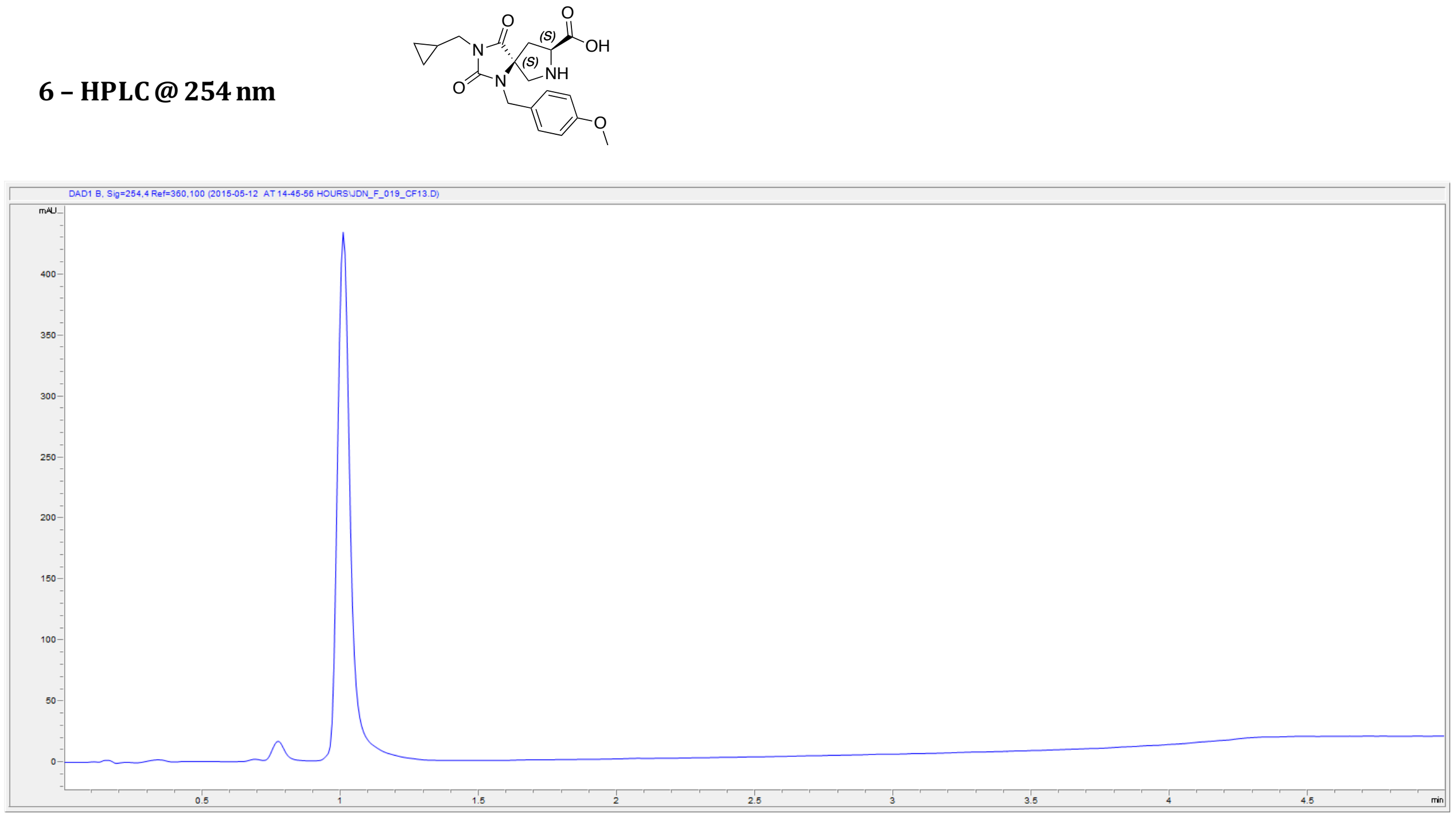
This report was created by ACD/NMR Processor Academic Edition. For more information go to www.acdlabs.com/nmrproc/

F019 Proton DMSO proton.atm

601901.esp

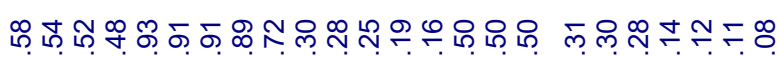

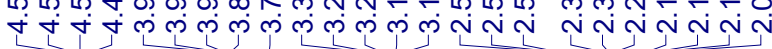

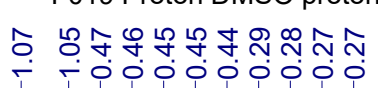

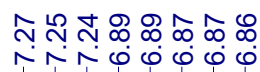

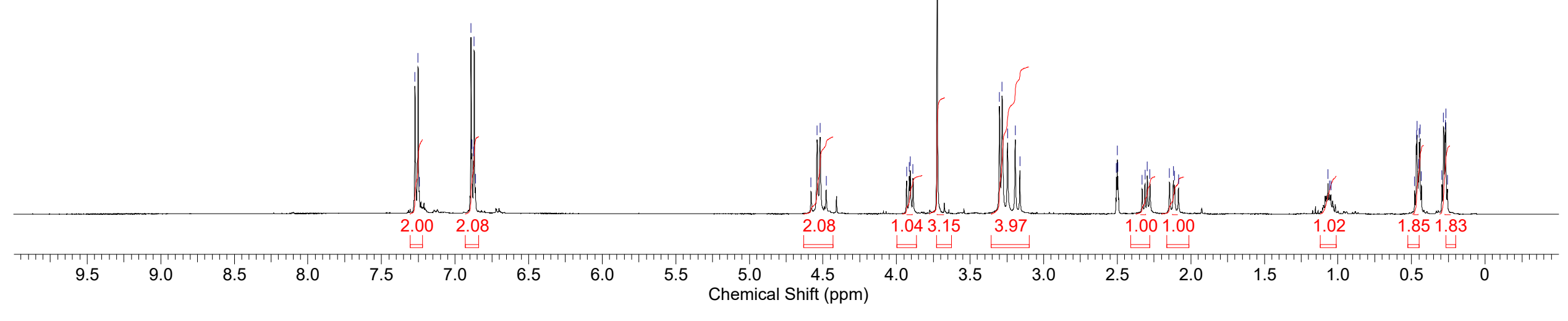


Page 32 of 127

This report was created by ACD/NMR Processor Academic Edition. For more information go to www.acdlabs.com/nmrproc/

F019 C13 DMSO carbon10MIN.atm

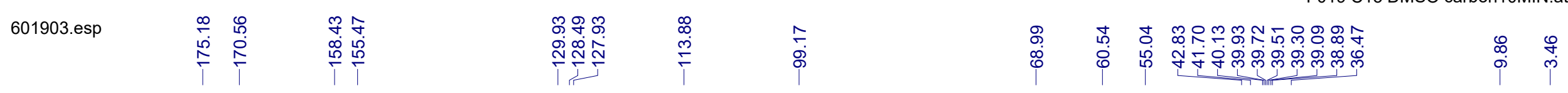

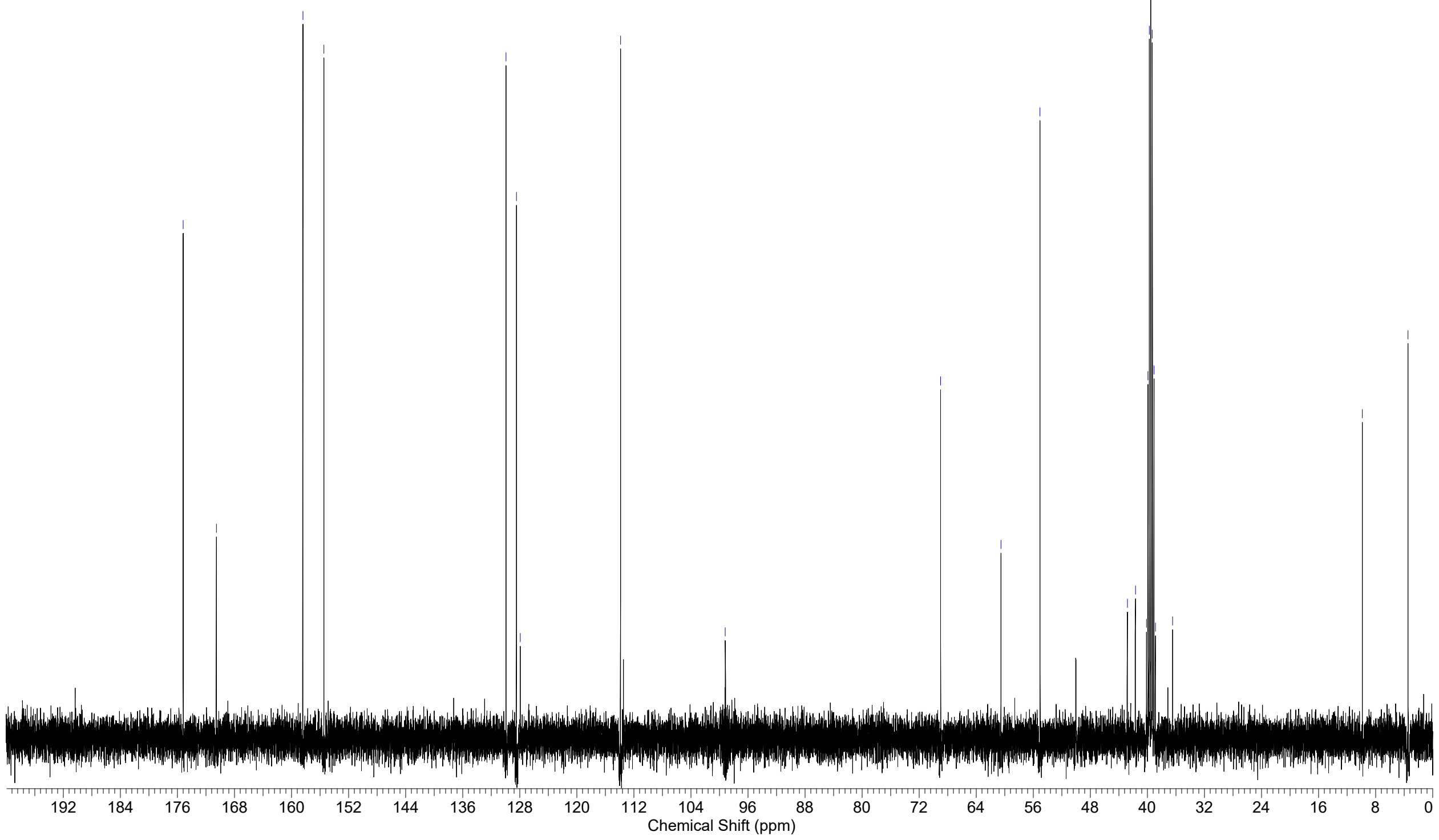


Page 33 of 127

This report was created by ACD/NMR Processor Academic Edition. For more information go to www.acdlabs.com/nmrproc/

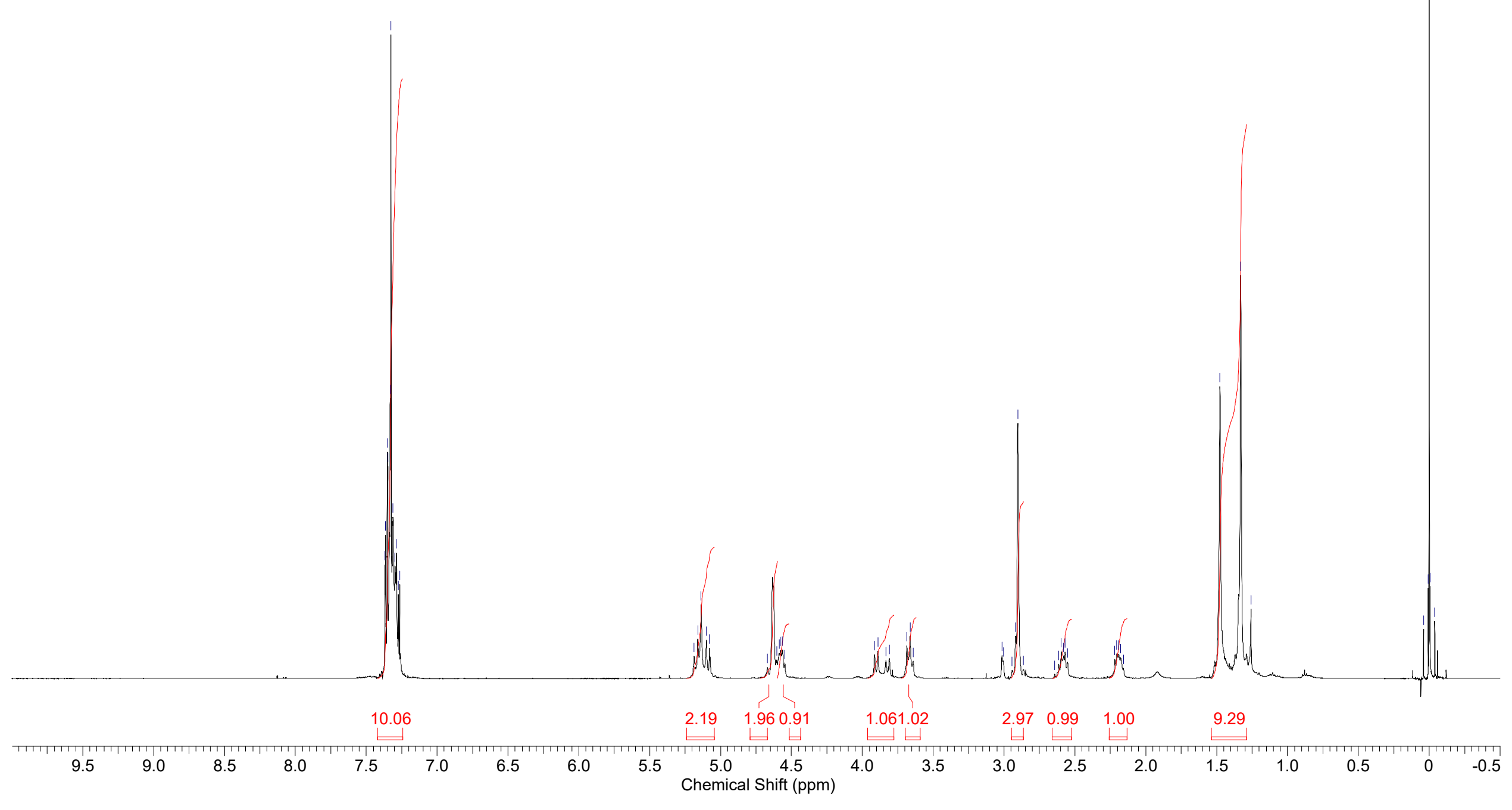


Page 34 of 127

This report was created by ACD/NMR Processor Academic Edition. For more information go to www.acdlabs.com/nmrproc/

G_060_02.esp

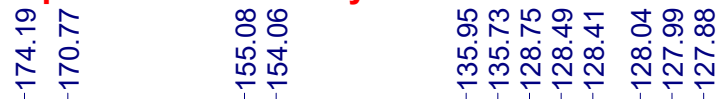

们

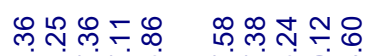

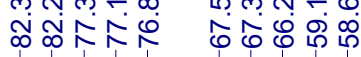

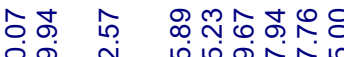

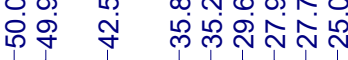

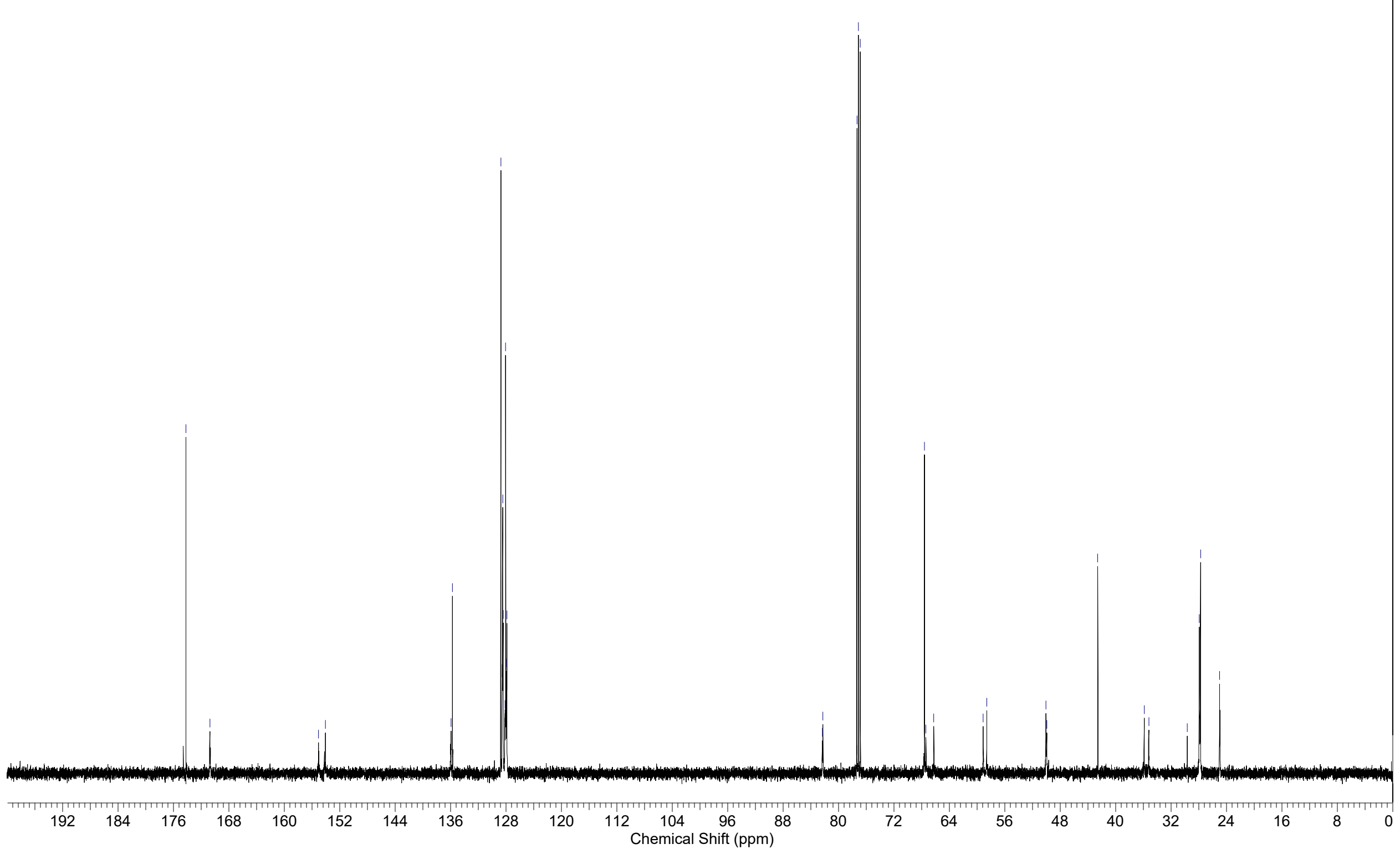


Page 35 of 127

7 - HPLC @ 254 nm
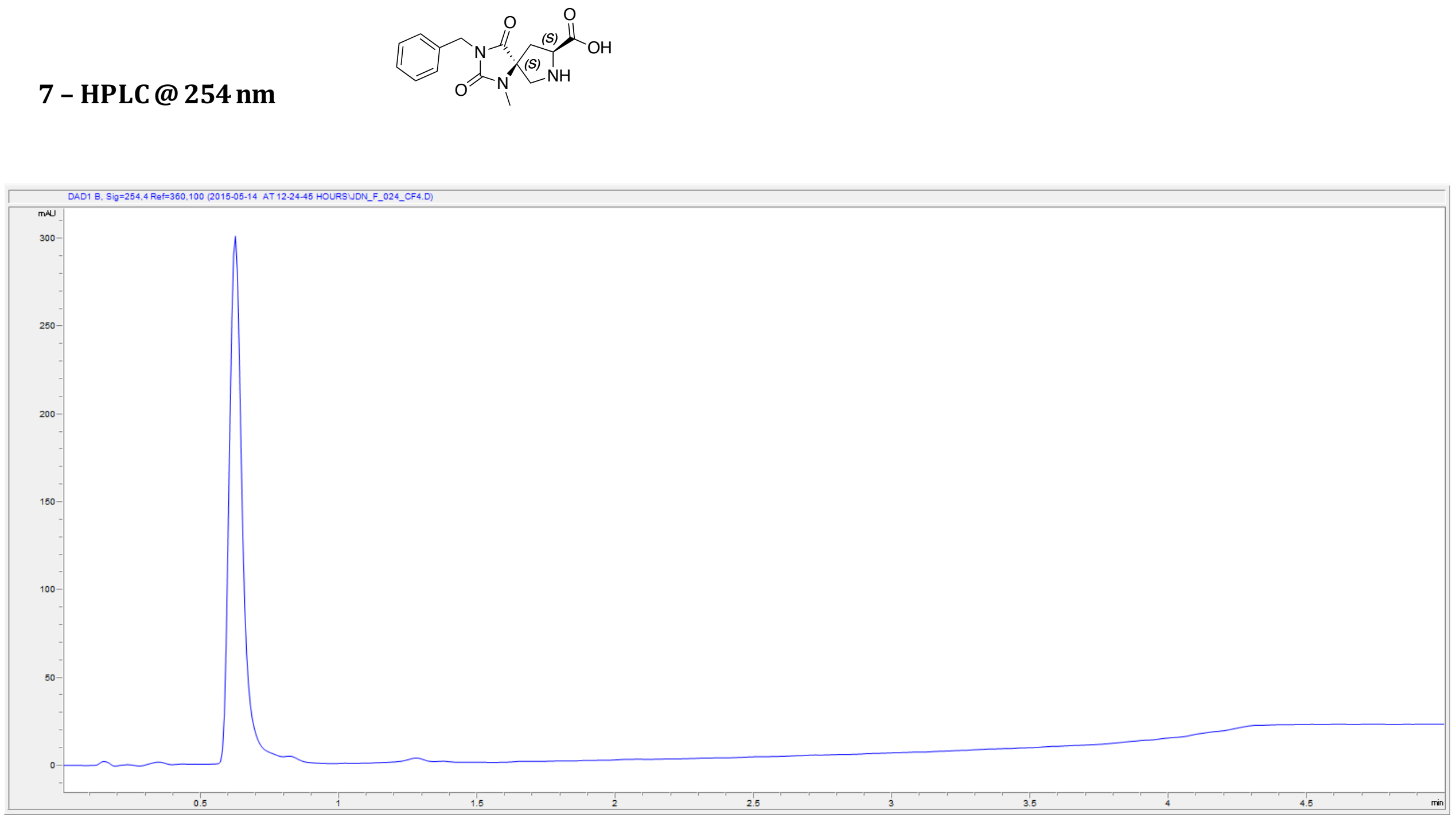
This report was created by ACD/NMR Processor Academic Edition. For more information go to www.acdlabs.com/nmrproc/

F024 1H DMSO proton.atm

602401.esp

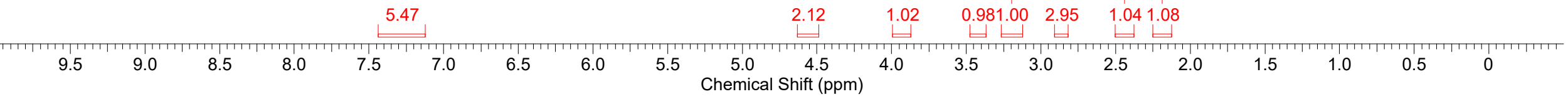


Page 37 of 127

This report was created by ACD/NMR Processor Academic Edition. For more information go to www.acdlabs.com/nmrproc/

F024 13C DMSO carbon10MIN.atm

602402.esp

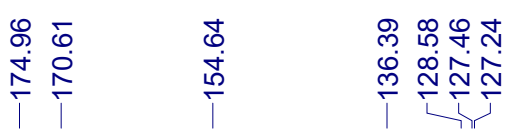

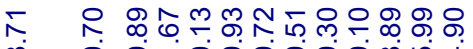

o

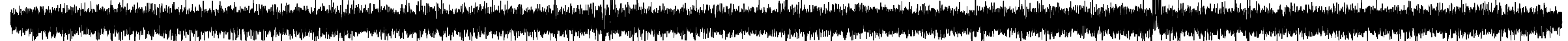

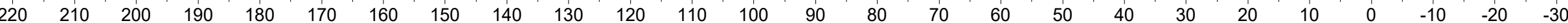
Chemical Shift (ppm) 
Page 38 of 127

This report was created by ACD/NMR Processor Academic Edition. For more information go to www.acdlabs.com/nmrproc/

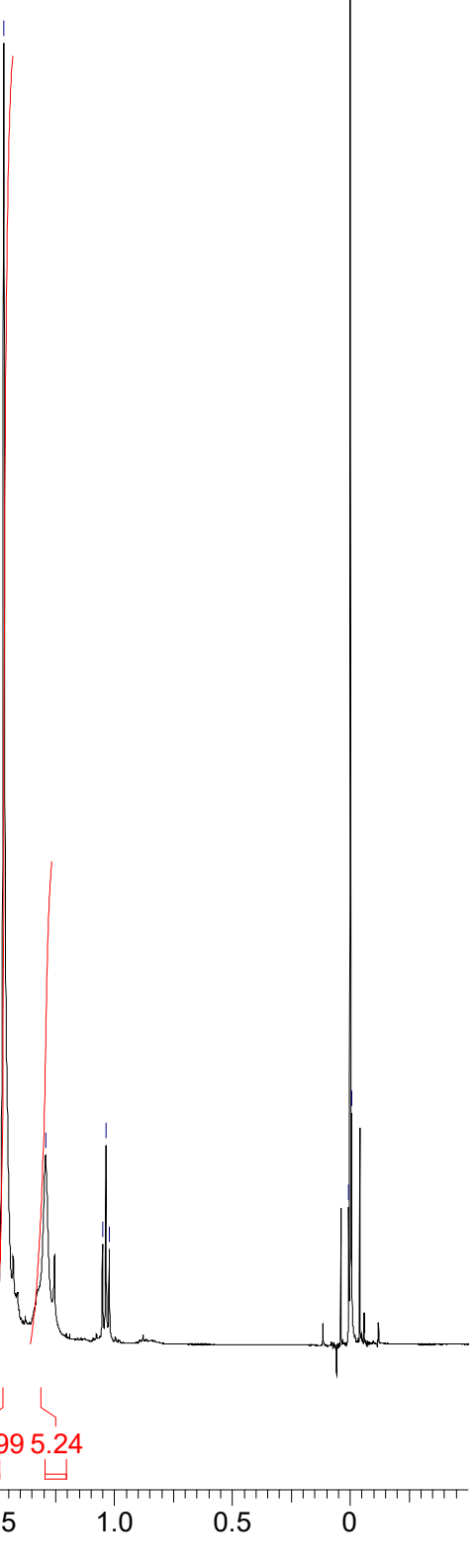


Page 39 of 127

This report was created by ACD/NMR Processor Academic Edition. For more information go to www.acdlabs.com/nmrproc/

G_061_02.esp
$\infty$
R

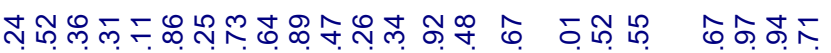

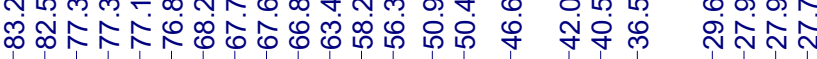

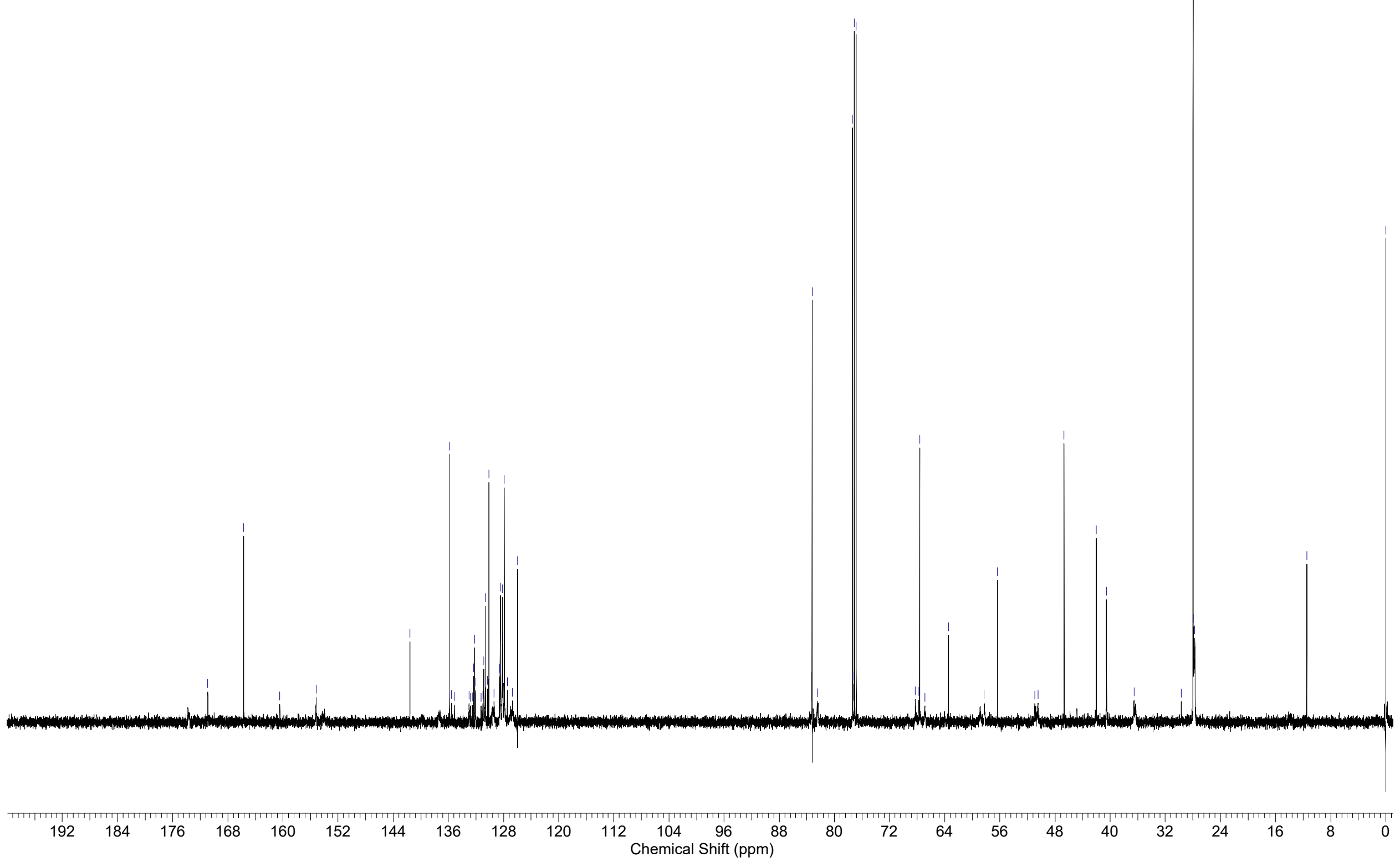


Page 40 of 127

8 - HPLC@ 254 nm
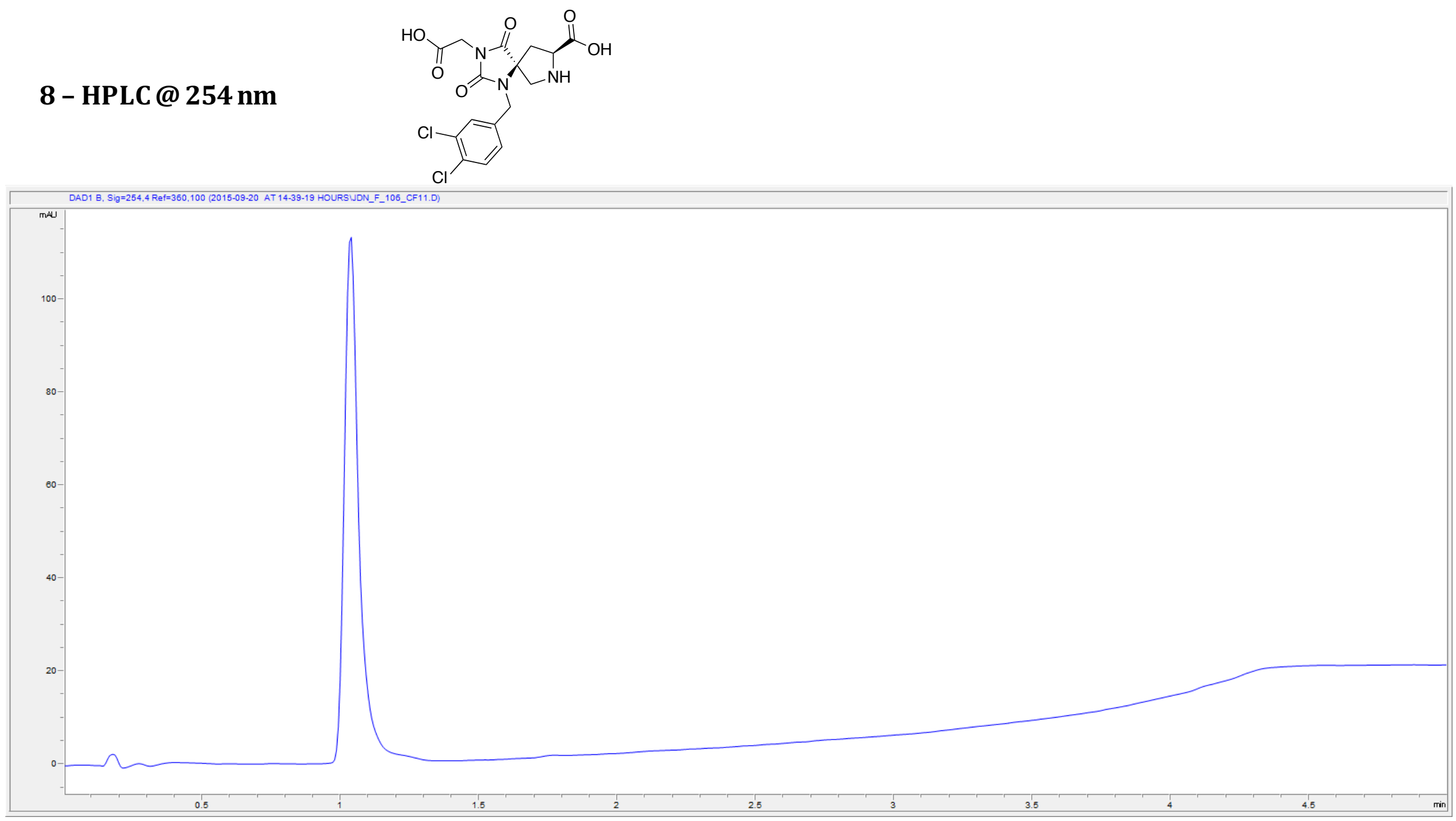
This report was created by ACD/NMR Processor Academic Edition. For more information go to www.acdlabs.com/nmrproc/

610601.esp

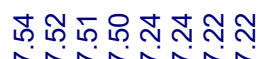

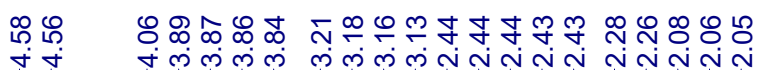

F106 1H DMSO proton.atm

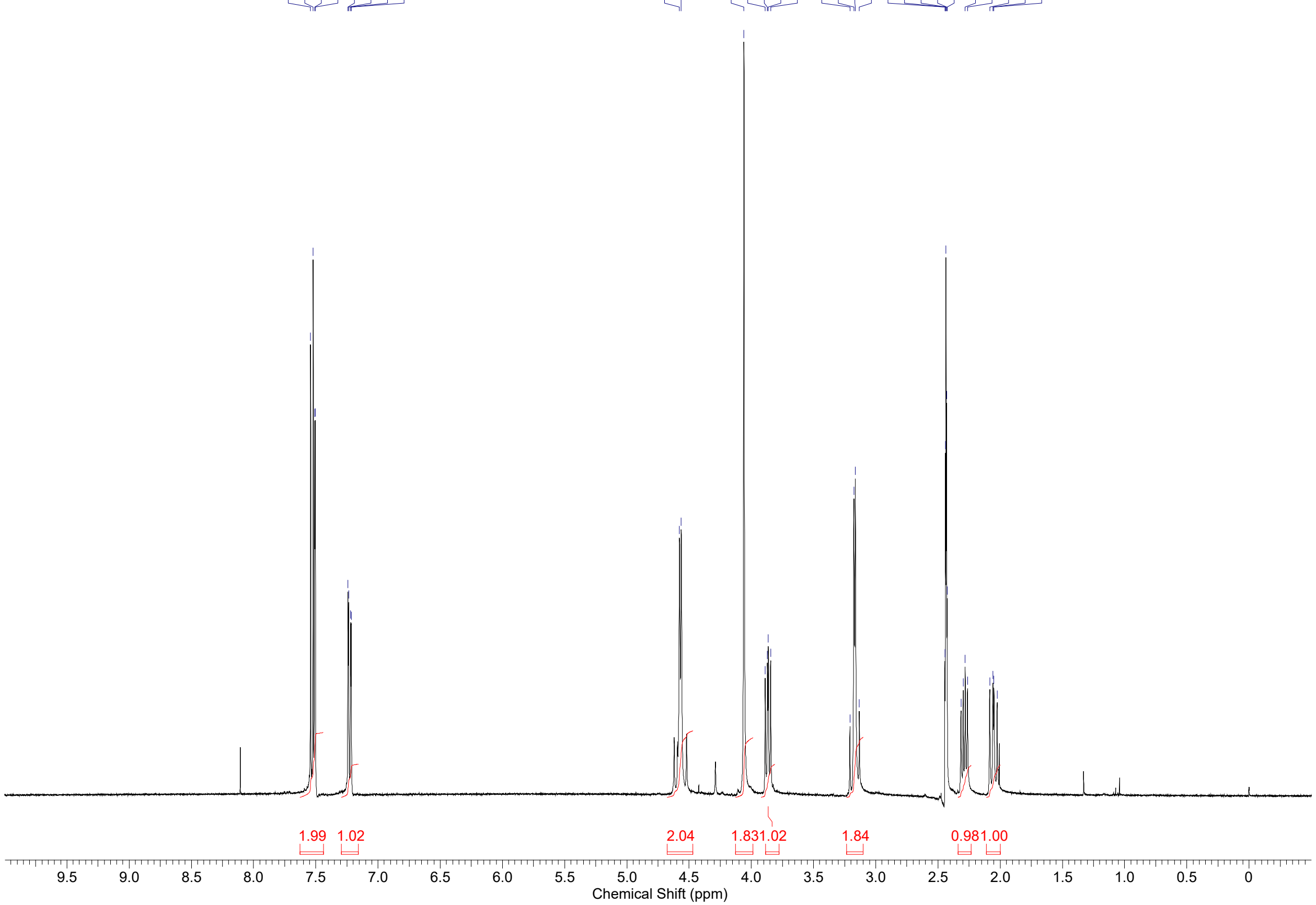


Page 42 of 127

This report was created by ACD/NMR Processor Academic Edition. For more information go to www.acdlabs.com/nmrproc/

\begin{tabular}{|c|c|c|c|c|}
\hline 610602.esp & 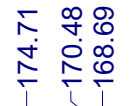 & ర్ & 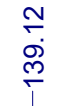 & 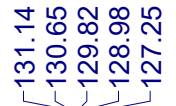 \\
\hline
\end{tabular}

F106 13C DMSO carbon10MIN.atm

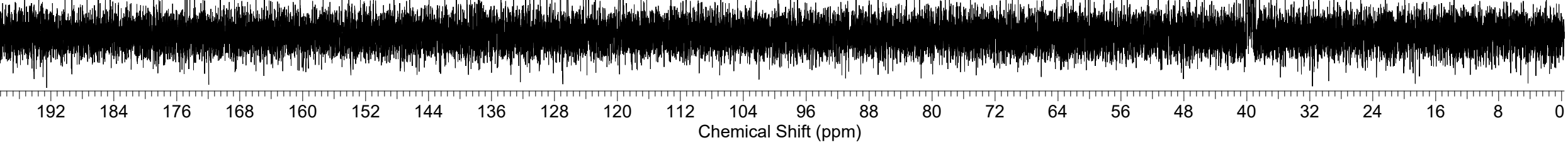


Page 43 of 127

This report was created by ACD/NMR Processor Academic Edition. For more information go to www.acdlabs.com/nmrproc/

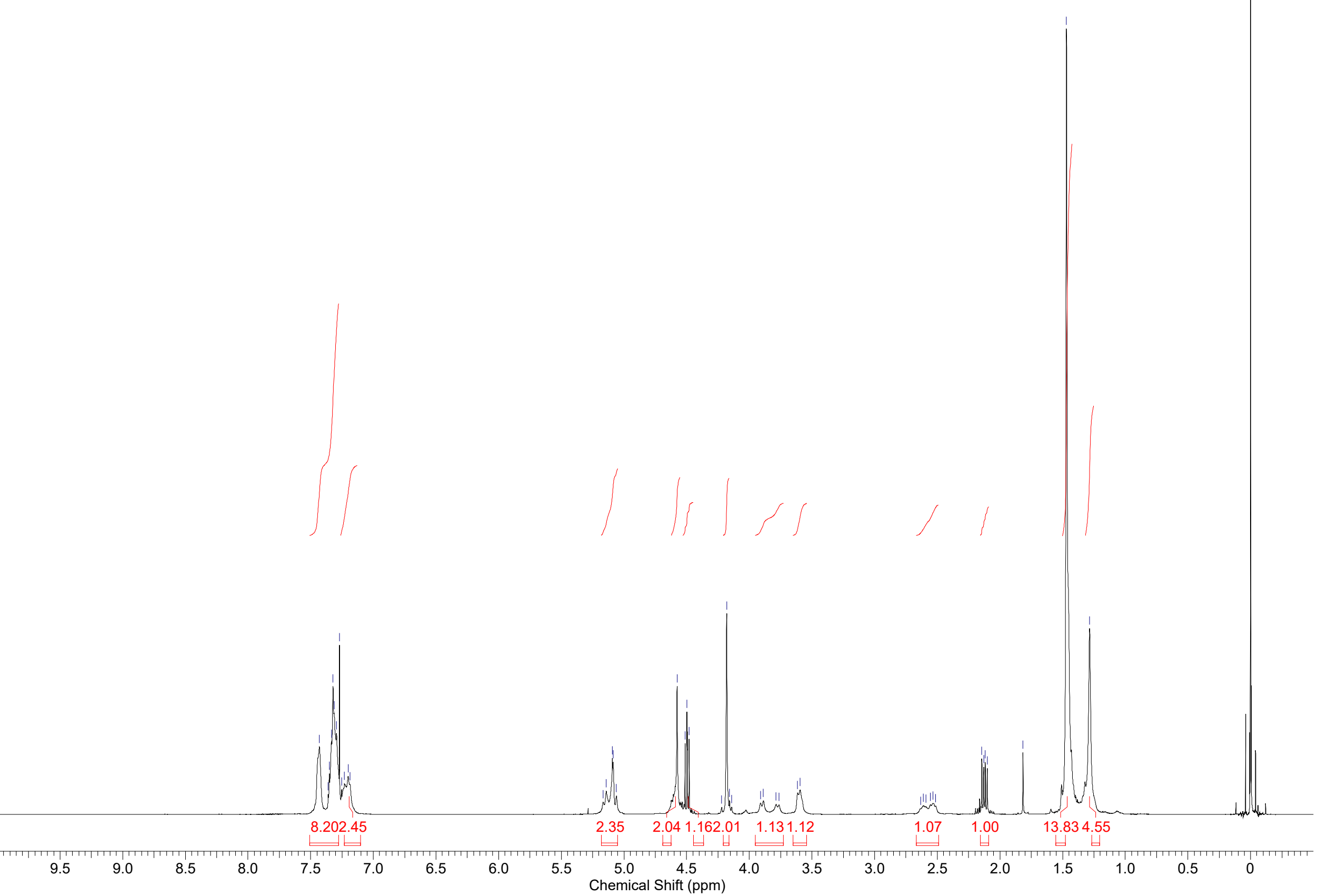


Page 44 of 127

This report was created by ACD/NMR Processor Academic Edition. For more information go to www.acdlabs.com/nmrproc/

$\begin{array}{llllll}\text { G_062_02.esp } & \infty & 0 & 0 & 0 & 0\end{array}$

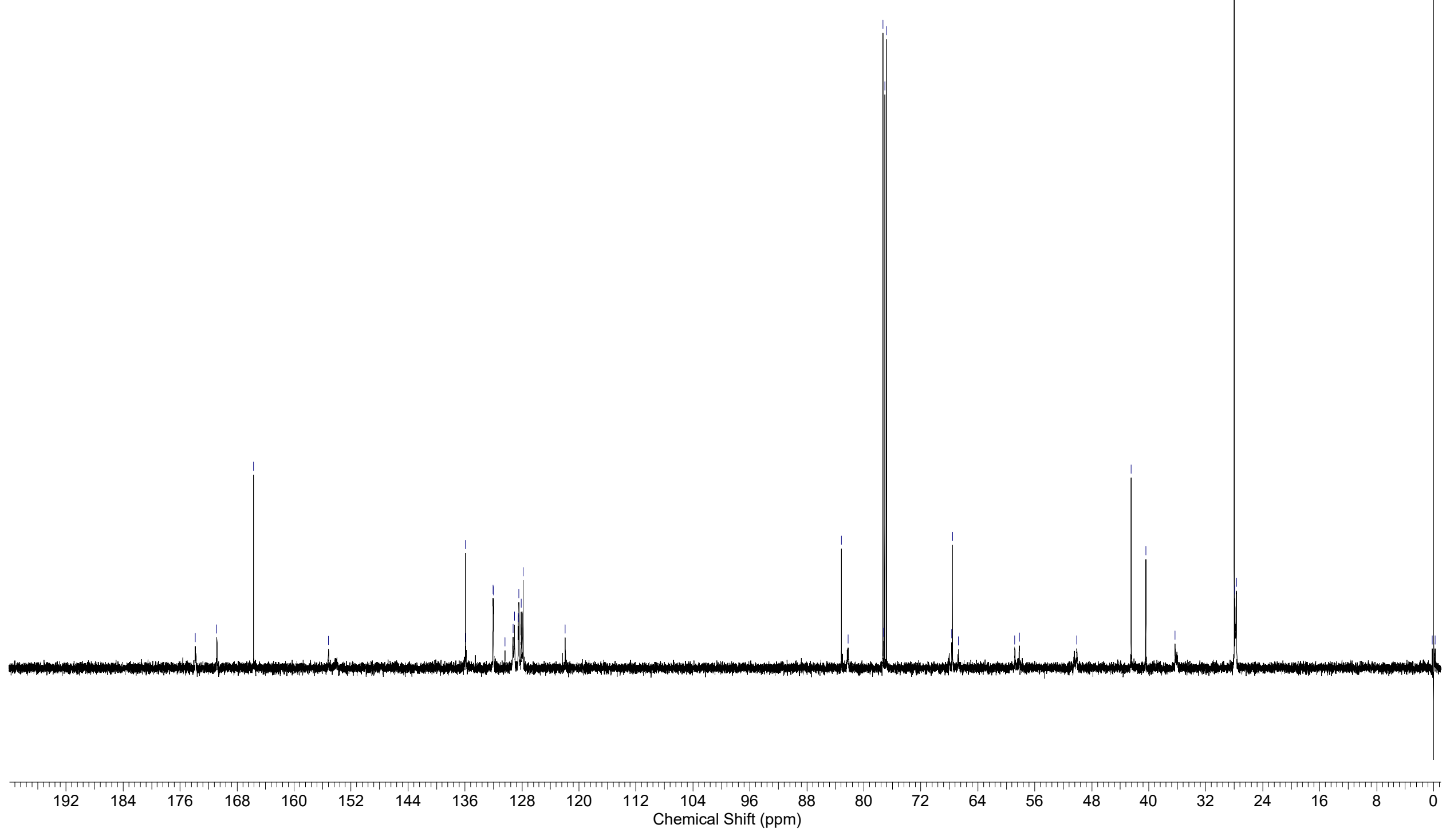




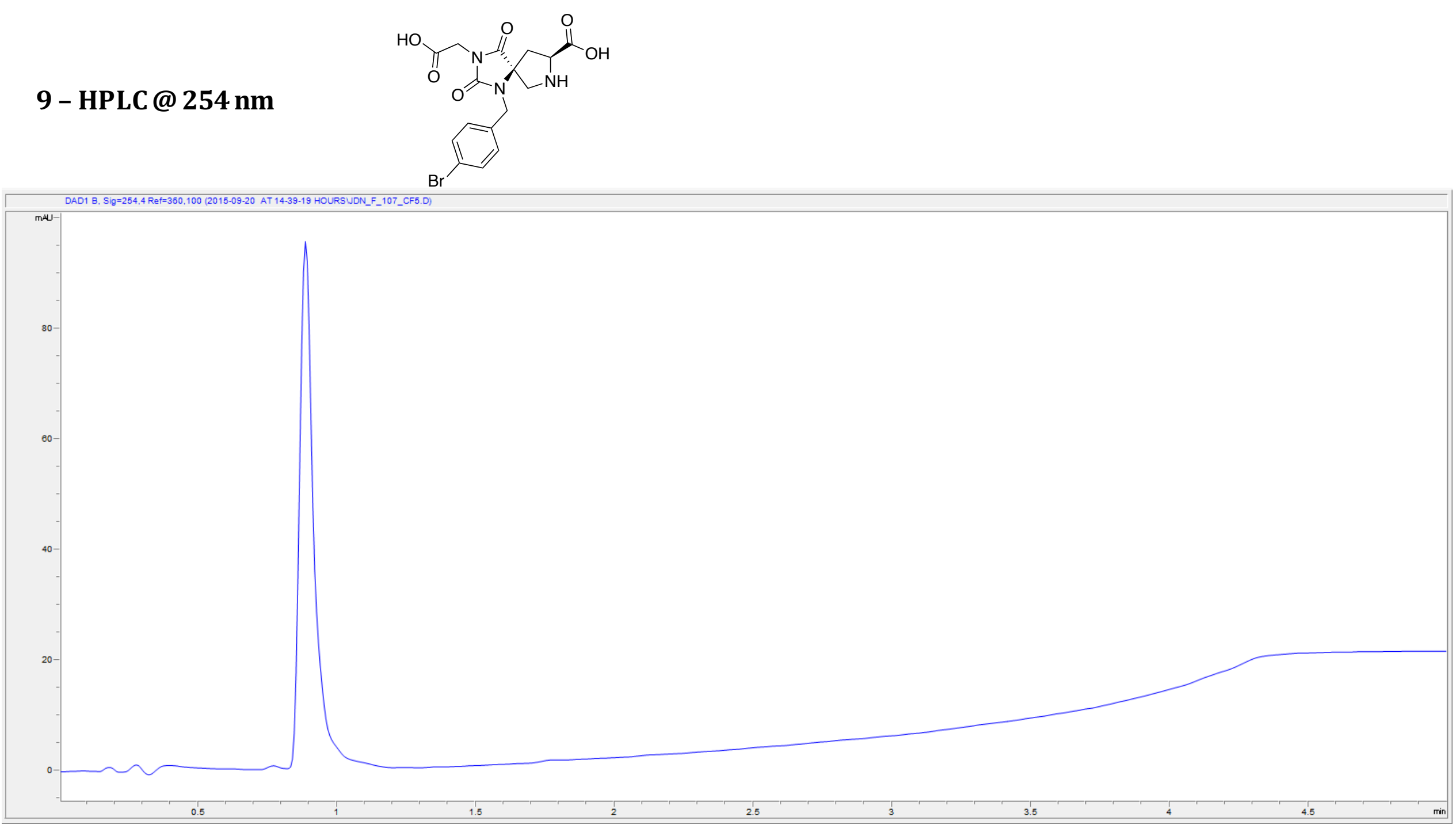


Page 46 of 127

This report was created by ACD/NMR Processor Academic Edition. For more information go to www.acdlabs.com/nmrproc/

610701.esp

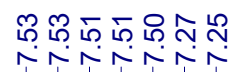

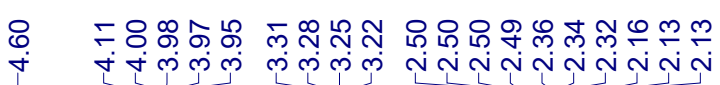

F107 1H DMSO proton.atm

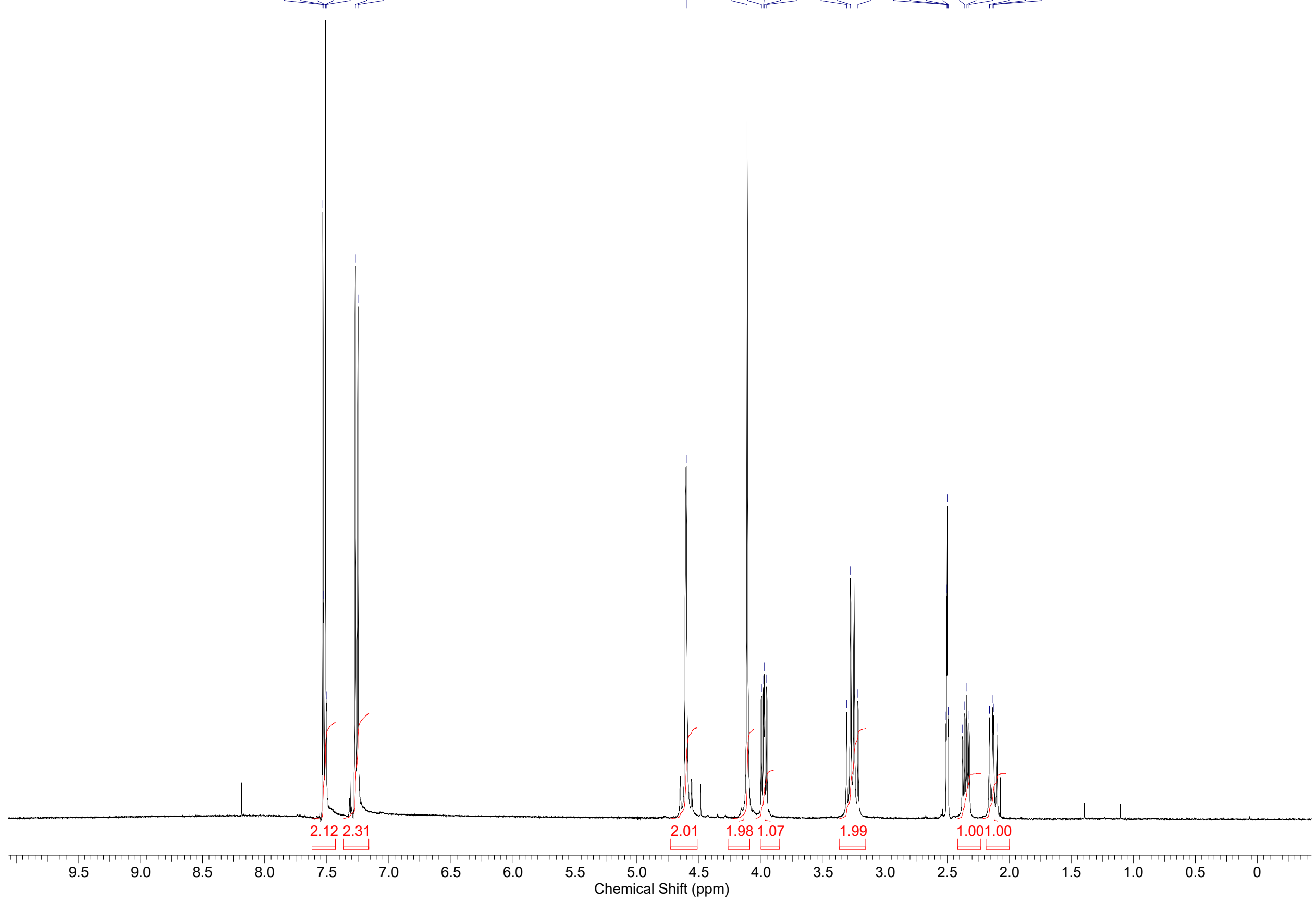


Page 47 of 127

This report was created by ACD/NMR Processor Academic Edition. For more information go to www.acdlabs.com/nmrproc/

F107 13C DMSO carbon30MIN.atm

\begin{tabular}{|c|c|c|c|c|c|c|c|c|c|}
\hline 610702.esp & 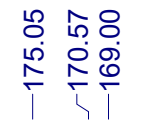 & 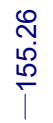 & $\begin{array}{l}\stackrel{8}{0} \\
\stackrel{m}{i}\end{array}$ & $\begin{array}{l}\text { 웅 } \\
\text { 혼 }\end{array}$ & \begin{tabular}{l}
\multirow{0}{0}{} \\
$\stackrel{N}{~}$
\end{tabular} & 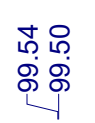 & $\begin{array}{l}\text { शे } \\
\text { ఠं } \\
1\end{array}$ & $\begin{array}{l}\stackrel{m}{+} \\
\stackrel{0}{\varphi}\end{array}$ & 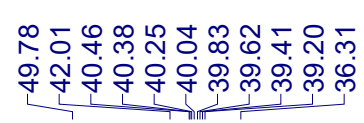 \\
\hline
\end{tabular}

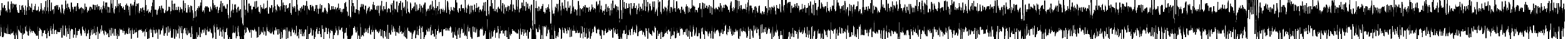


Page 48 of 127

This report was created by ACD/NMR Processor Academic Edition. For more information go to www.acdlabs.com/nmrproc/

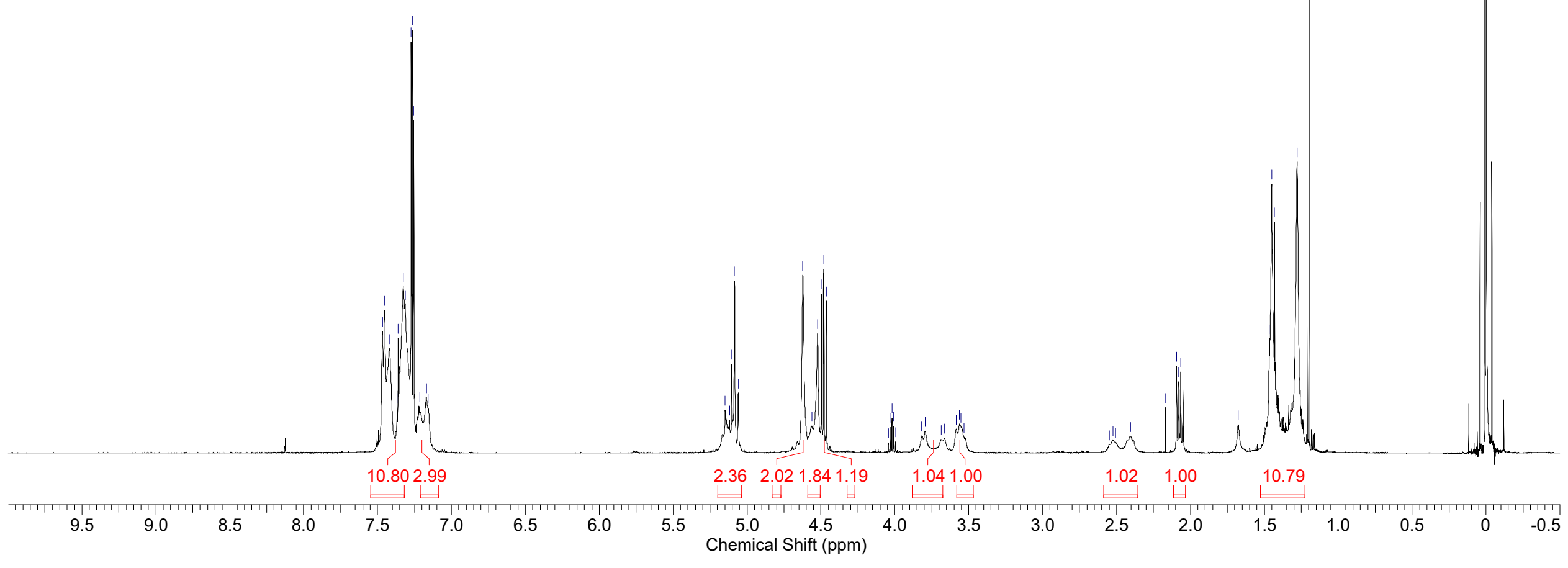


Page 49 of 127

This report was created by ACD/NMR Processor Academic Edition. For more information go to www.acdlabs.com/nmrproc/

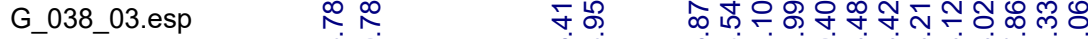

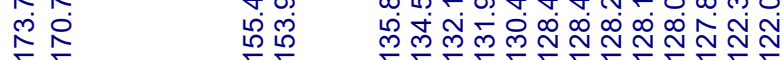
N

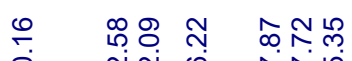

施

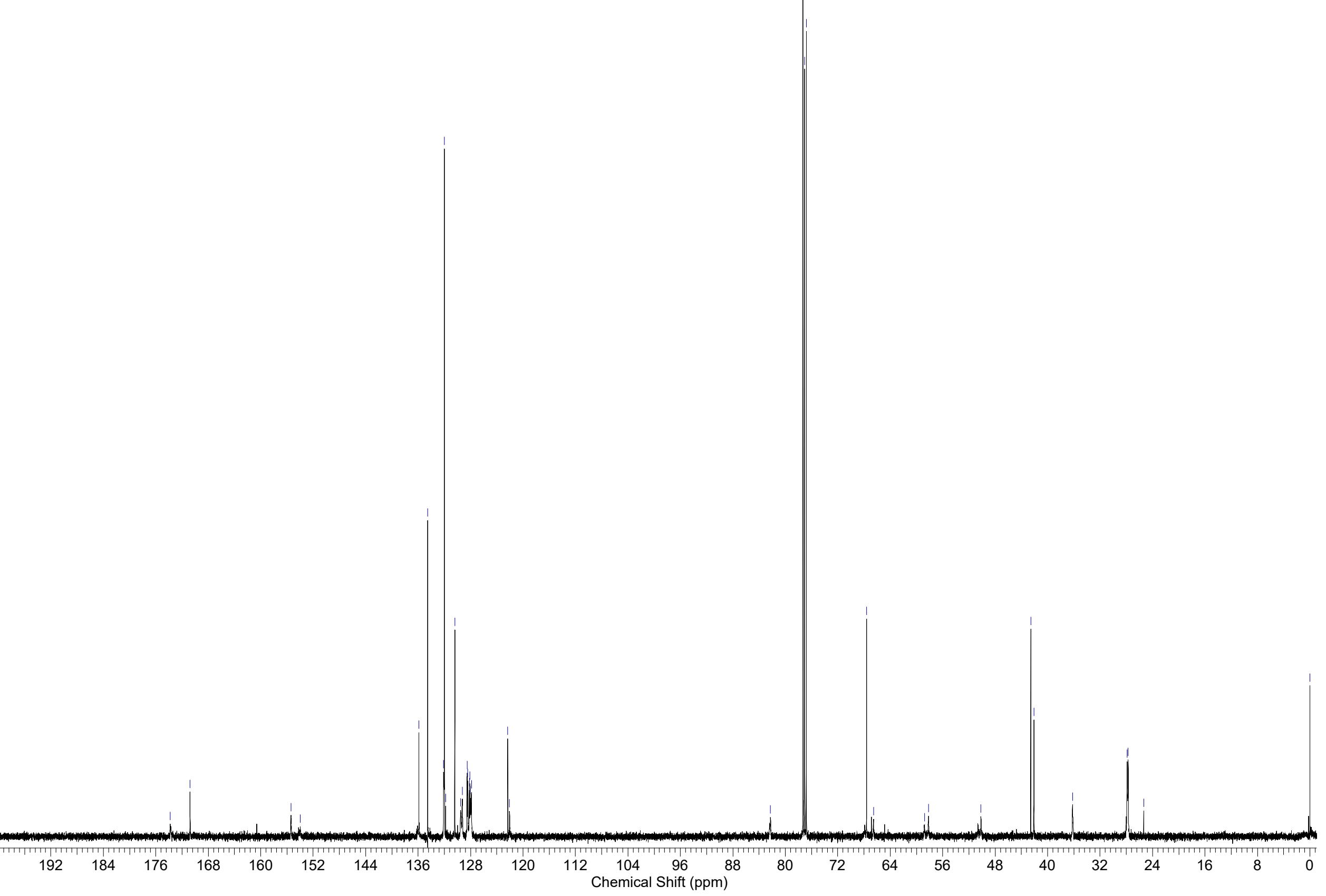




\section{0 - HPLC@ 220 nm}
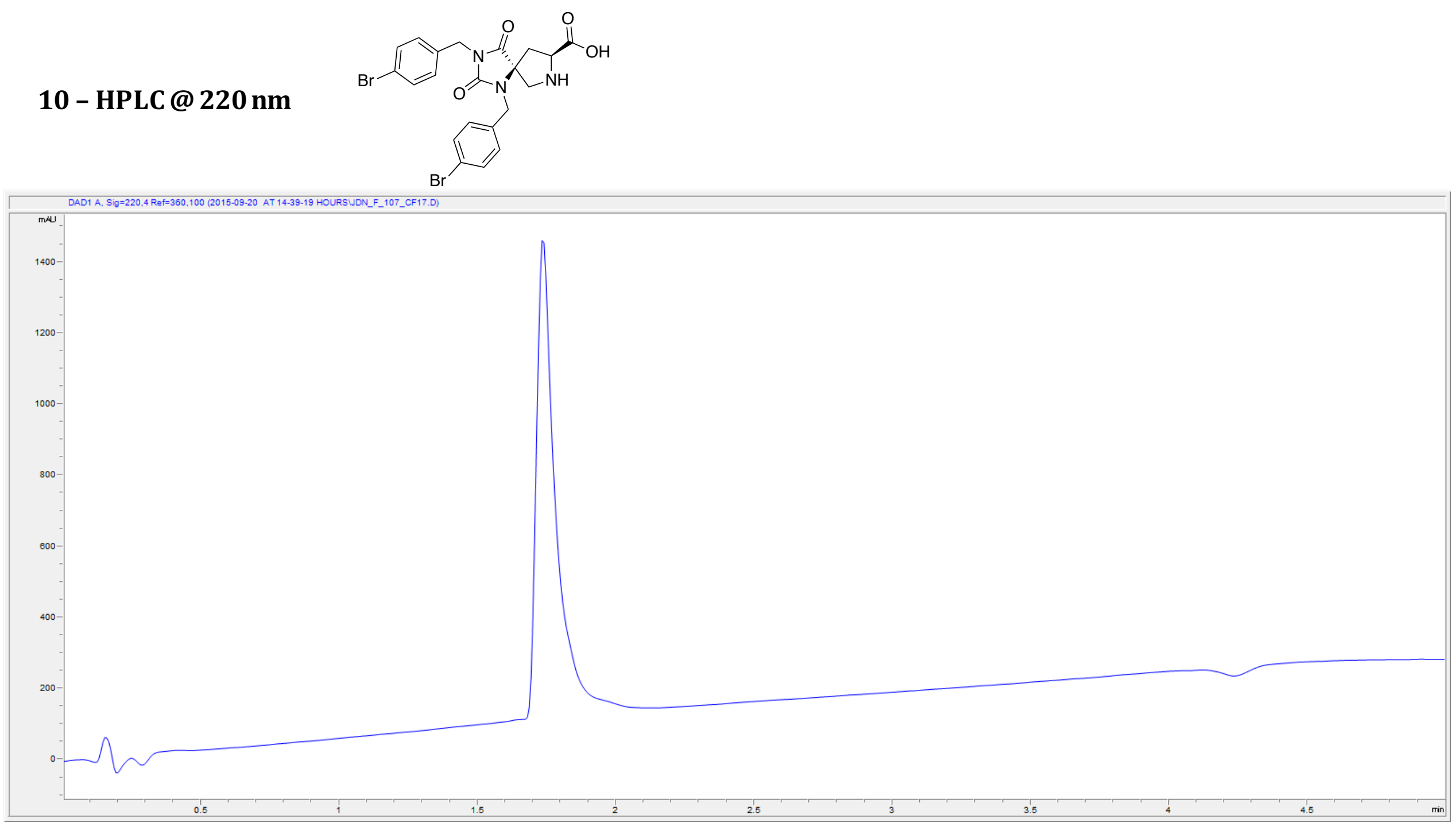
Page 51 of 127

This report was created by ACD/NMR Processor Academic Edition. For more information go to www.acdlabs.com/nmrproc/

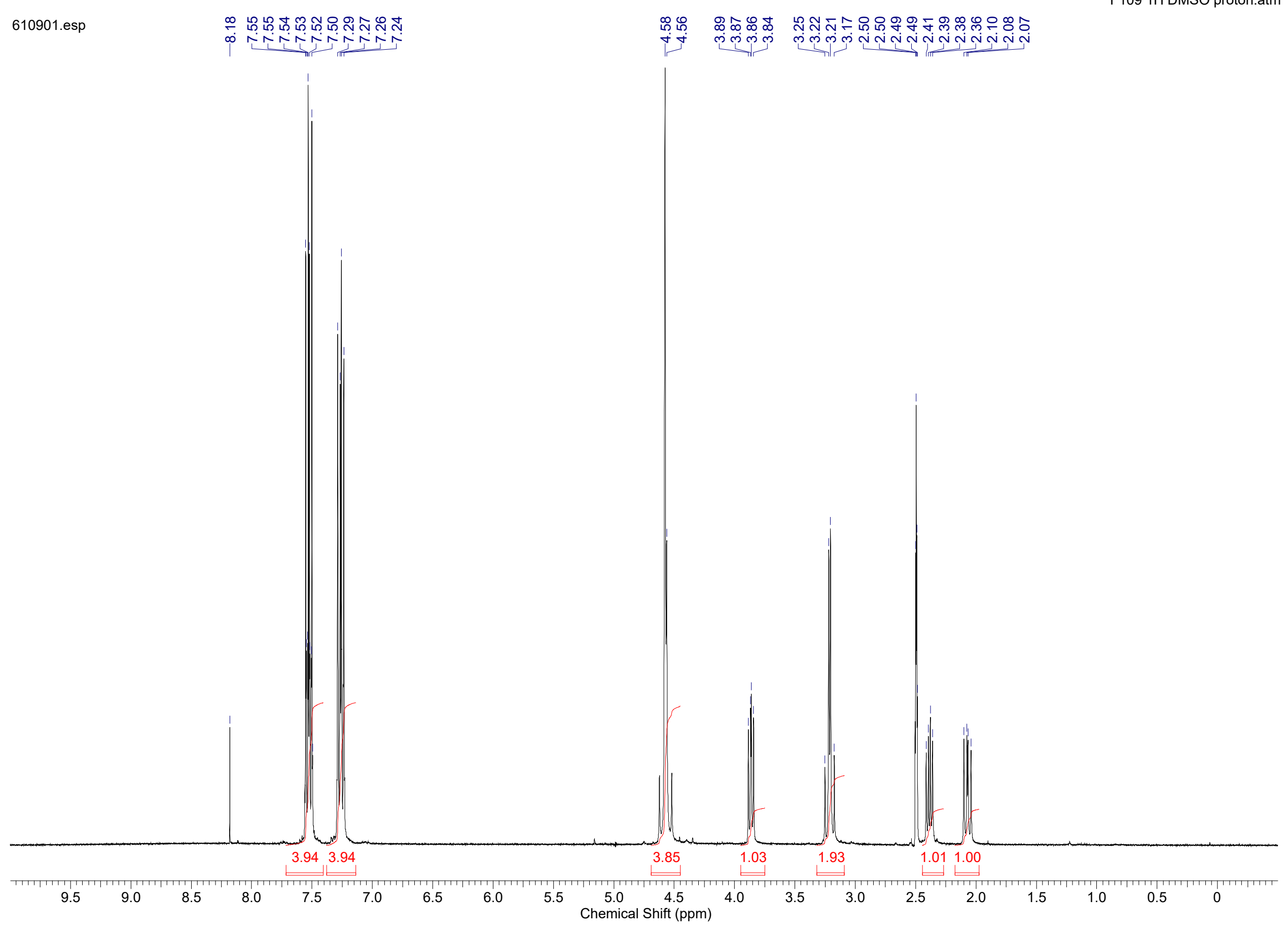


Page 52 of 127

This report was created by ACD/NMR Processor Academic Edition. For more information go to www.acdlabs.com/nmrproc/

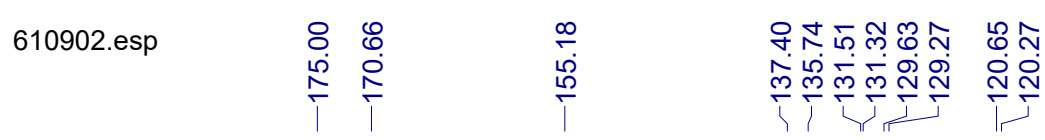

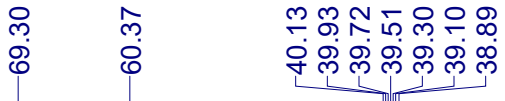

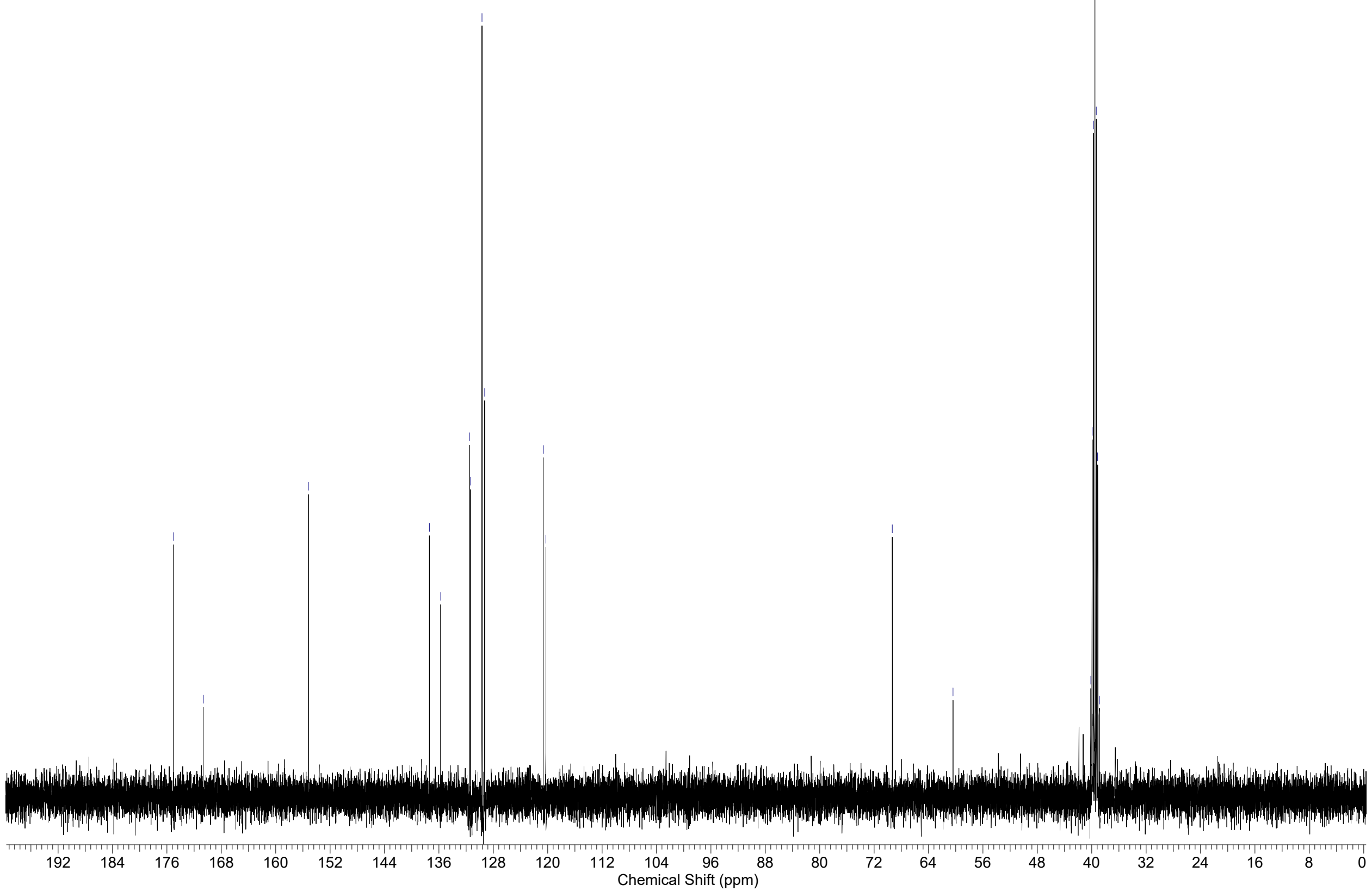


Page 53 of 127

This report was created by ACD/NMR Processor Academic Edition. For more information go to www.acdlabs.com/nmrproc/ 611801.esp

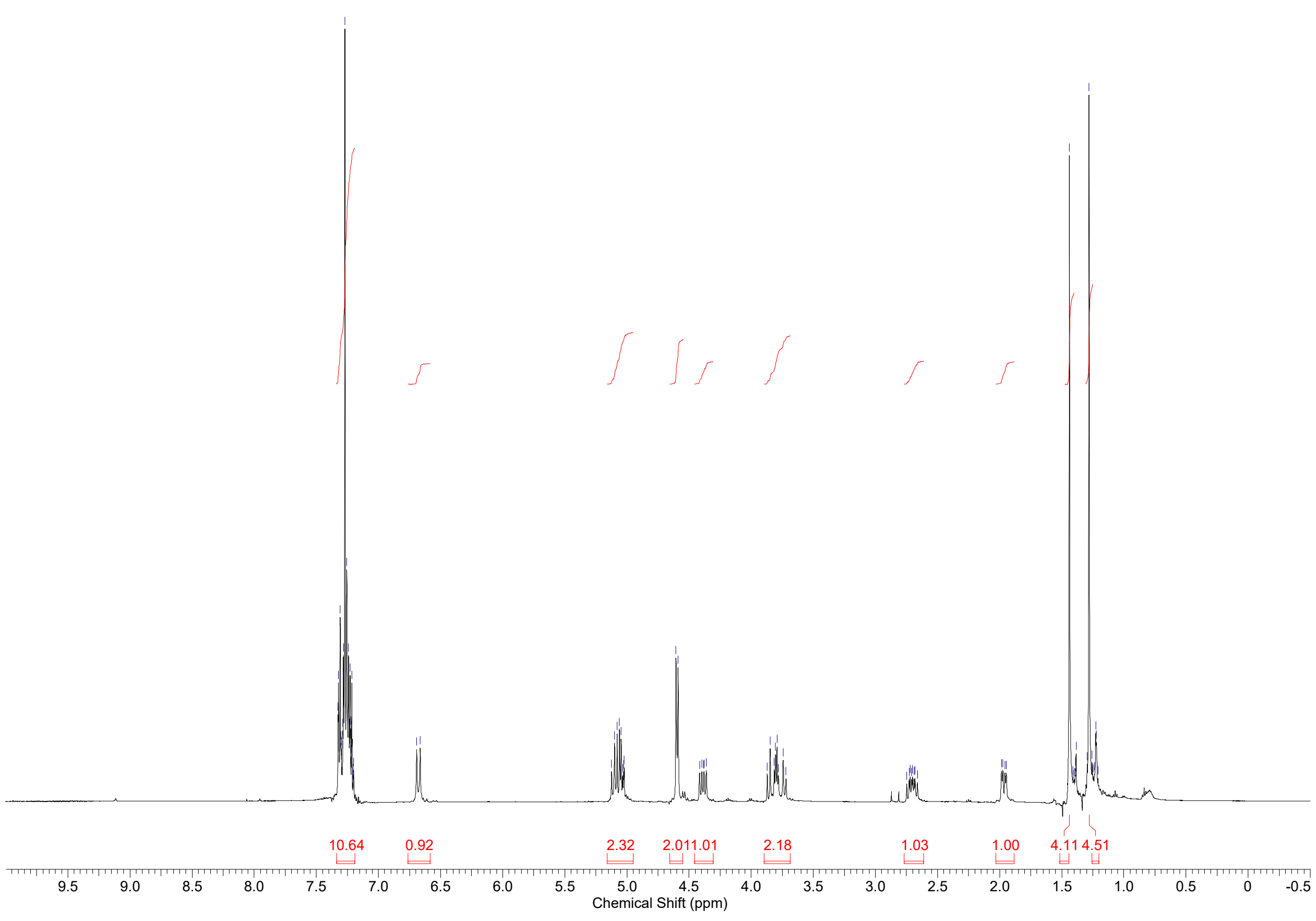


Page 54 of 127

This report was created by ACD/NMR Processor Academic Edition. For more information go to www.acdlabs.com/nmrproc/

611802.pdf.esp

\begin{tabular}{|c|c|}
\hline$\vec{v}$ & 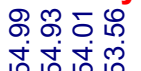 \\
\hline
\end{tabular}

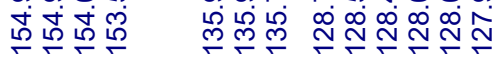

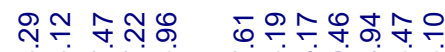

นํ요

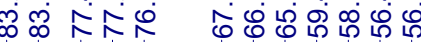

ㄱํํं लं

กัก

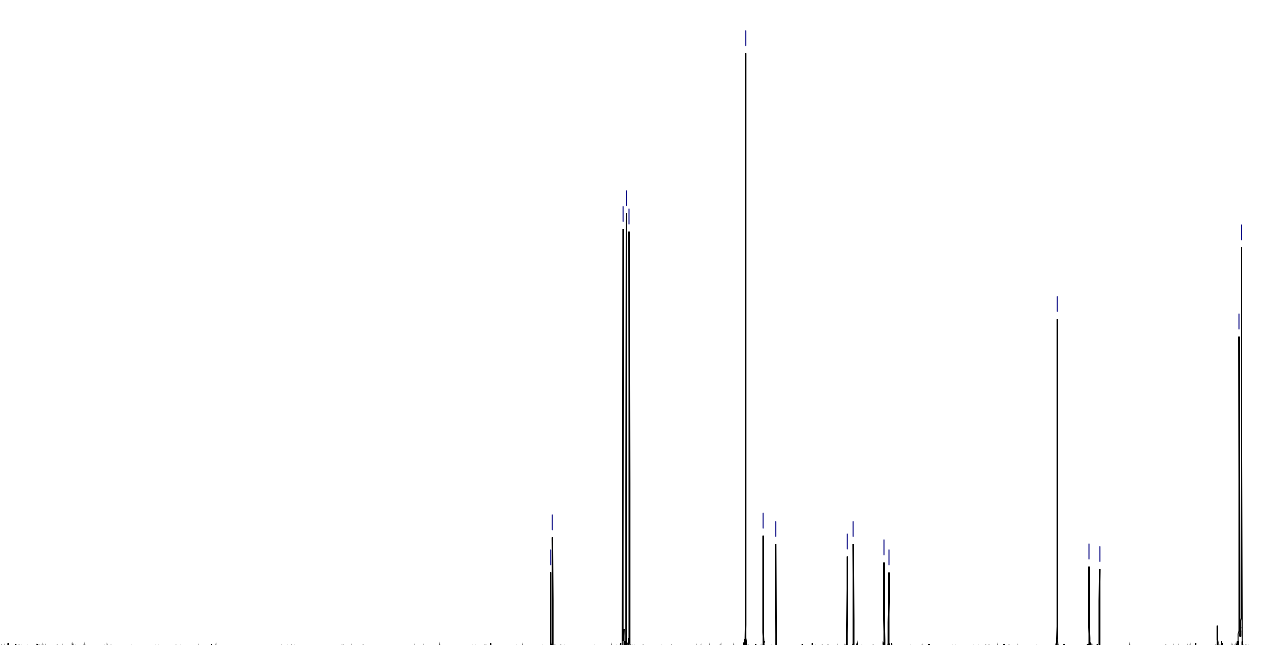

192

$84 \quad 176$ 
Page 55 of 127

This report was created by ACD/NMR Processor Academic Edition. For more information go to www.acdlabs.com/nmrproc/

703401.esp

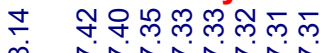

స̃

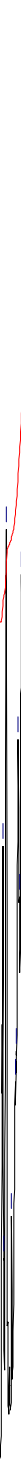

15.75

(5.75

6.5

2.152 .082 .050 .94

$4.0 \quad 3.5$

$\begin{array}{cc}5.0 & 4.5 \\ \text { Chemical Shift (ppm) }\end{array}$ 
Page 56 of 127

This report was created by ACD/NMR Processor Academic Edition. For more information go to www.acdlabs.com/nmrproc/

703402.esp
吕 ฮ
进的的N

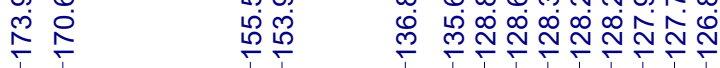

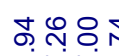

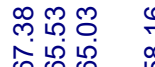

유

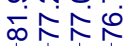

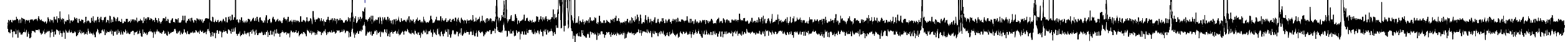

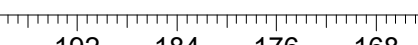


Page 57 of 127

This report was created by ACD/NMR Processor Academic Edition. For more information go to www.acdlabs.com/nmrproc/ 702201.esp

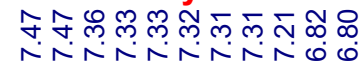

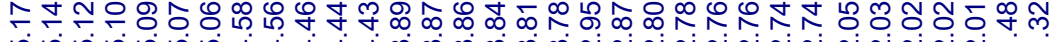

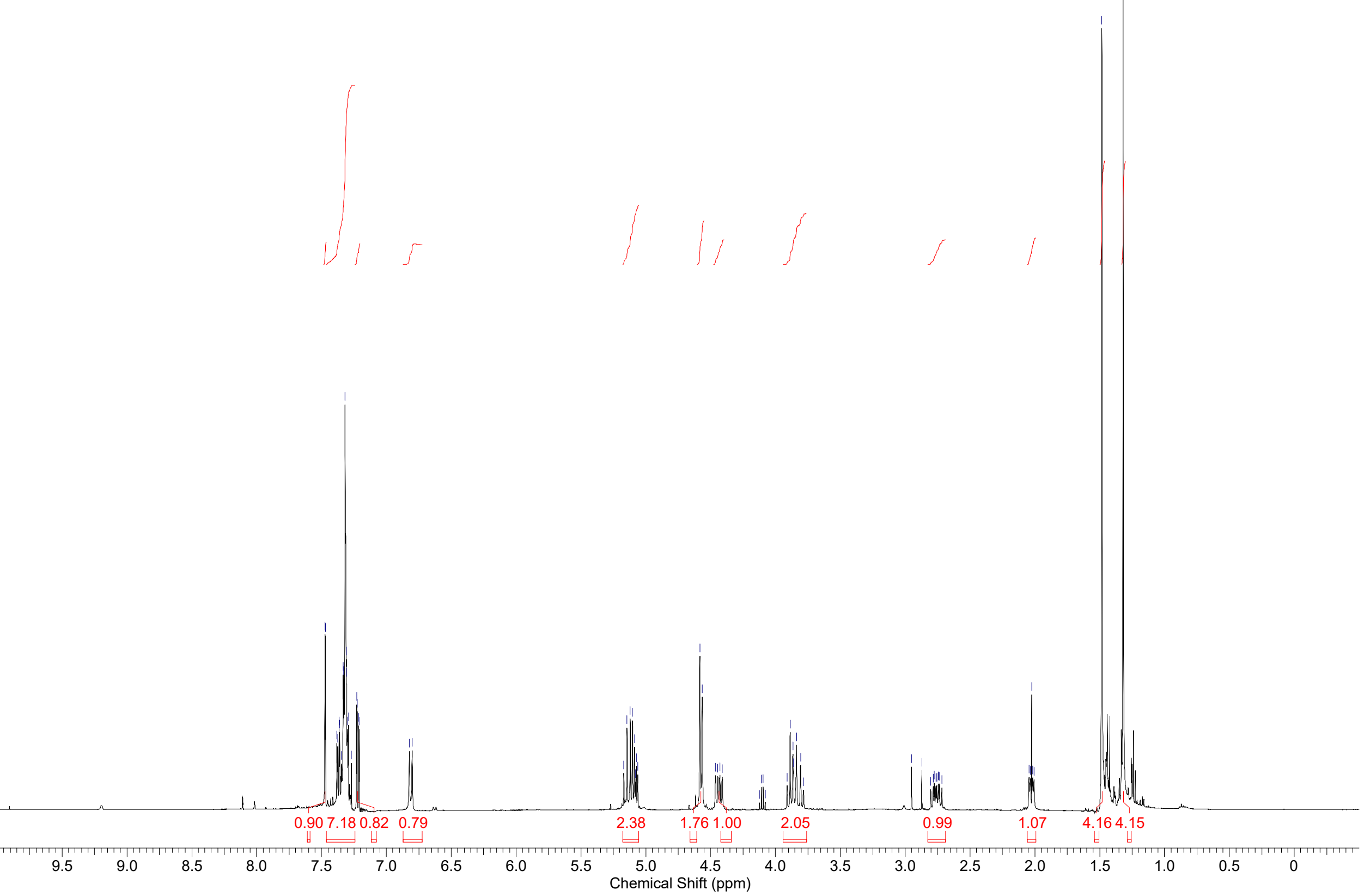


Page 58 of 127

This report was created by ACD/NMR Processor Academic Edition. For more information go to www.acdlabs.com/nmrproc/

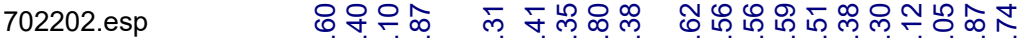

Nine

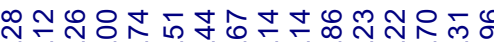

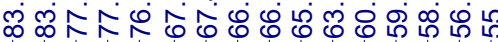

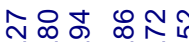

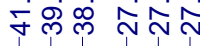

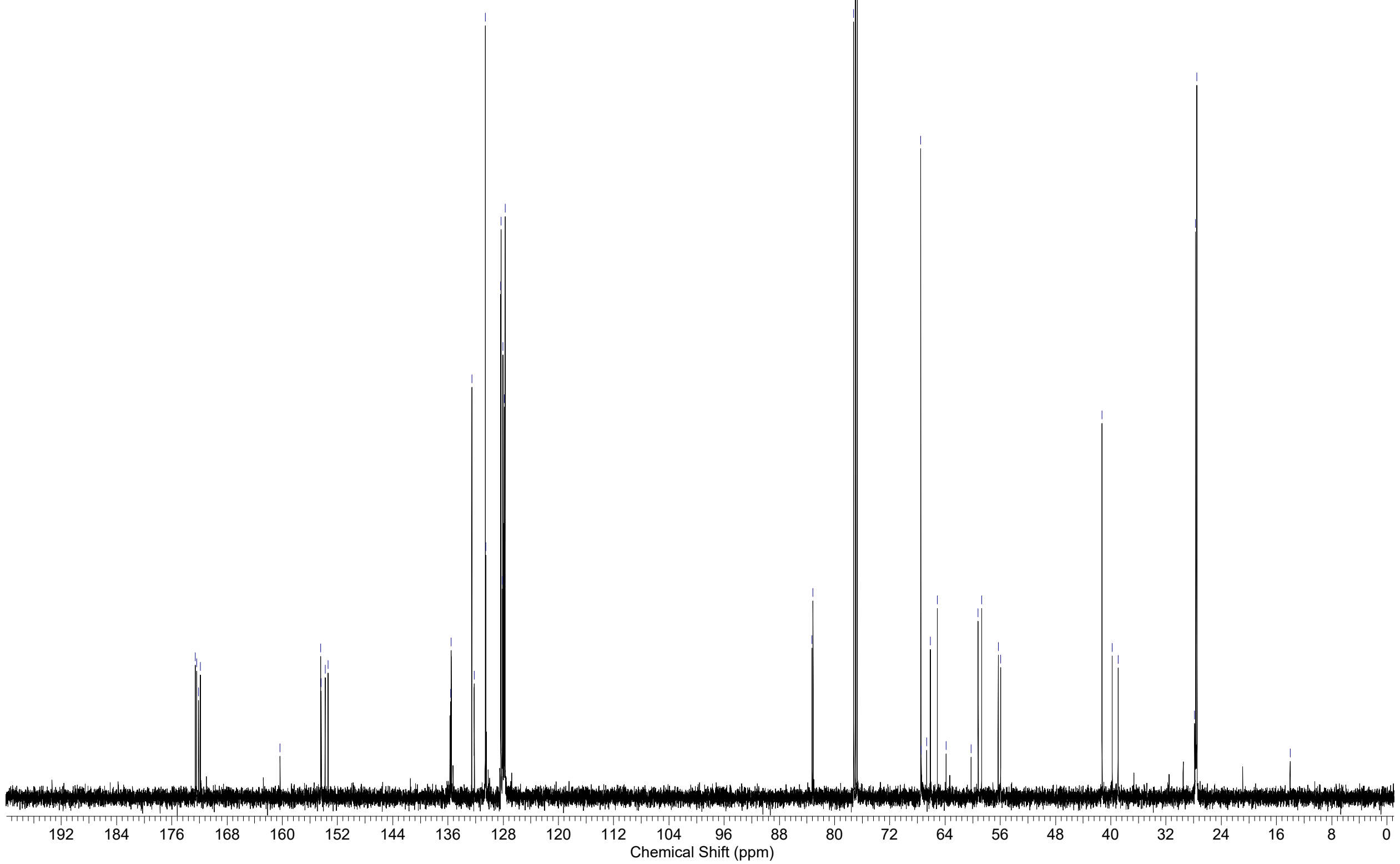


Page 59 of 127

This report was created by ACD/NMR Processor Academic Edition. For more information go to www.acdlabs.com/nmrproc/

704201.esp

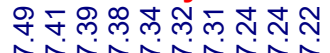

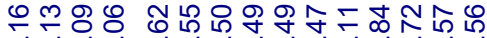

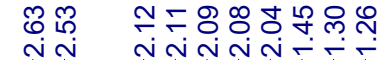

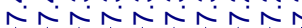

ம் ம் ம்

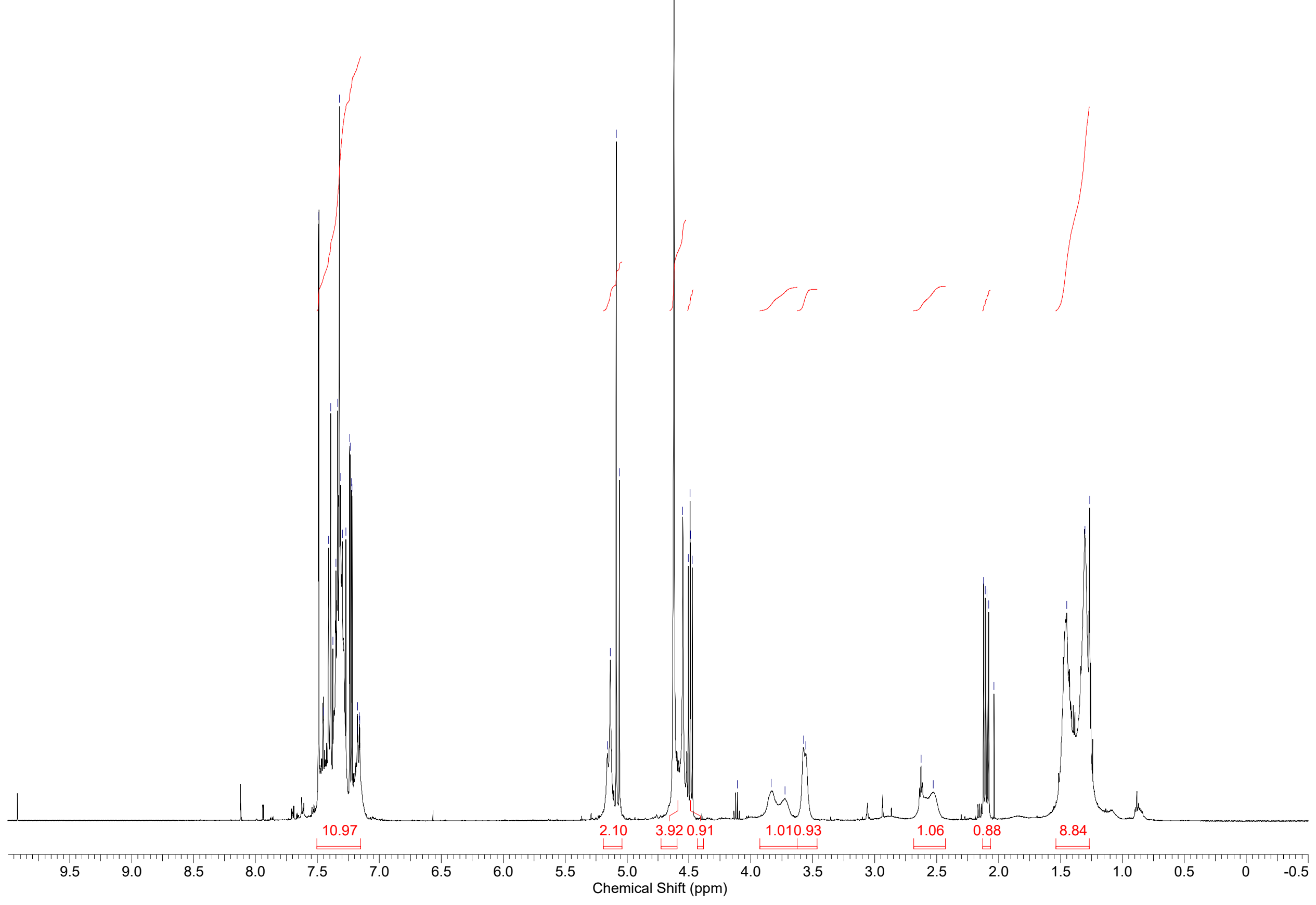


Page 60 of 127

G_042_002.esp

This report was created by ACD/NMR Processor Academic Edition. For more information go to www.acdlabs.com/nmrproc/

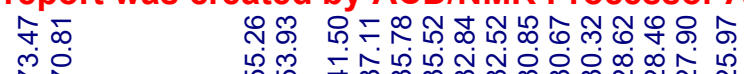

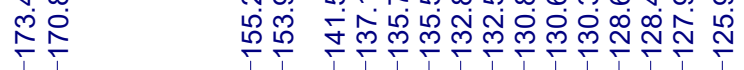

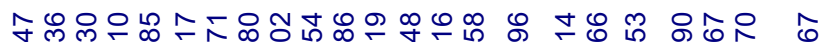

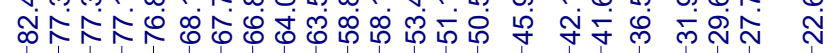

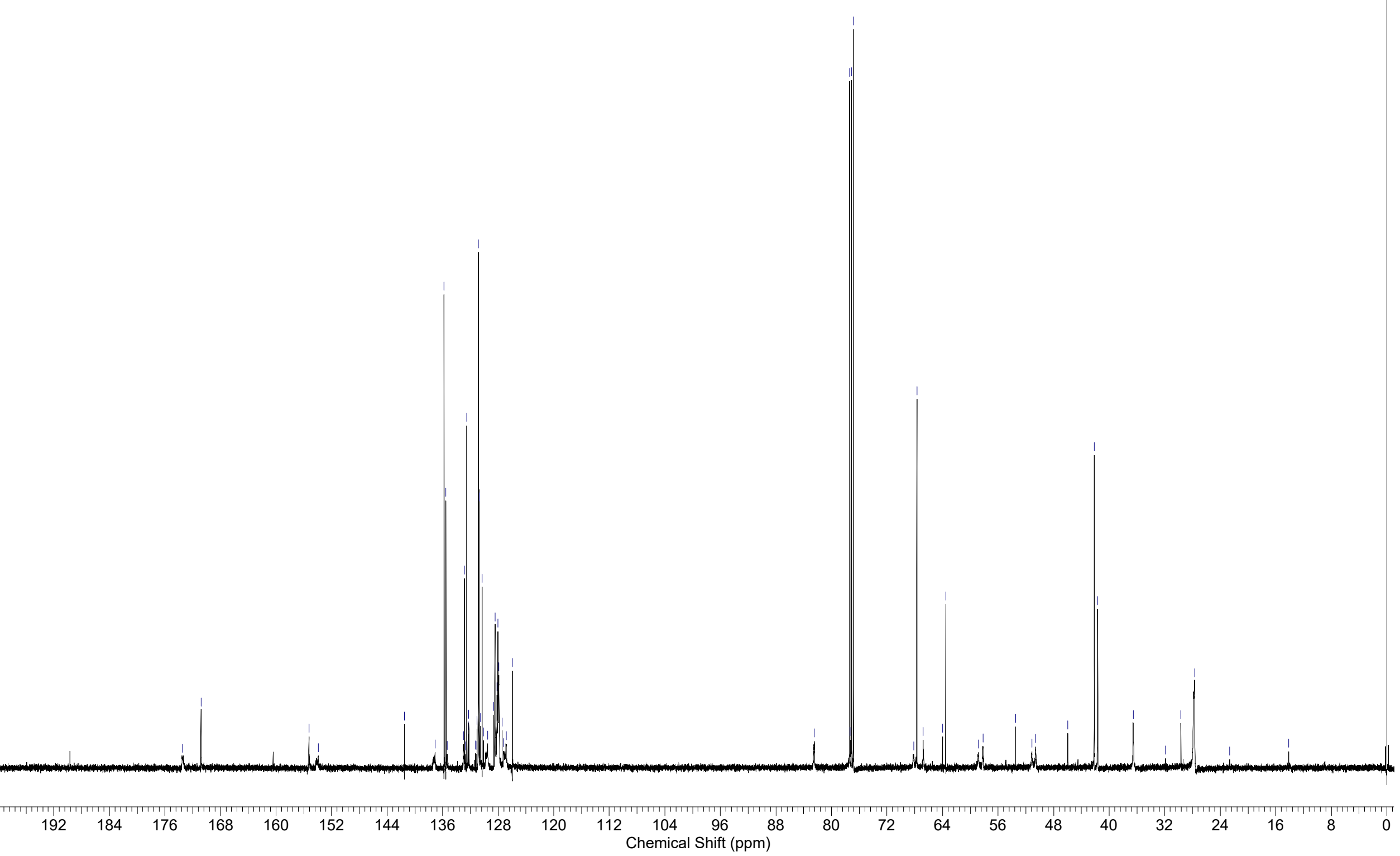


Page 61 of 127

This report was created by ACD/NMR Processor Academic Edition. For more information go to www.acdlabs.com/nmrproc/ 615801.esp

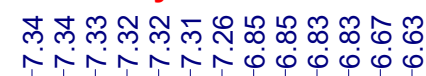

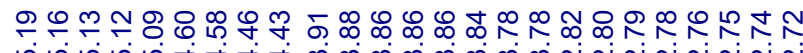

ษัธ

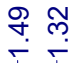

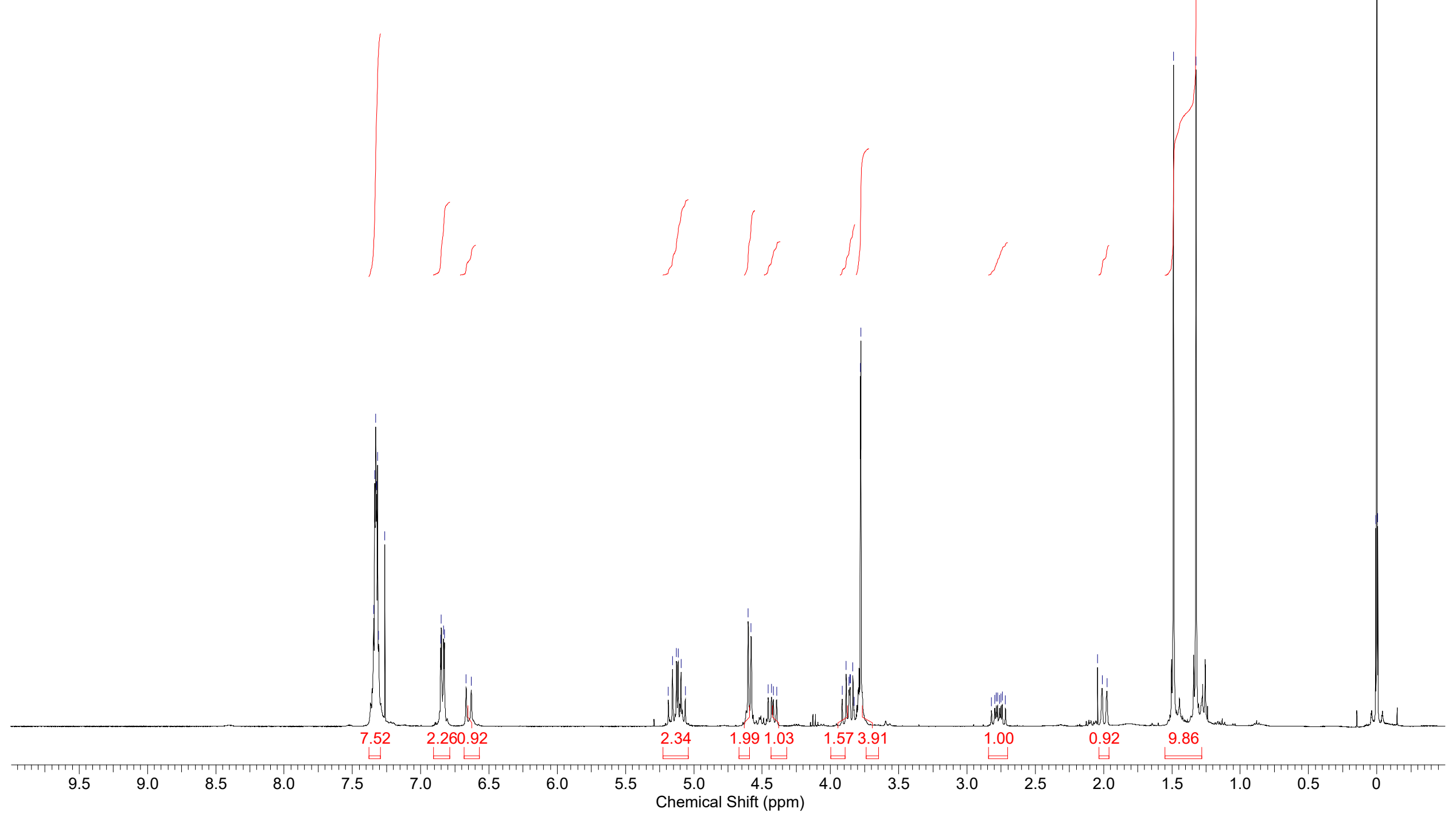


Page 62 of 127

This report was created by ACD/NMR Processor Academic Edition. For more information go to www.acdlabs.com/nmrproc/

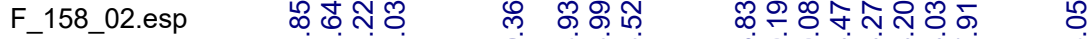

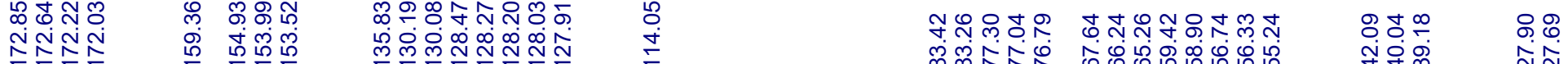

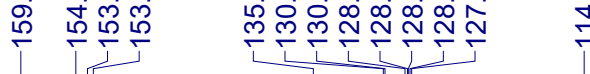

i่

ษ่

ลิ่ง

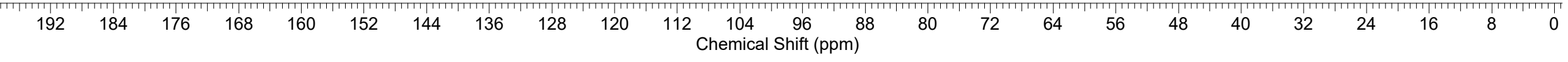


Page 63 of 127

This report was created by ACD/NMR Processor Academic Edition. For more information go to www.acdlabs.com/nmrproc/ 703501.esp

舟

ம்

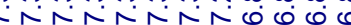
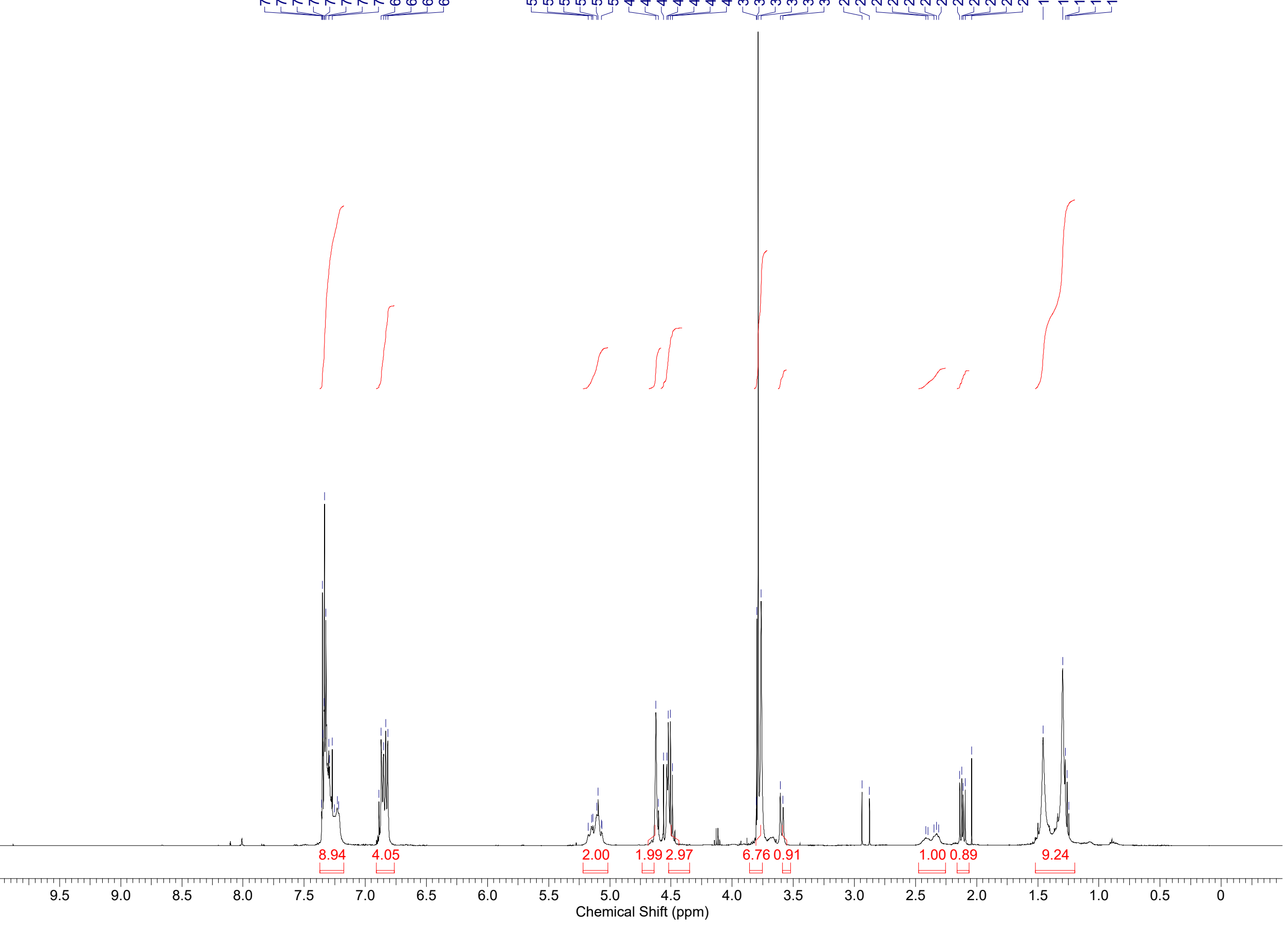
Page 64 of 127

This report was created by ACD/NMR Processor Academic Edition. For more information go to www.acdlabs.com/nmrproc/

703502.esp
$=\infty \quad 0 \% \bar{m}$

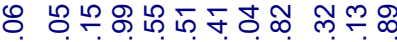
空定

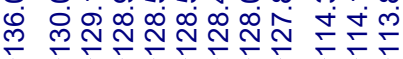

৪)

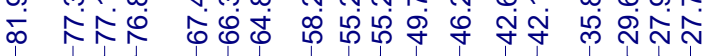

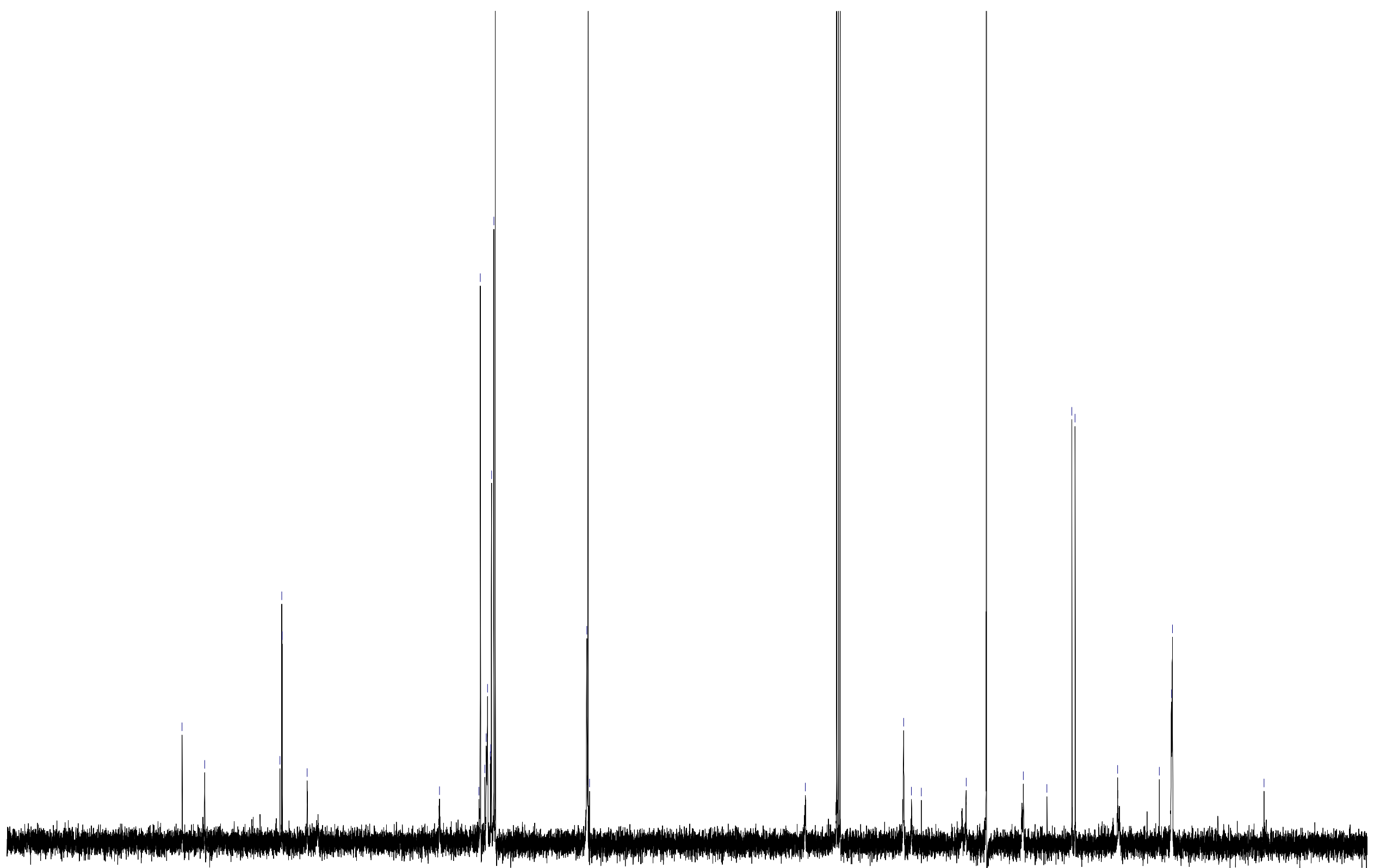


Page 66 of 127

\section{F_159_02.esp}

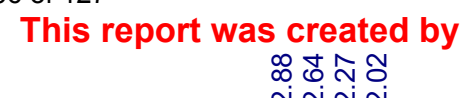

ํํำ

ing

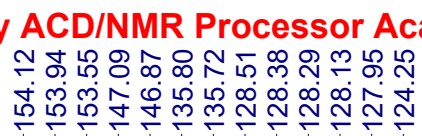

For more information go to www.acdlabs.com/nmrproc/

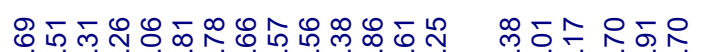
ळ

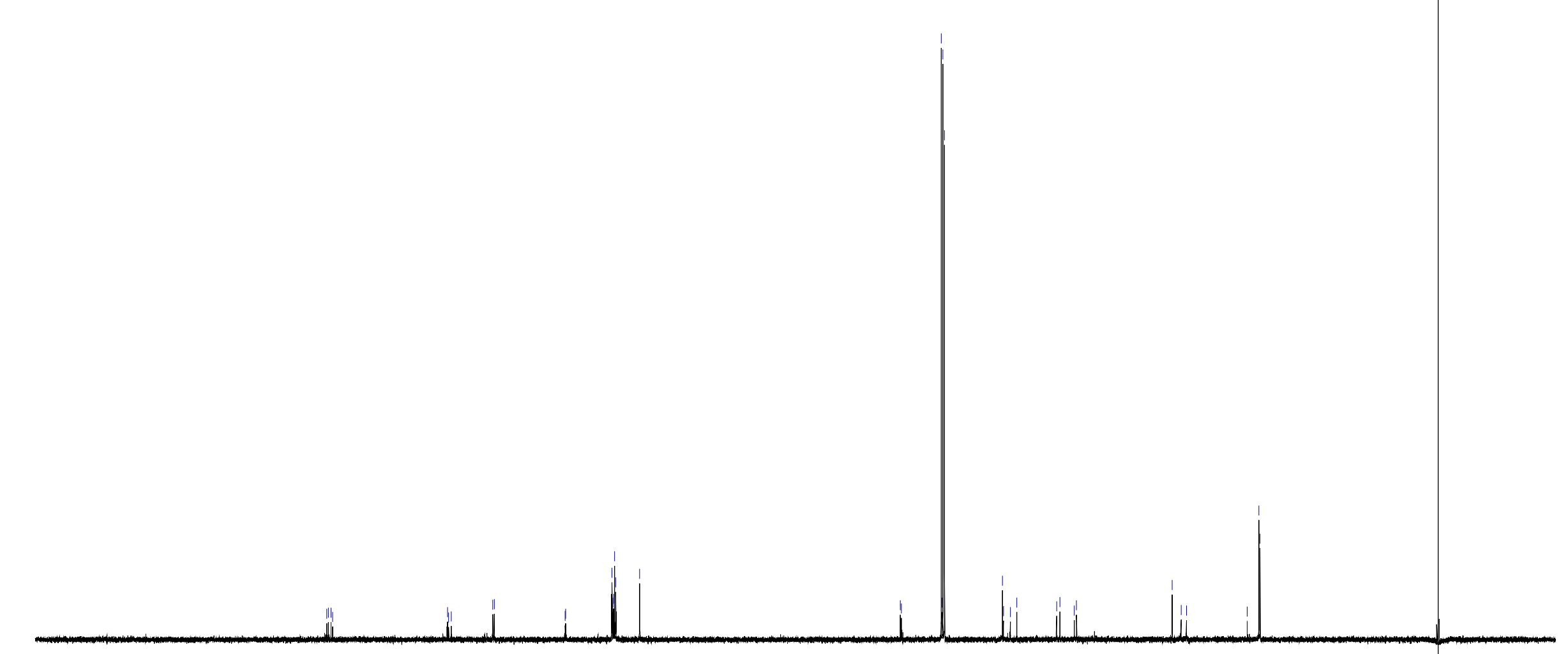


Page 67 of 127

This report was created by ACD/NMR Processor Academic Edition. For more information go to www.acdlabs.com/nmrproc/

702901.esp

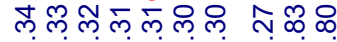

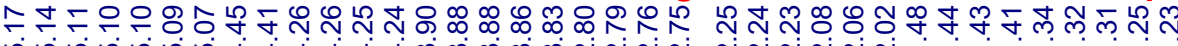

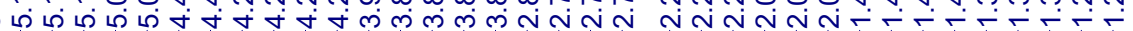

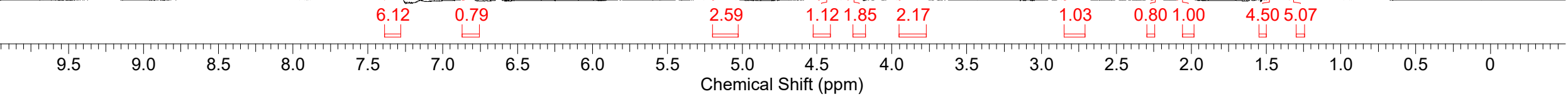


Page 68 of 127

This report was created by ACD/NMR Processor Academic Edition. For more information go to www.acdlabs.com/nmrproc/

702902.esp

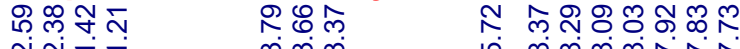

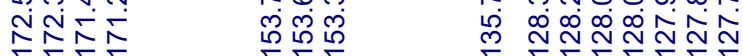

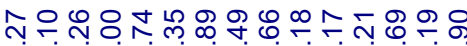

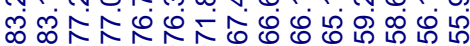

요 수쇼요

mळ

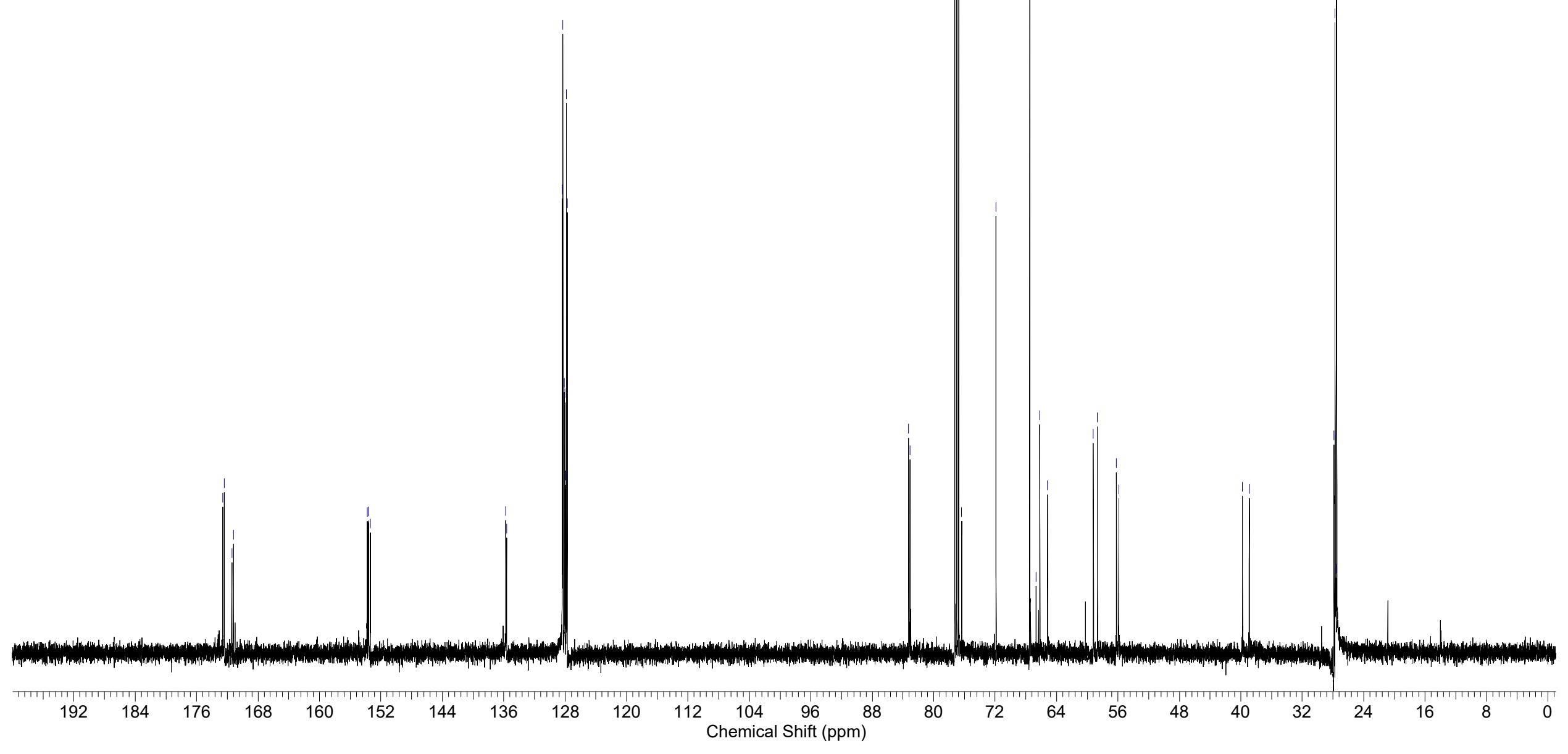


Page 69 of 127

This report was created by ACD/NMR Processor Academic Edition. For more information go to www.acdlabs.com/nmrproc/ 705101.esp

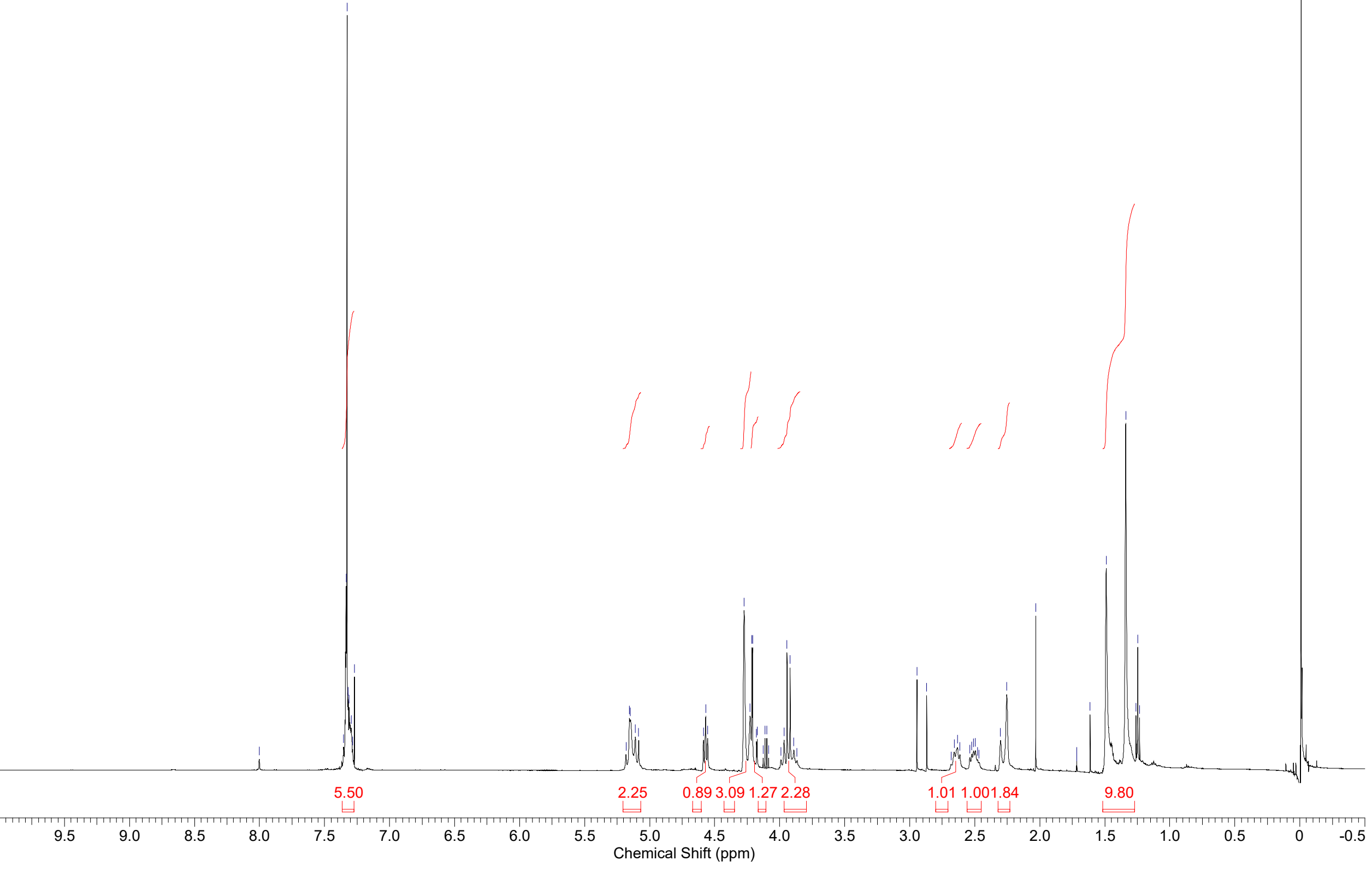


Page 70 of 127

This report was created by ACD/NMR Processor Academic Edition. For more information go to www.acdlabs.com/nmrproc/

705102.esp

N $m-1$

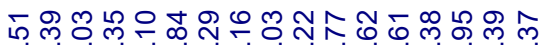

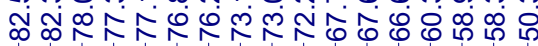

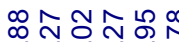

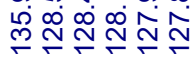

ம்

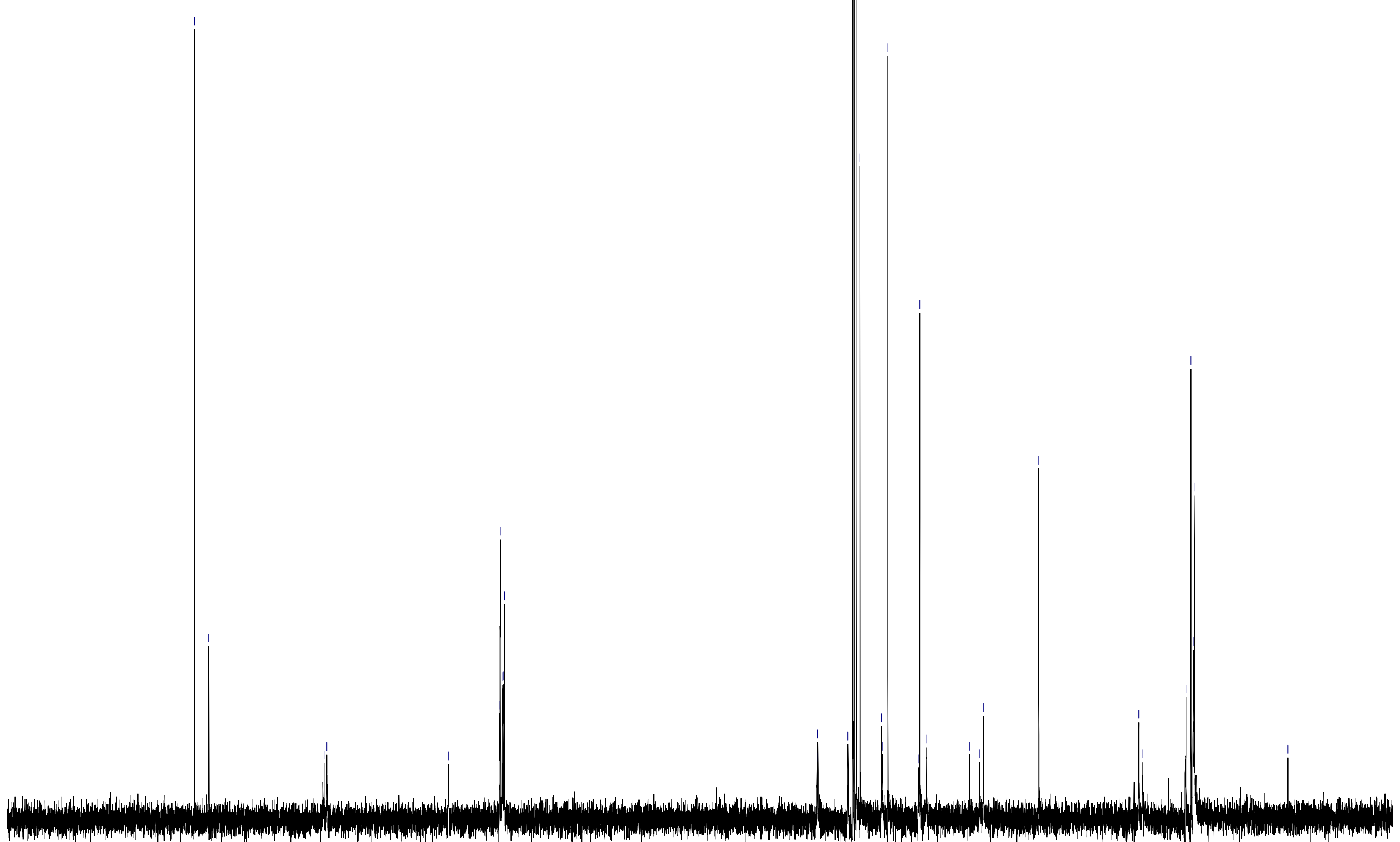


Page 71 of 127

This report was created by ACD/NMR Processor Academic Edition. For more information go to www.acdlabs.com/nmrproc/

702301.esp

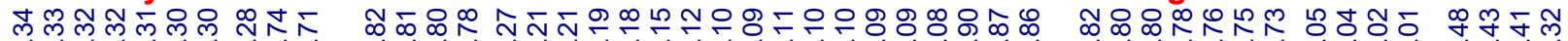

m

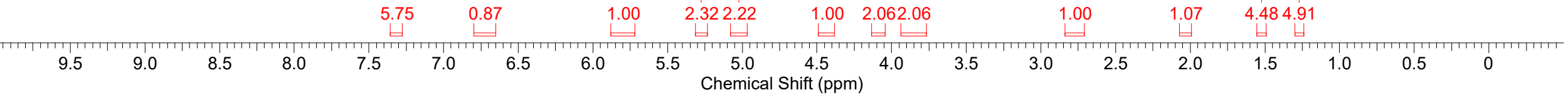


Page 72 of 127

This report was created by ACD/NMR Processor Academic Edition. For more information go to www.acdlabs.com/nmrproc/

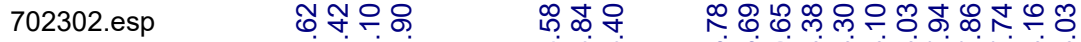

等

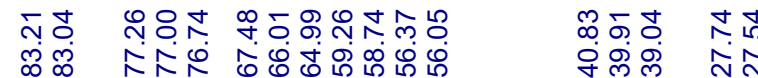

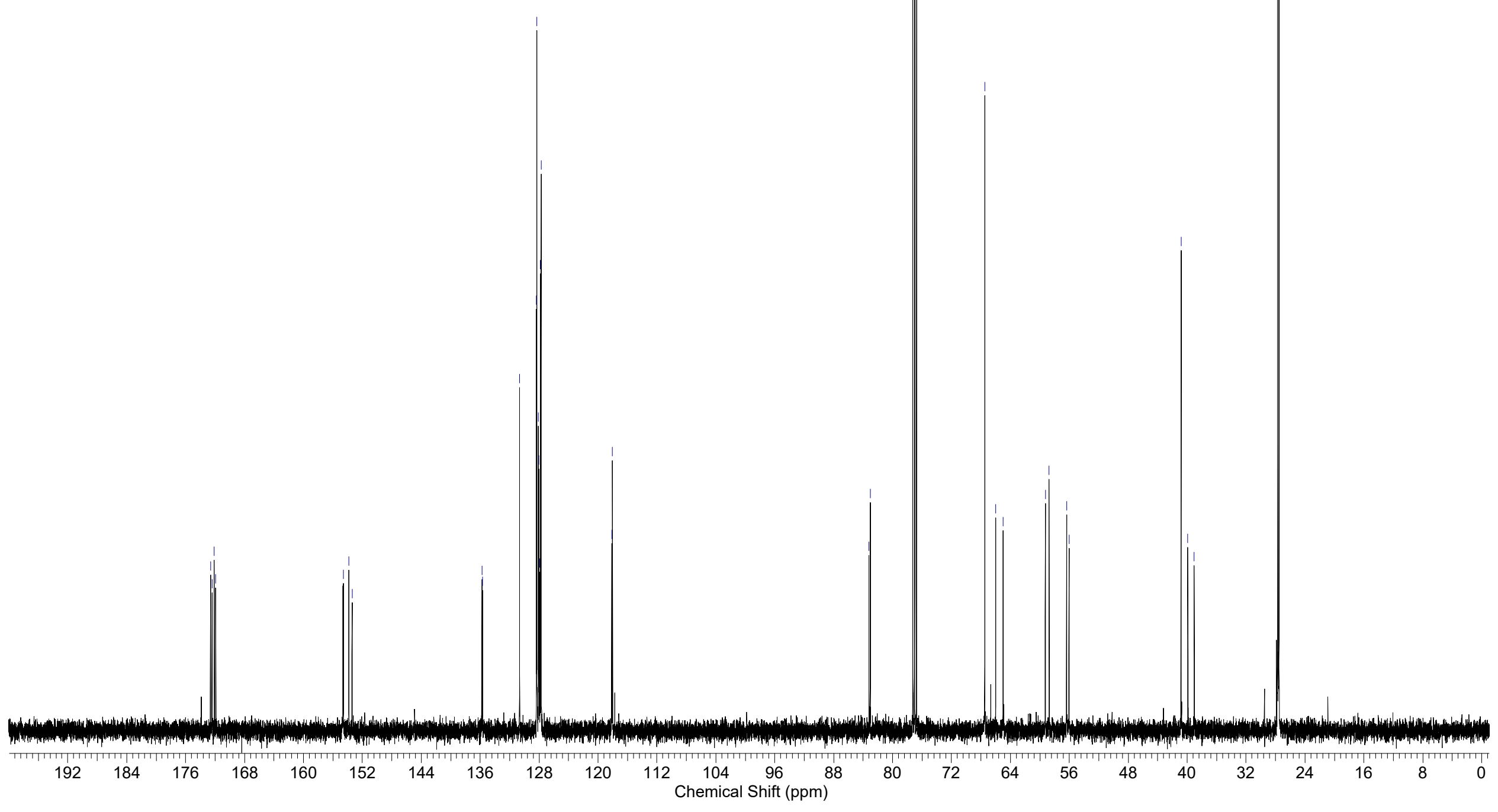


Page 73 of 127

This report was created by ACD/NMR Processor Academic Edition. For more information go to www.acdlabs.com/nmrproc/

704501.esp

ద్లెల్ల స్లె న్స

œ

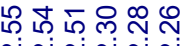

จ กิ กุ

ヘヘNヘN

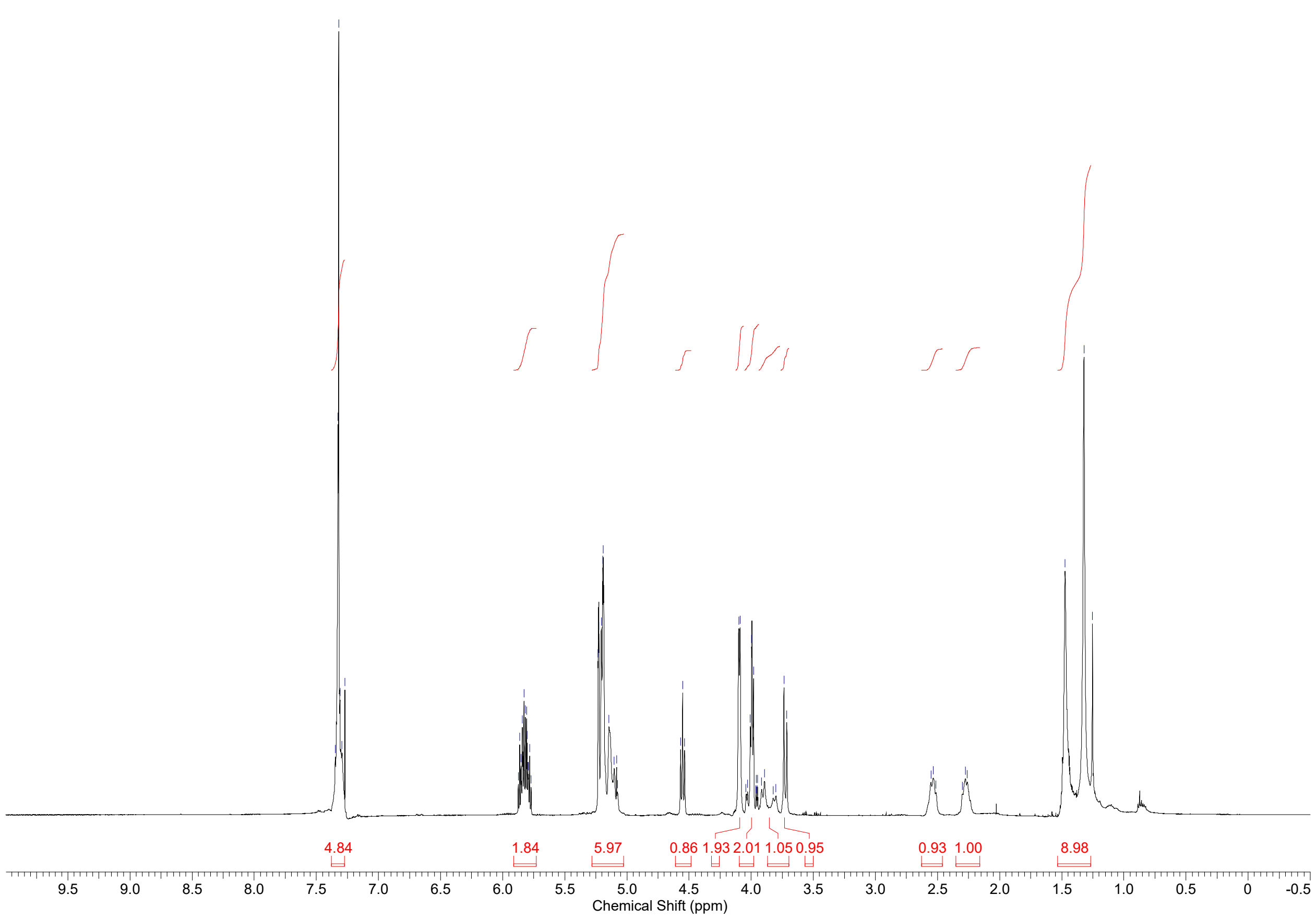


Page 74 of 127

This report was created by ACD/NMR Processor Academic Edition. For more information go to www.acdlabs.com/nmrproc/

704502.esp
垨 $\mathrm{o}$

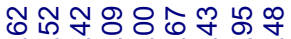

$\stackrel{1}{\stackrel{1}{r}}$

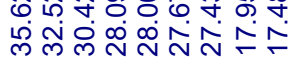

苗

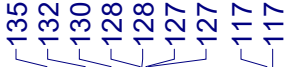

ㅊํำ ซ

$\forall \stackrel{\circ}{\forall}$ in

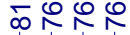

बें山ि

-

(1)

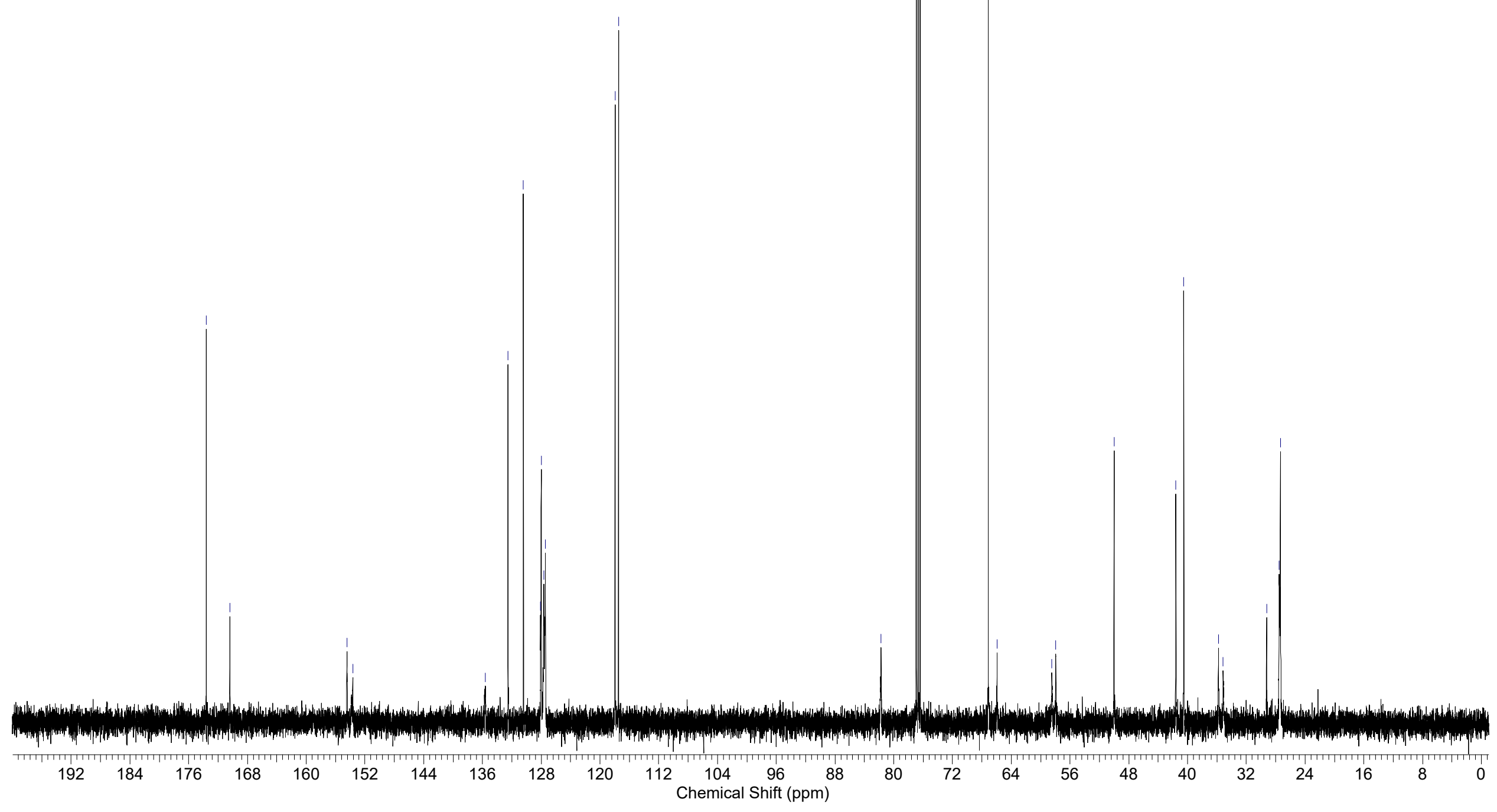


Page 75 of 127

This report was created by ACD/NMR Processor Academic Edition. For more information go to www.acdlabs.com/nmrproc/ 702701.esp

○

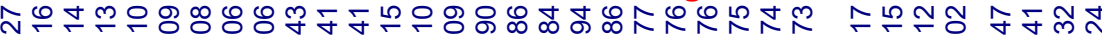

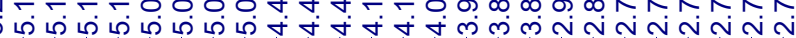

inisistrits

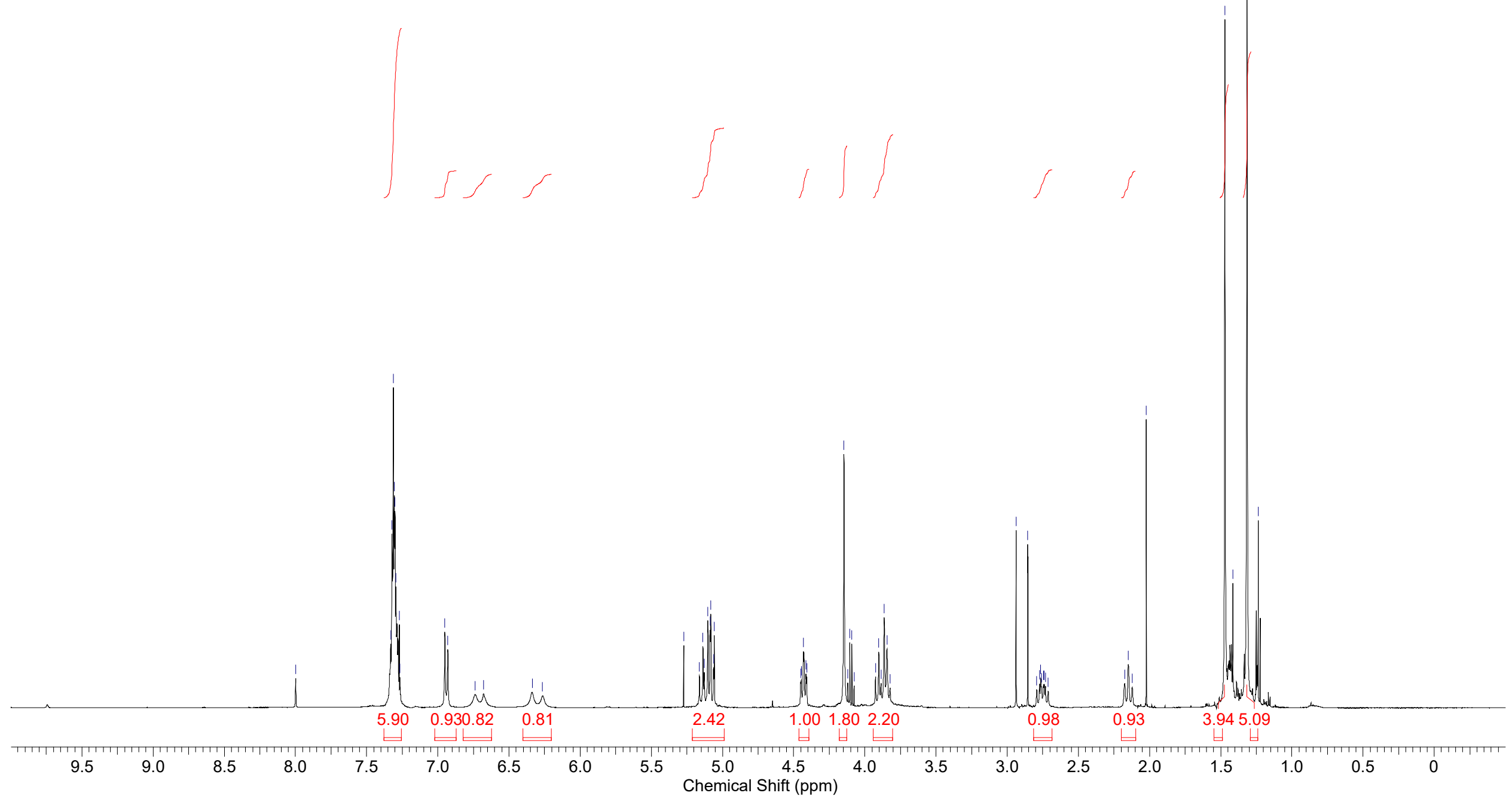


Page 76 of 127

This report was created by ACD/NMR Processor Academic Edition. For more information go to www.acdlabs.com/nmrproc/

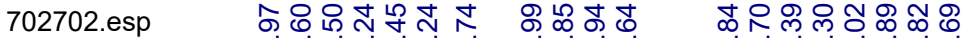

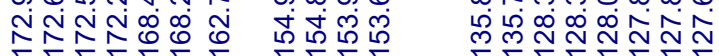

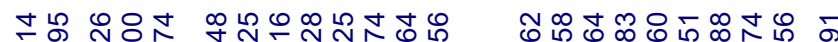

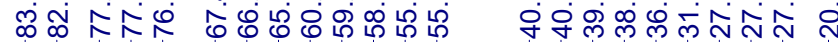

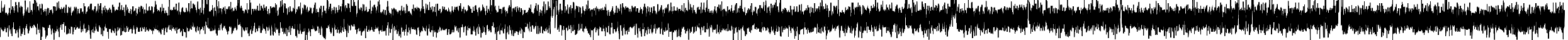

192

184

$176 \quad 168$

$160 \quad 152$

144

136

120

Chemical Shift (ppm)

40

$\begin{array}{lll}16 & 8 & 0\end{array}$ 
Page 77 of 127

704901.esp

This report was created by ACD/NMR Processor Academic Edition. For more information go to www.acdlabs.com/nmrproc/

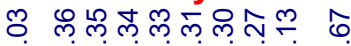

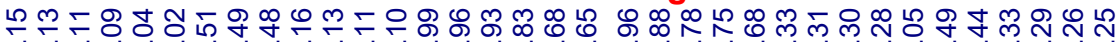

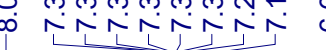

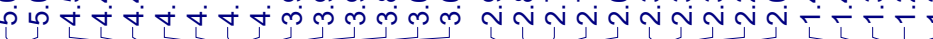

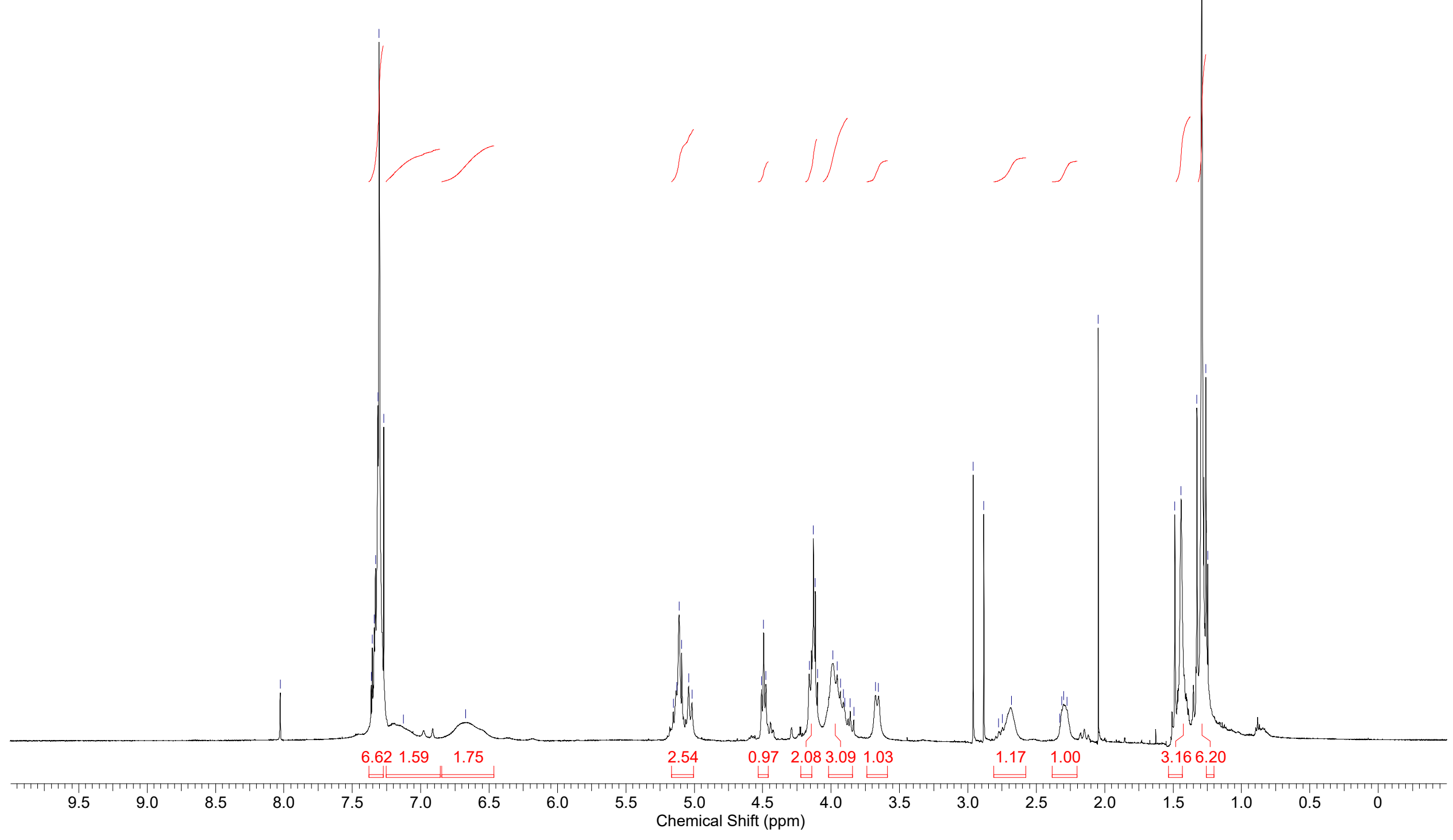


Page 78 of 127

This report was created by ACD/NMR Processor Academic Edition. For more information go to www.acdlabs.com/nmrproc/

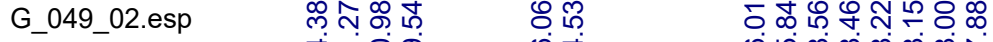

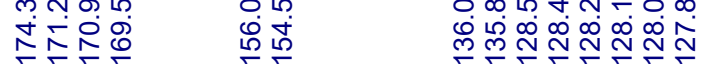

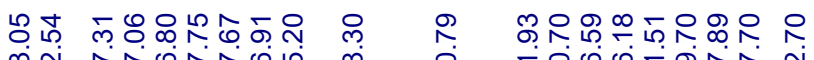

ळ 
Page 79 of 127

This report was created by ACD/NMR Processor Academic Edition. For more information go to www.acdlabs.com/nmrproc/

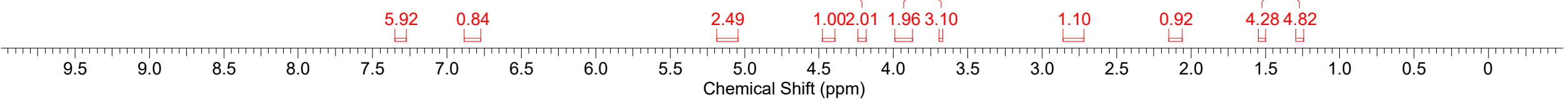


Page 80 of 127

This report was created by ACD/NMR Processor Academic Edition. For more information go to www.acdlabs.com/nmrproc/

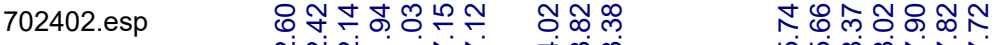

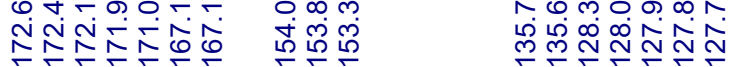

กุํำ

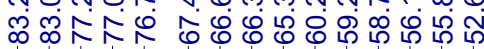

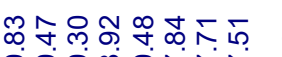

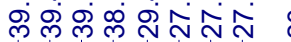

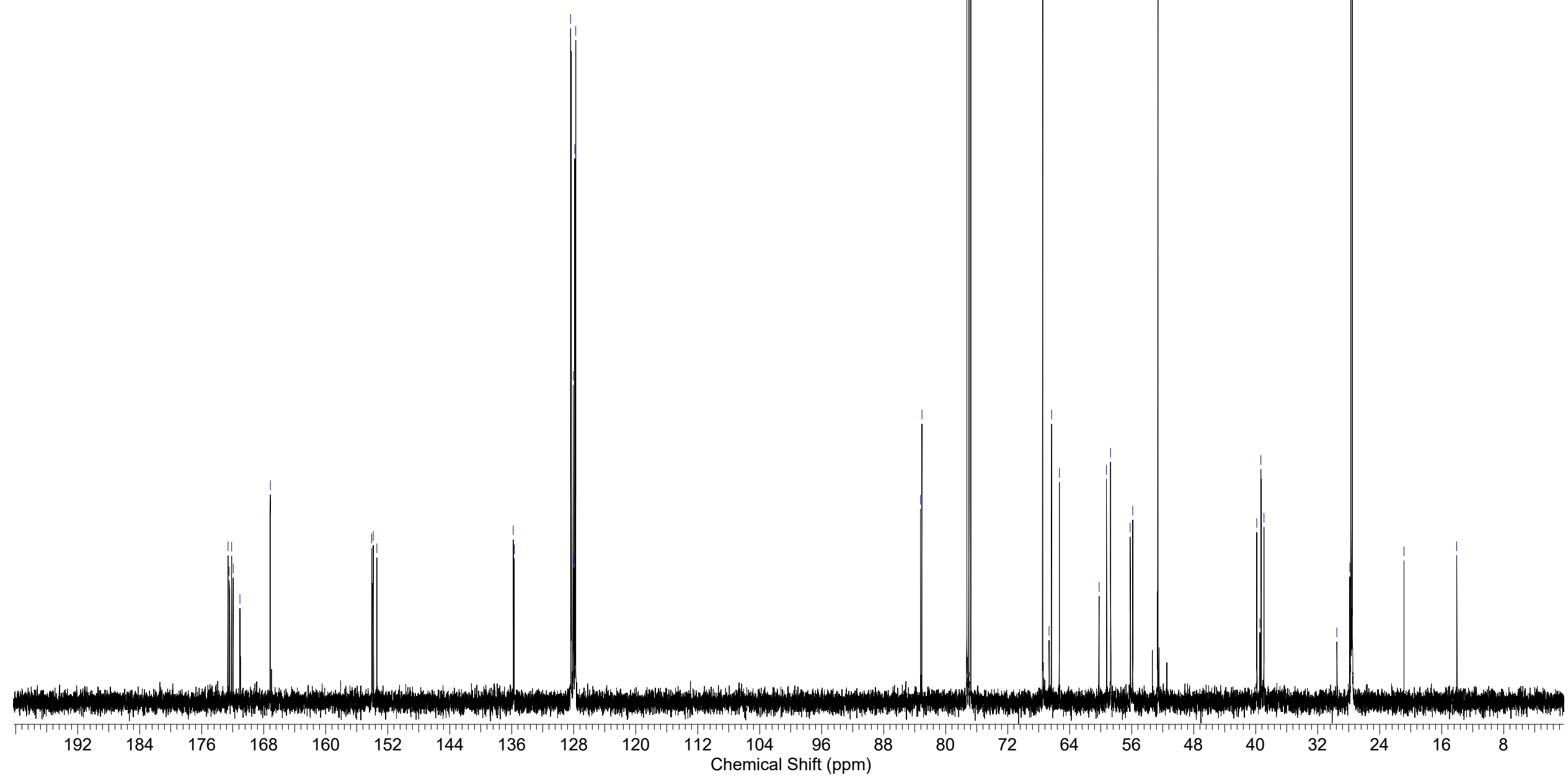


Page 81 of 127

This report was created by ACD/NMR Processor Academic Edition. For more information go to www.acdlabs.com/nmrproc/

704601.esp

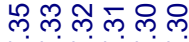

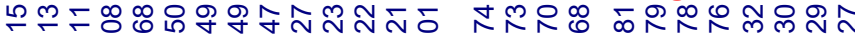

$\stackrel{0}{+}$

ベNベN

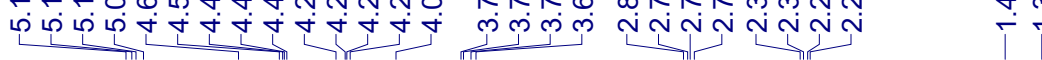

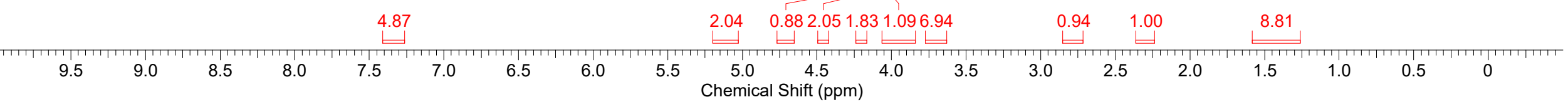


Page 82 of 127

This report was created by ACD/NMR Processor Academic Edition. For more information go to www.acdlabs.com/nmrproc/

704602.esp

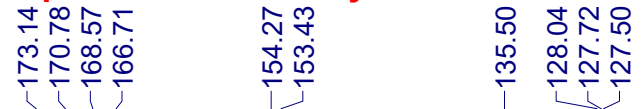

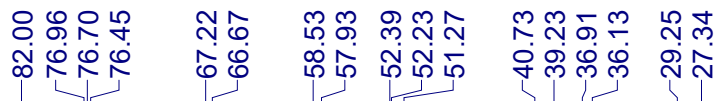

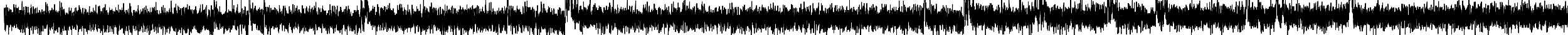

$\begin{array}{llllll}192 & 184 & 176 & 168 & 160 & 152\end{array}$

$2144 \quad 136$

128

120

Chemical Shift (ppm) 
Page 83 of 127

This report was created by ACD/NMR Processor Academic Edition. For more information go to www.acdlabs.com/nmrproc/ 616301.esp

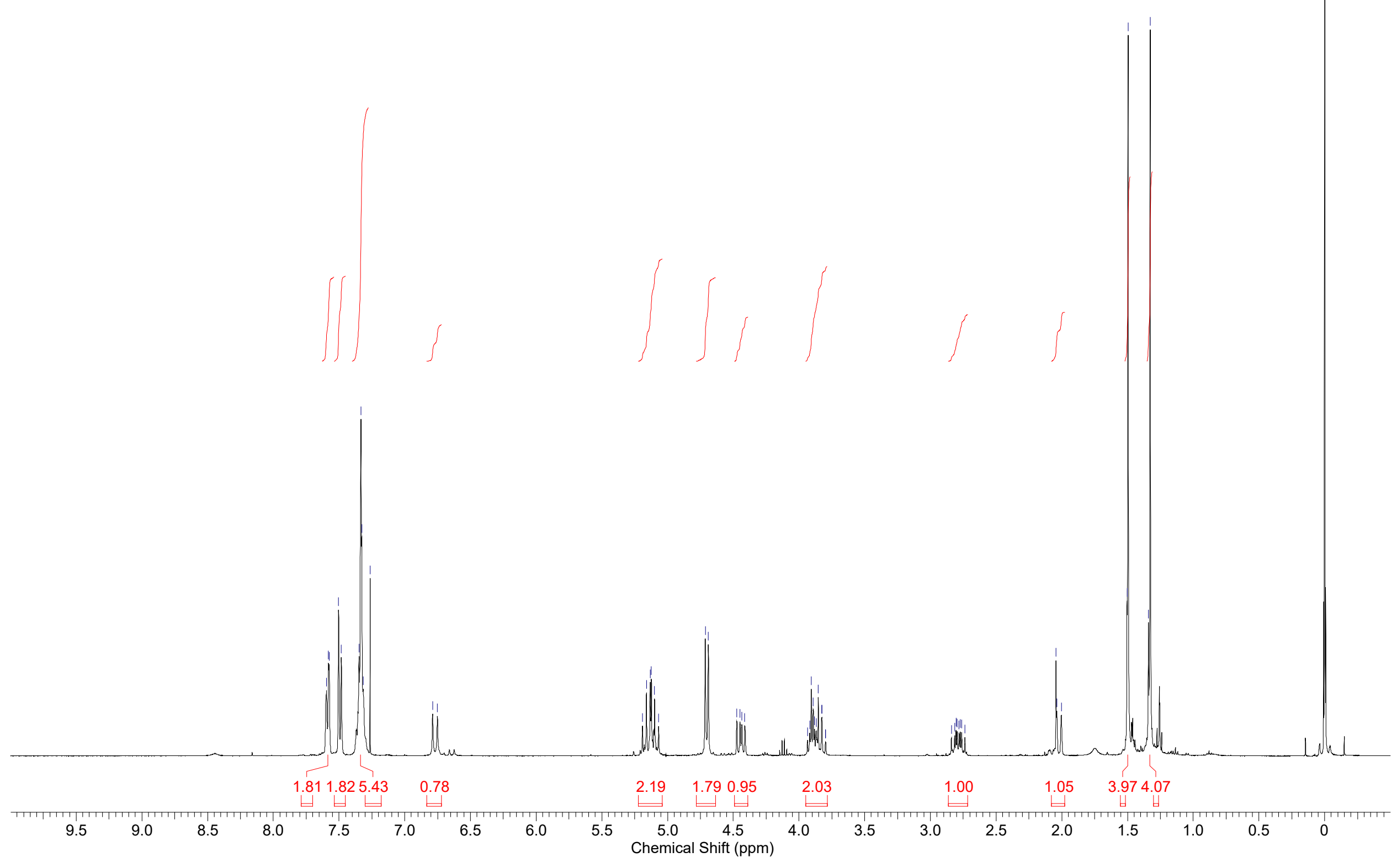


Page 84 of 127

This report was created by ACD/NMR Processor Academic Edition. For more information go to www.acdlabs.com/nmrproc/

616302.esp

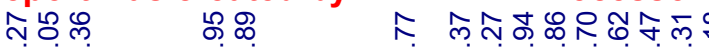

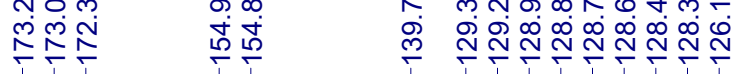

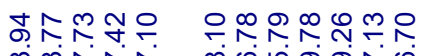

$\forall$ 梁怘

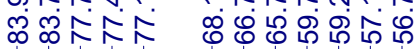

กิ 8
$\infty$
$\infty$
1

1

아요

$\stackrel{\infty}{\sim}$

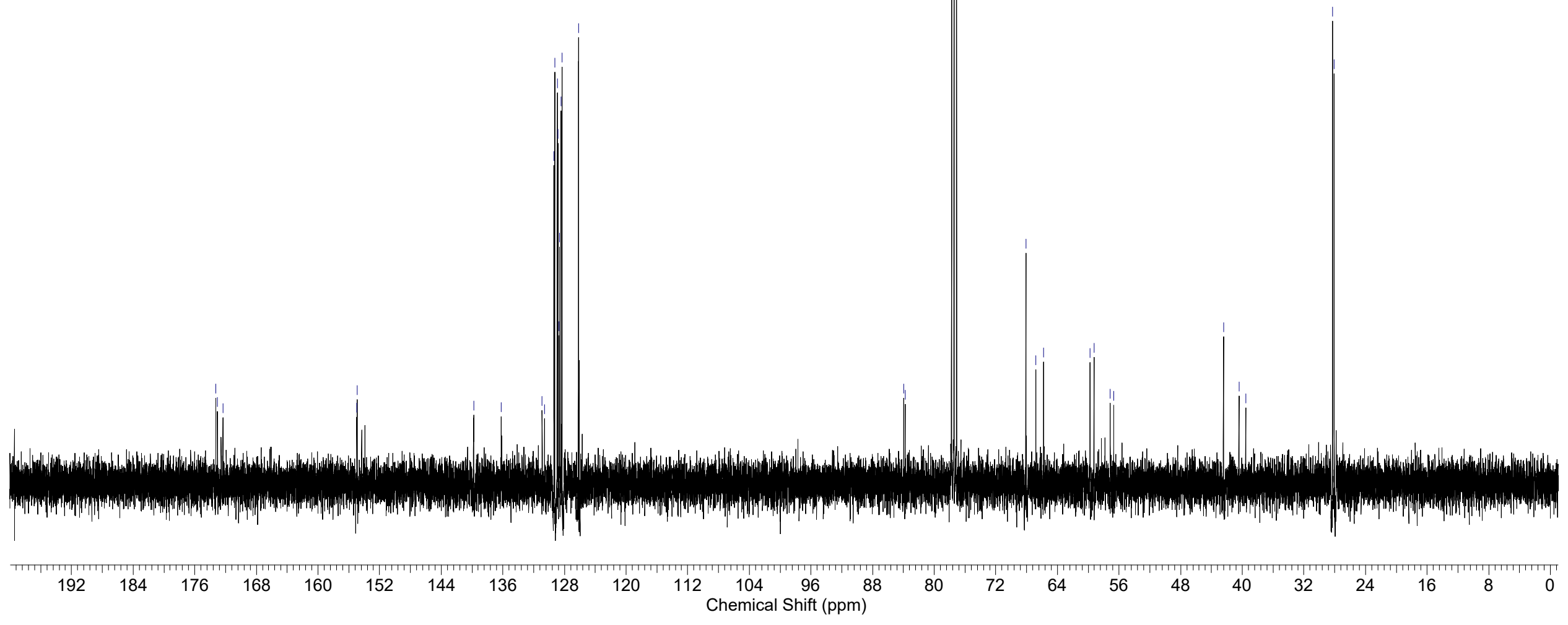


Page 85 of 127

This report was created by ACD/NMR Processor Academic Edition. For more information go to www.acdlabs.com/nmrproc/

616101.esp

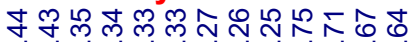

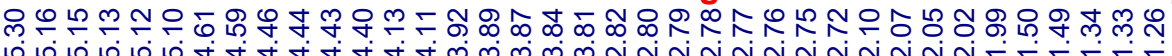

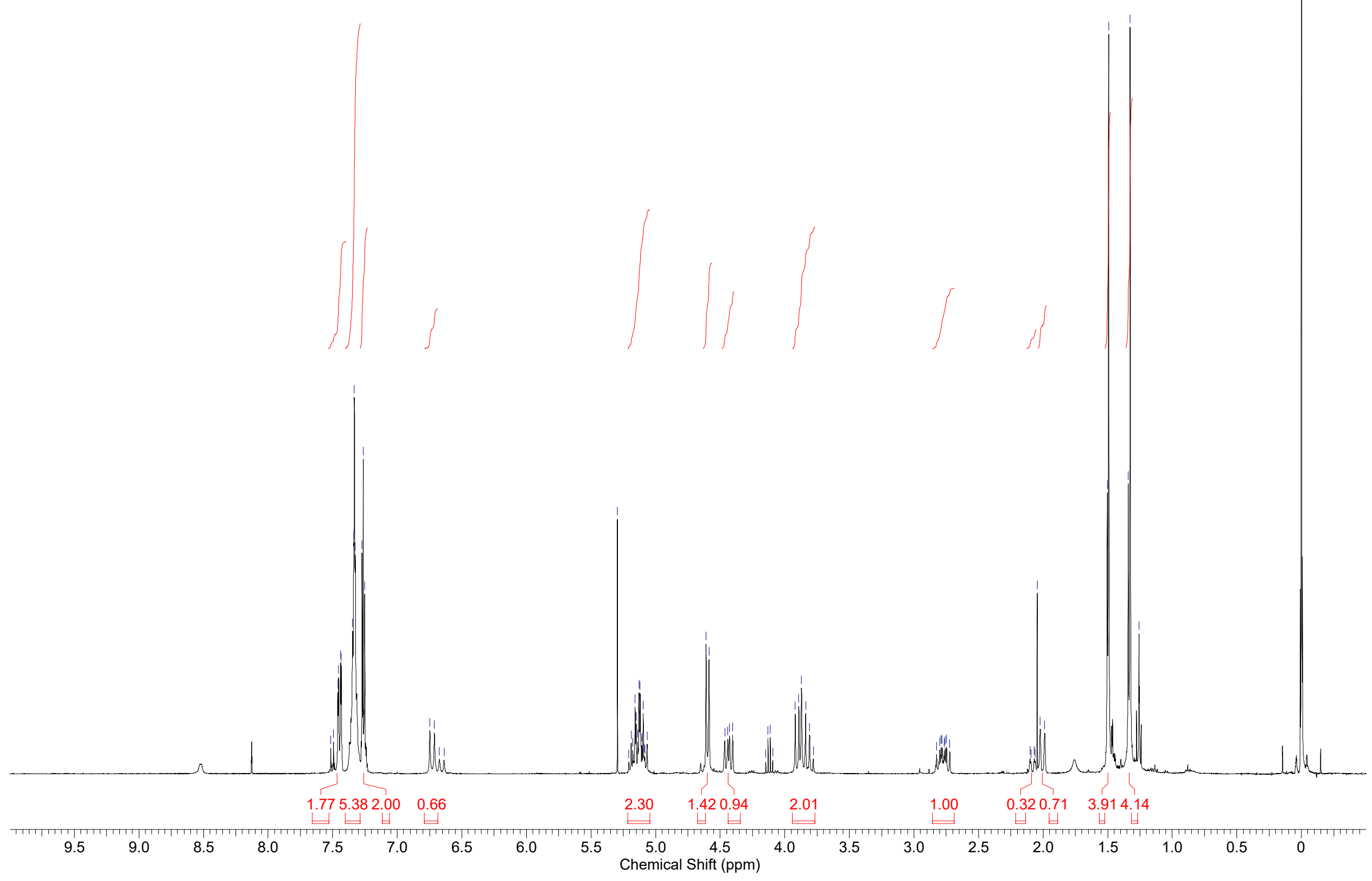


Page 86 of 127

This report was created by ACD/NMR Processor Academic Edition. For more information go to www.acdlabs.com/nmrproc/

616102.esp

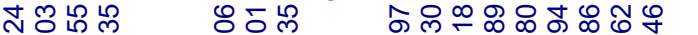

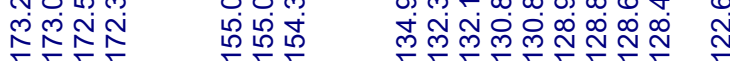

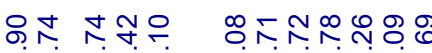

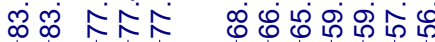

电员

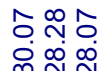

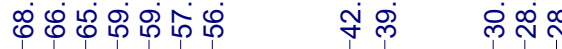

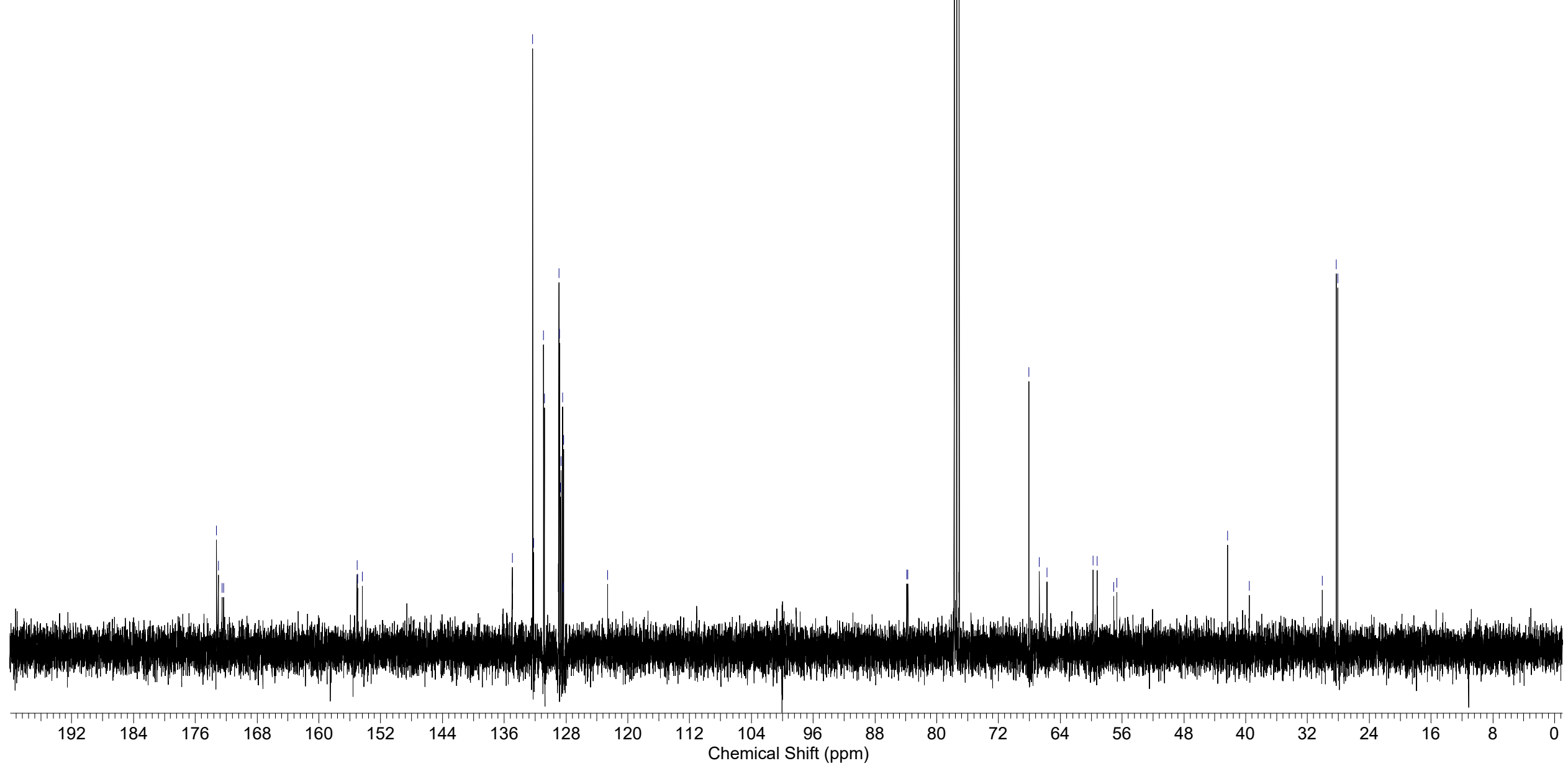


Page 87 of 127

This report was created by ACD/NMR Processor Academic Edition. For more information go to www.acdlabs.com/nmrproc/ 616001.esp

ம்

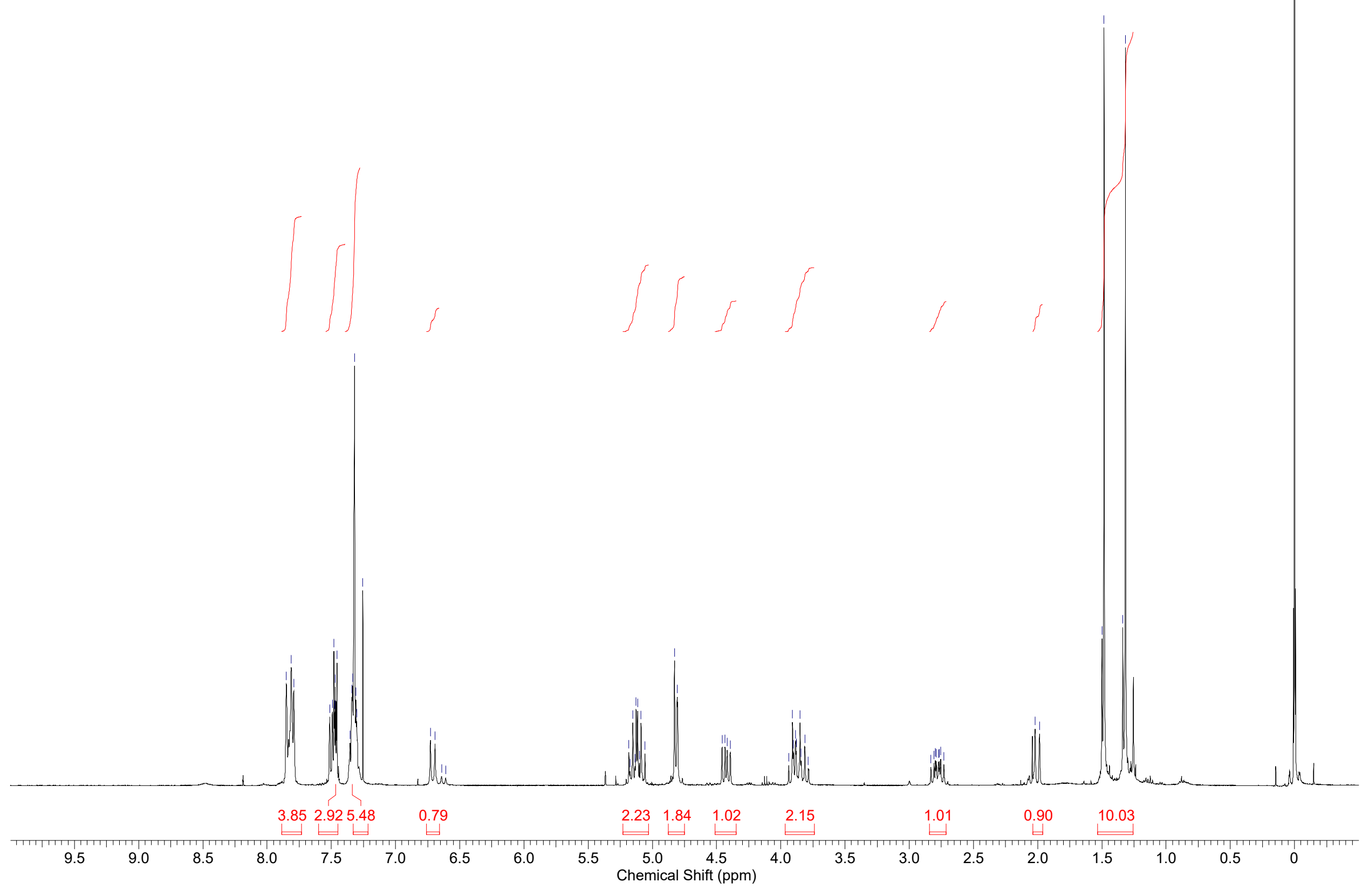


Page 88 of 127

This report was created by ACD/NMR Processor Academic Edition. For more information go to www.acdlabs.com/nmrproc/

\section{F_160_02.esp}

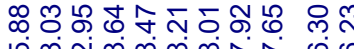

峞

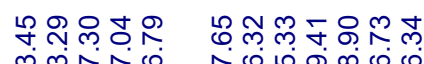

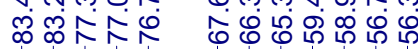

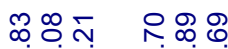

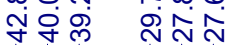

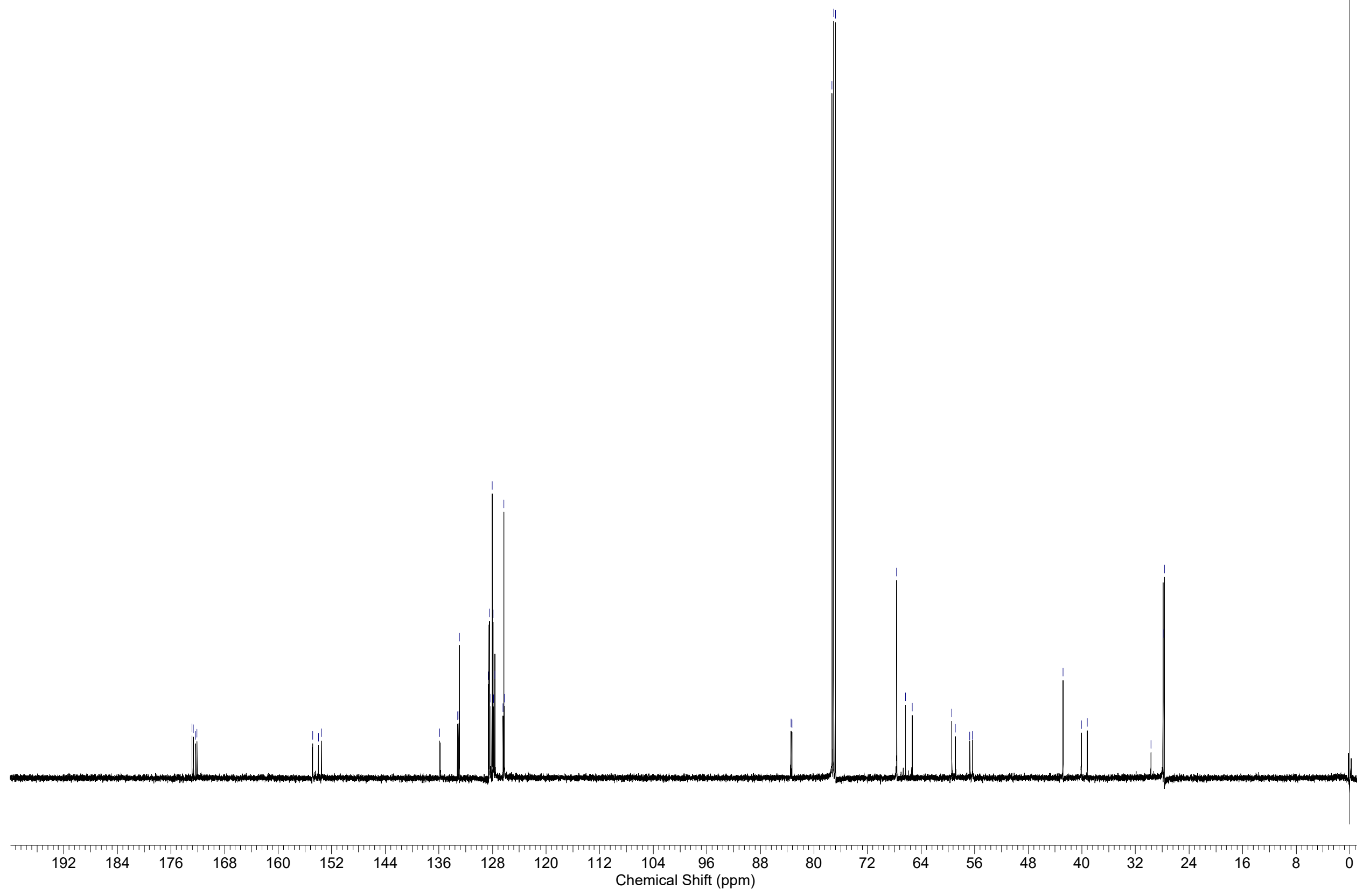


Page 89 of 127

This report was created by ACD/NMR Processor Academic Edition. For more information go to www.acdlabs.com/nmrproc/

611901.esp

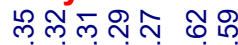

ritín

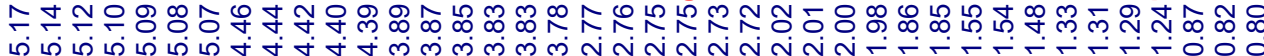

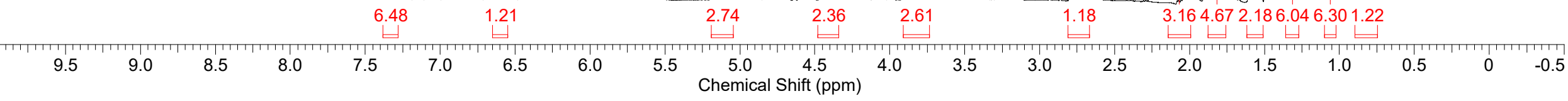


Page 90 of 127

This report was created by ACD/NMR Processor Academic Edition. For more information go to www.acdlabs.com/nmrproc/

611902.esp

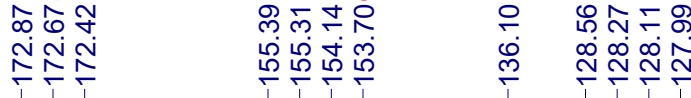

员㶽它总

它

ำ 우유요

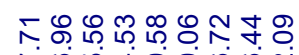

ผู้

$\therefore \frac{1}{12}$

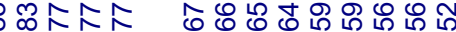

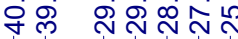

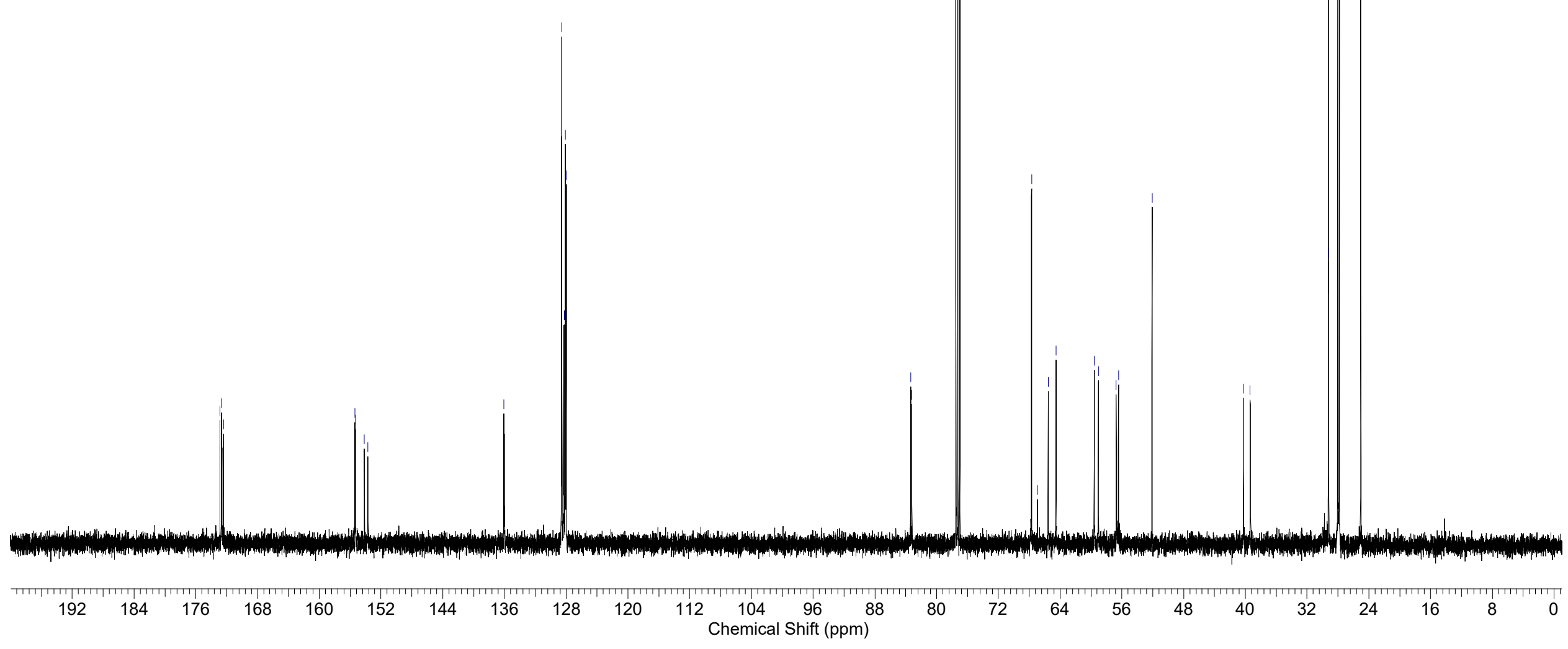


Page 91 of 127

This report was created by ACD/NMR Processor Academic Edition. For more information go to www.acdlabs.com/nmrproc/

702801.esp

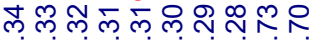

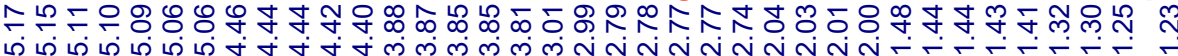

今र

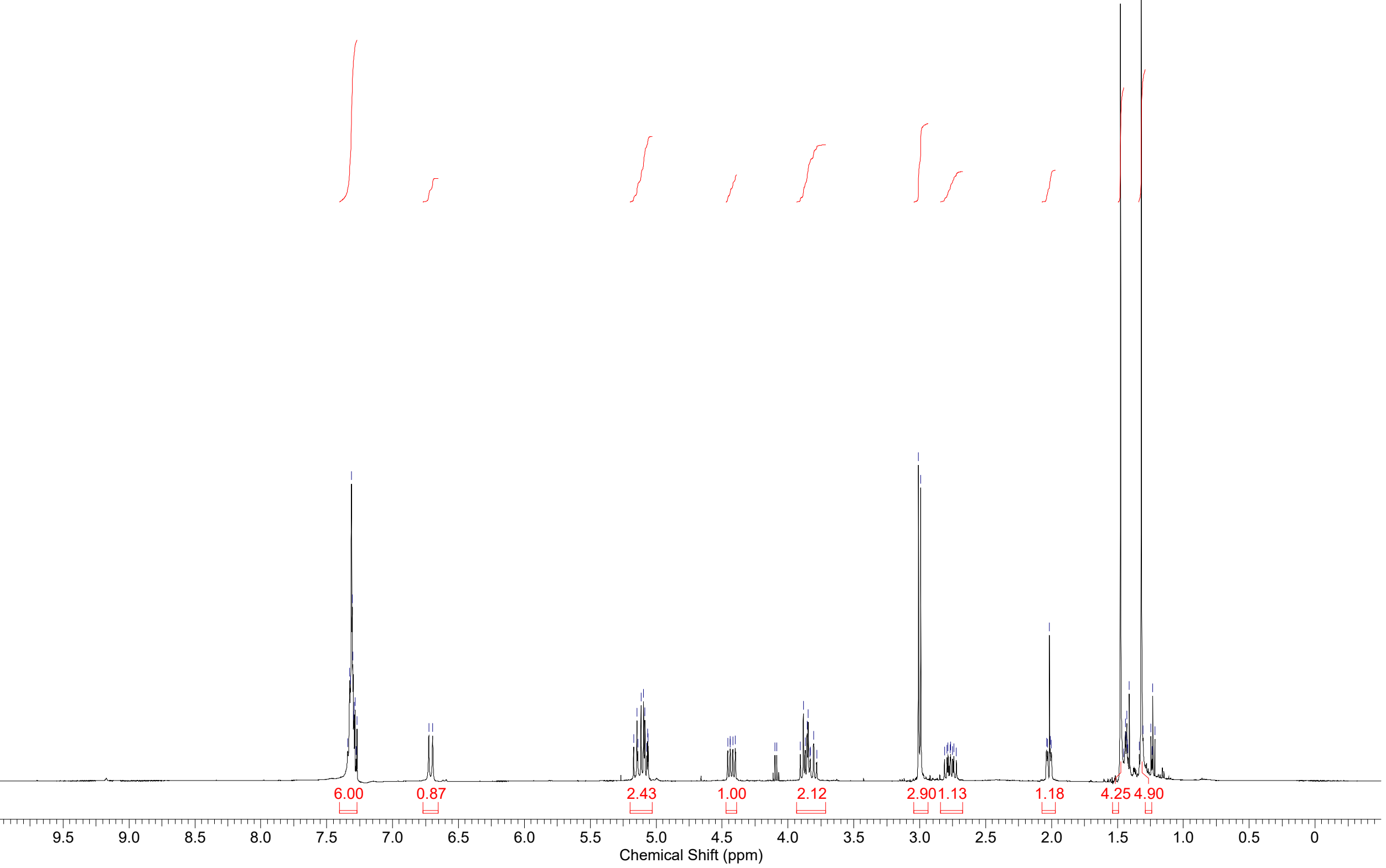


Page 92 of 127

This report was created by ACD/NMR Processor Academic Edition. For more information go to www.acdlabs.com/nmrproc/

702802.esp

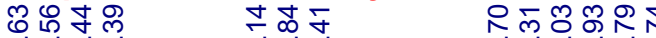

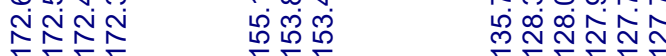

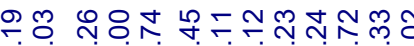

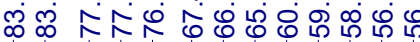

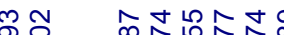

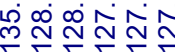

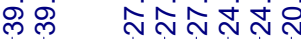

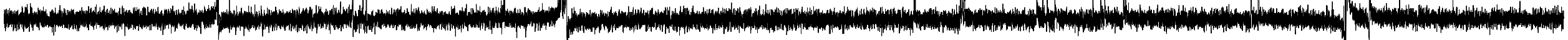

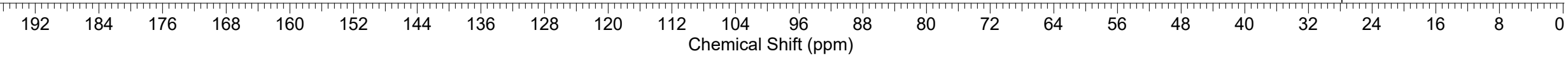


Page 93 of 127

This report was created by ACD/NMR Processor Academic Edition. For more information go to www.acdlabs.com/nmrproc/

705001.esp

商

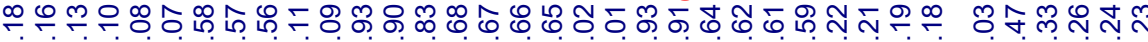

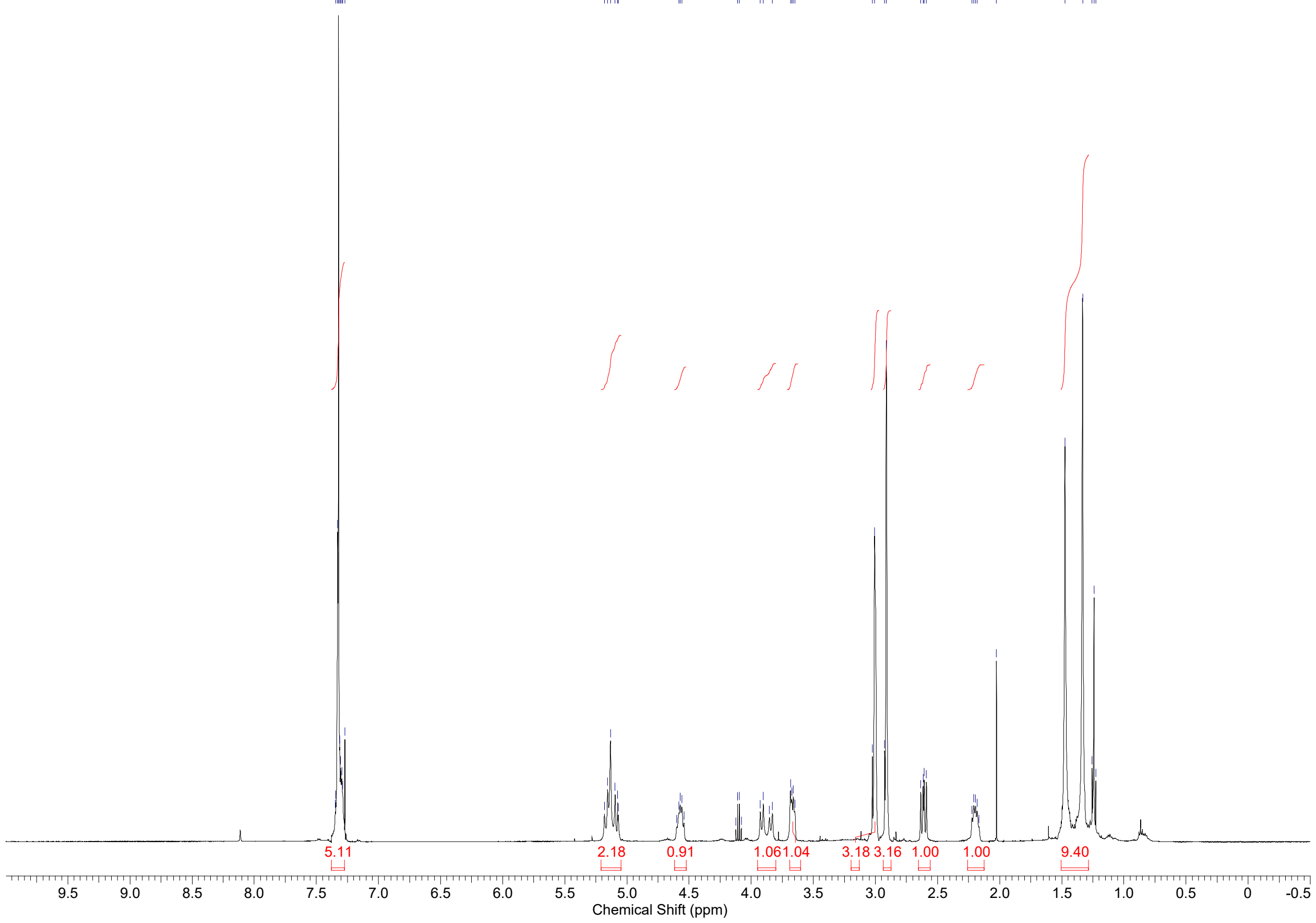


Page 94 of 127

This report was created by ACD/NMR Processor Academic Edition. For more information go to www.acdlabs.com/nmrproc/

705002.esp

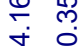
$\stackrel{i}{\stackrel{1}{r}}$
웅
ด 8ㅇํㅇำ

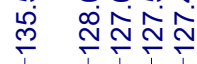
ก็ำ

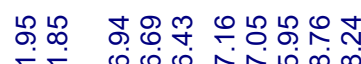

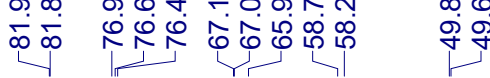

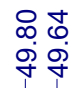

ธ。ํำ

† सम

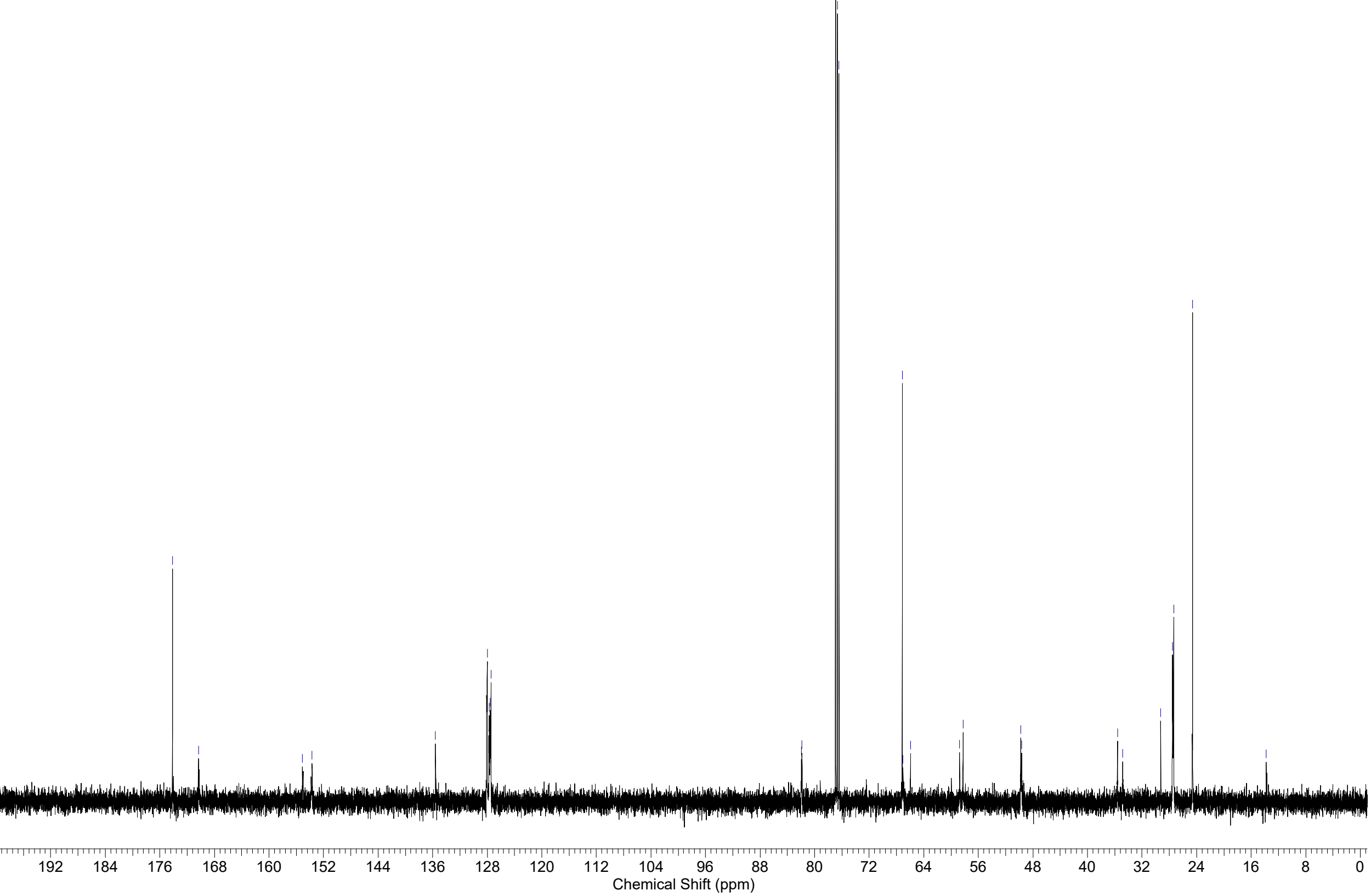


Page 95 of 127

This report was created by ACD/NMR Processor Academic Edition. For more information go to www.acdlabs.com/nmrproc/ 612101.esp

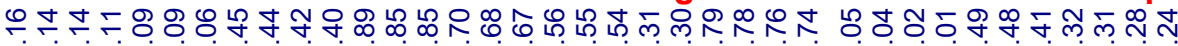

רิ

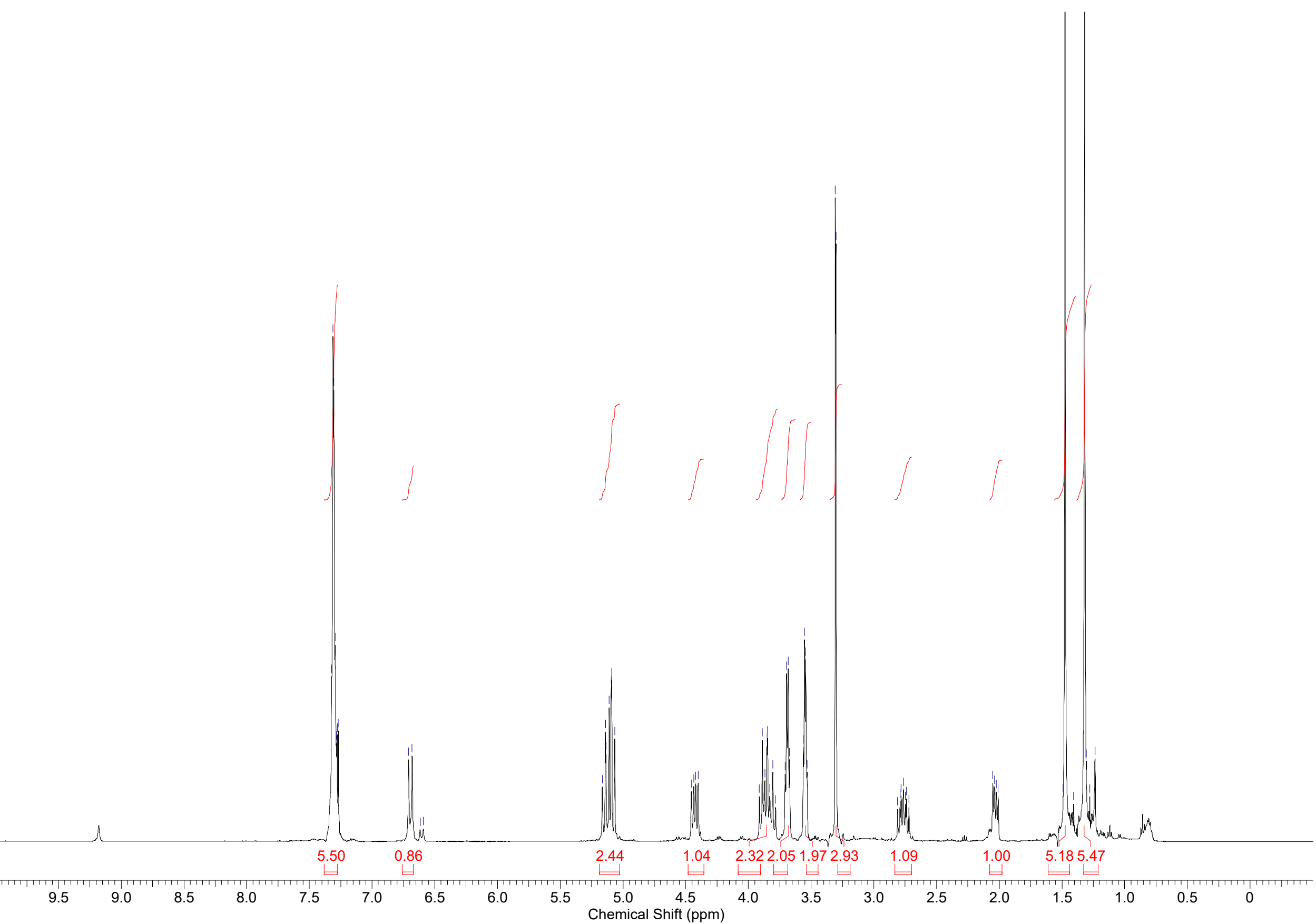


Page 96 of 127

This report was created by ACD/NMR Processor Academic Edition. For more information go to www.acdlabs.com/nmrproc/

612102.esp

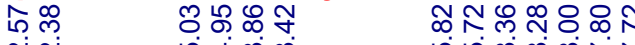

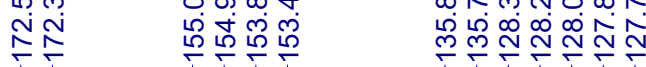

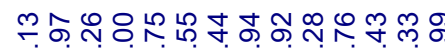

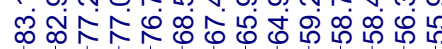

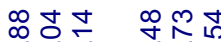

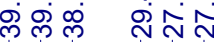

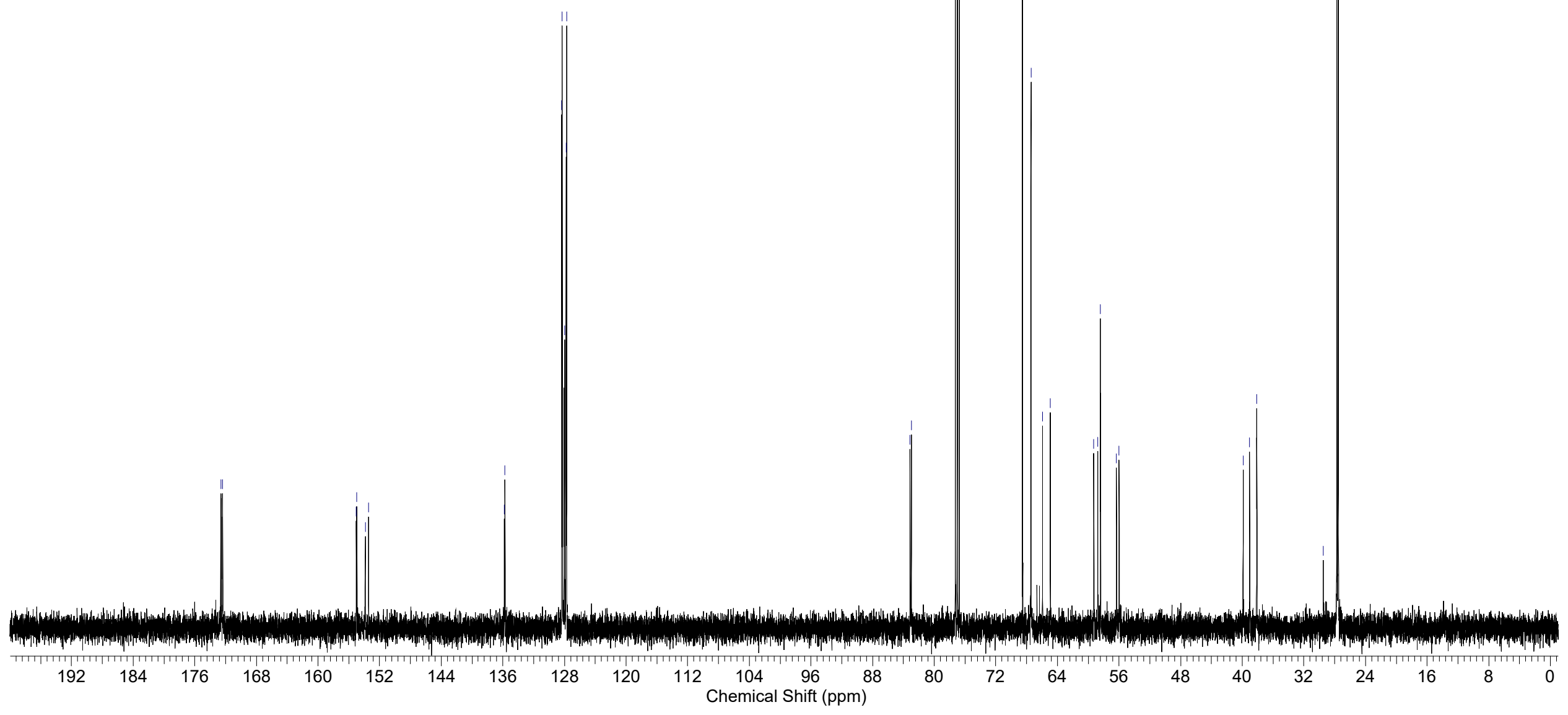


Page 97 of 127

This report was created by ACD/NMR Processor Academic Edition. For more information go to www.acdlabs.com/nmrproc/

613001.esp

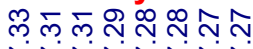

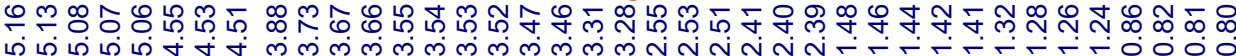

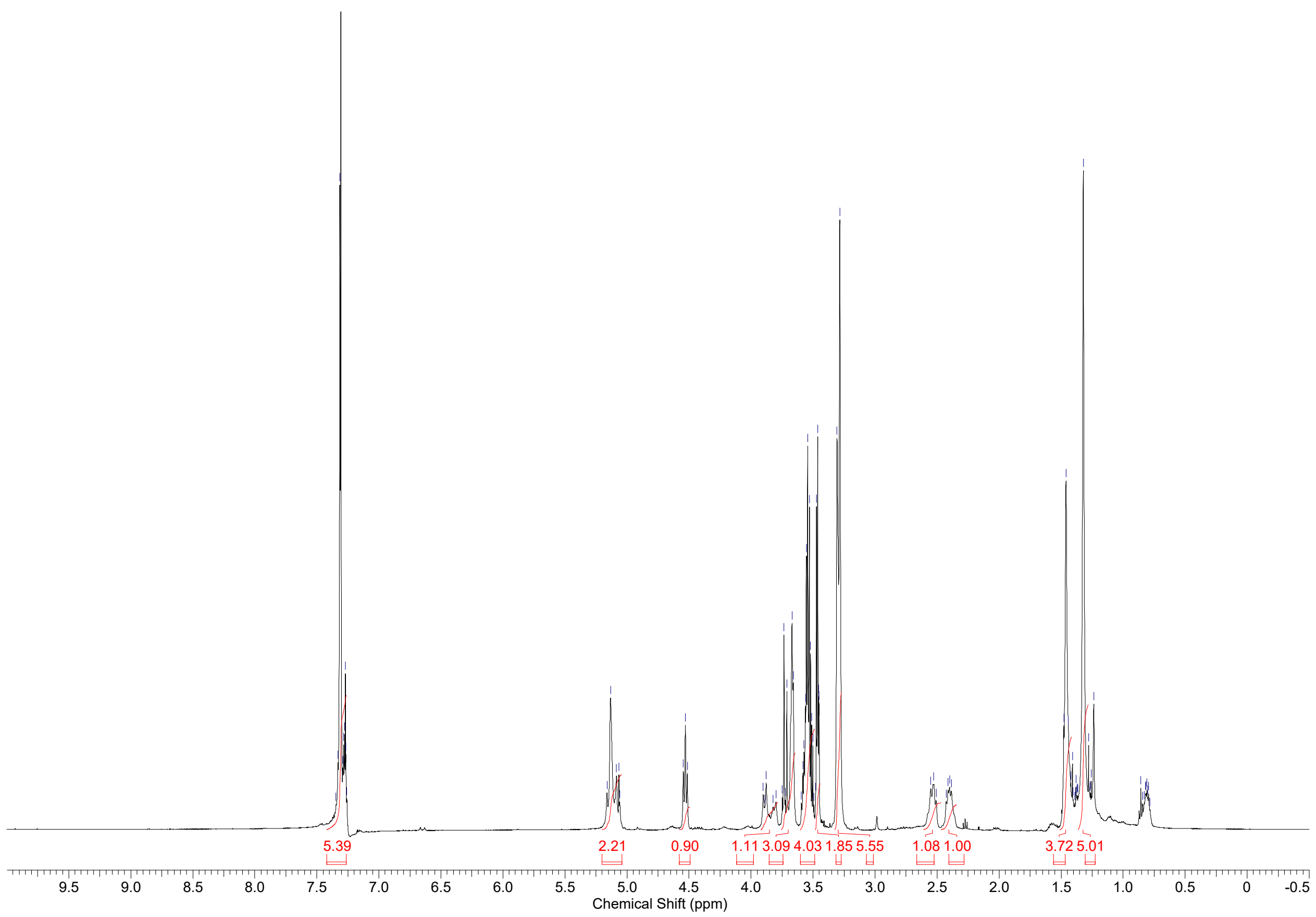


Page 98 of 127

This report was created by ACD/NMR Processor Academic Edition. For more information go to www.acdlabs.com/nmrproc/

613002.esp

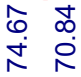

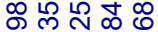

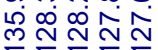

ल

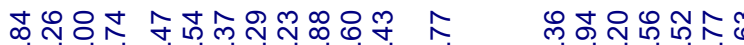

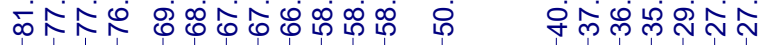

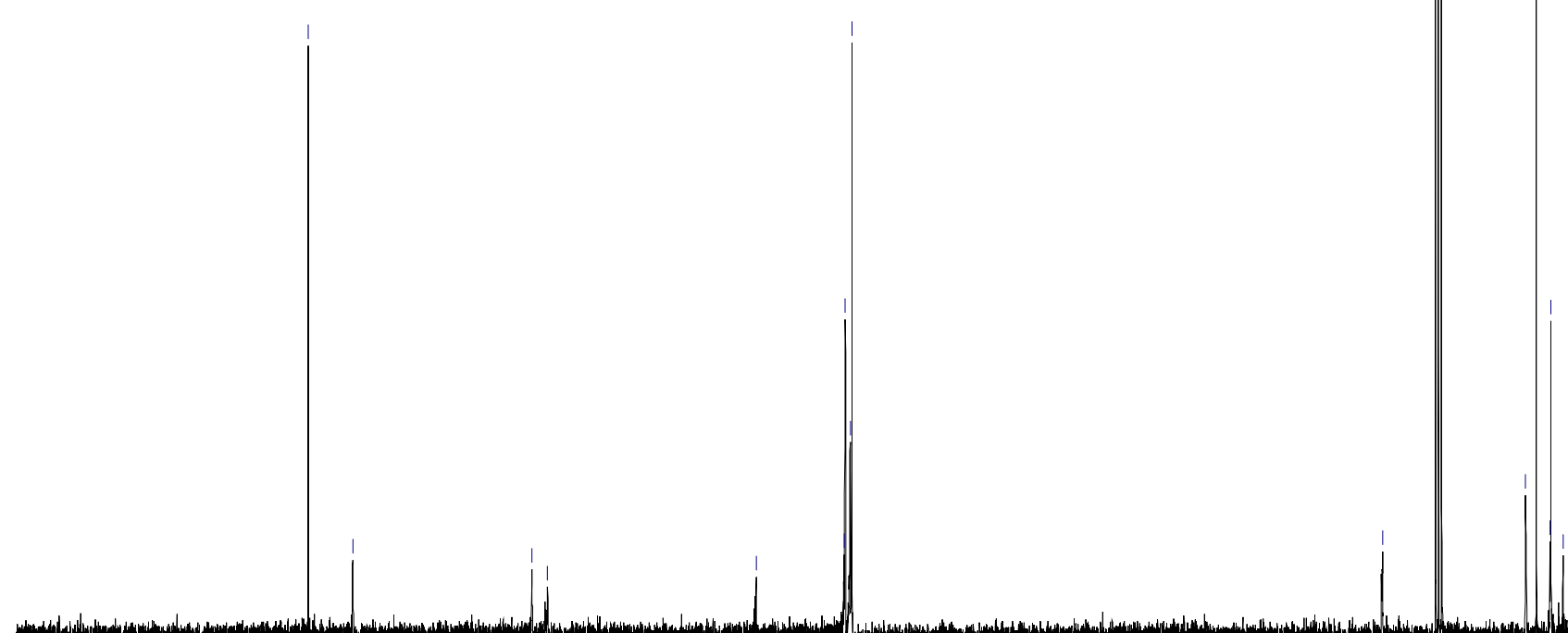

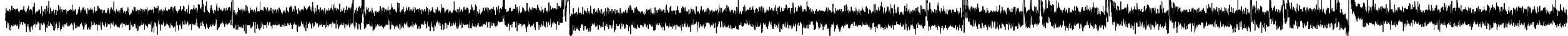

$192184 \quad 176$


Page 99 of 127

This report was created by ACD/NMR Processor Academic Edition. For more information go to www.acdlabs.com/nmrproc/

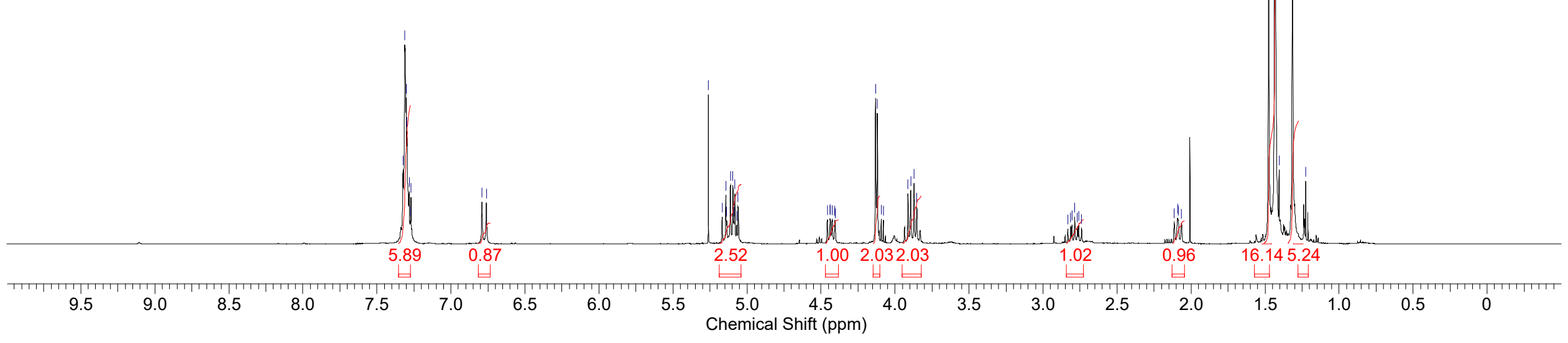


Page 100 of 127

This report was created by ACD/NMR Processor Academic Edition. For more information go to www.acdlabs.com/nmrproc/

702502.esp

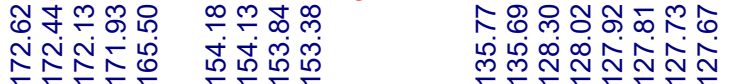

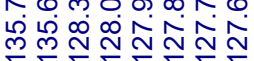

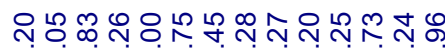

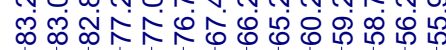

됴 ஜ

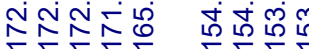

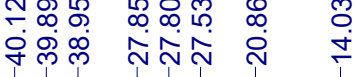

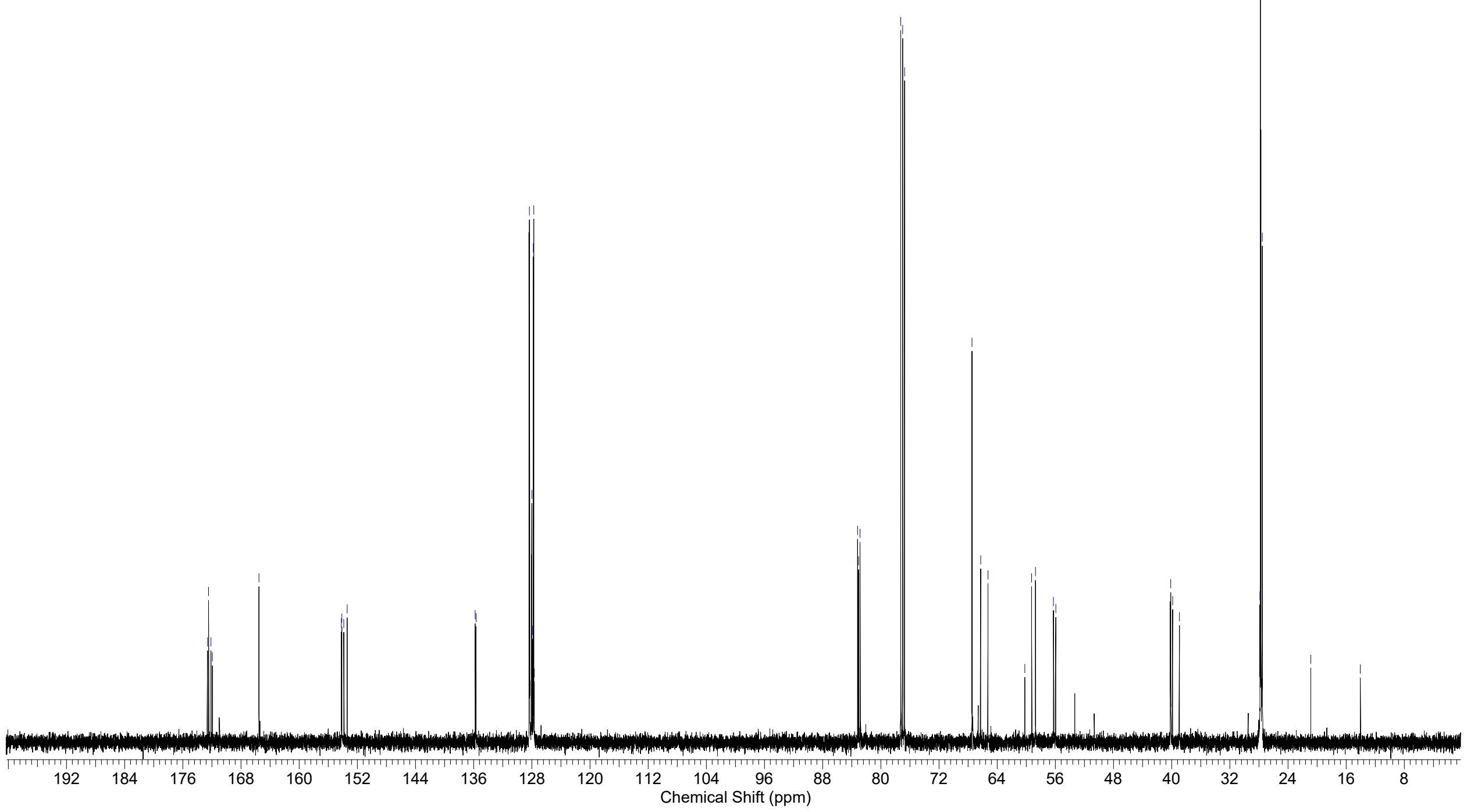


Page 101 of 127

This report was created by ACD/NMR Processor Academic Edition. For more information go to www.acdlabs.com/nmrproc/ 704701.esp

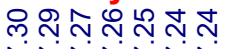

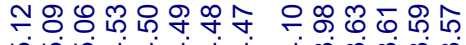

충유

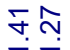

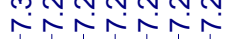

மं

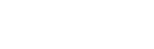

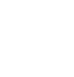


Page 102 of 127

This report was created by ACD/NMR Processor Academic Edition. For more information go to www.acdlabs.com/nmrproc/

704702.esp

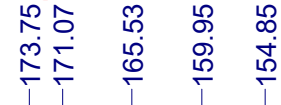

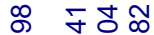
官 $\stackrel{\sim}{\sim} \stackrel{\sim}{\stackrel{N}{N}}$

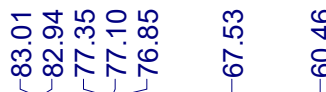
ஹ
৪ே்
$\stackrel{\infty}{\sim} \hat{N} \hat{N}$

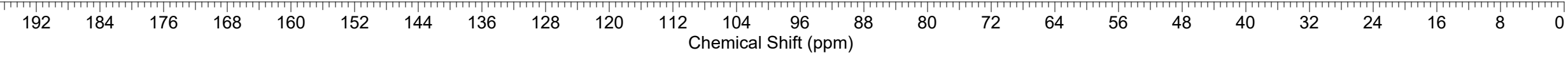


Page 103 of 127

This report was created by ACD/NMR Processor Academic Edition. For more information go to www.acdlabs.com/nmrproc/

702601.esp

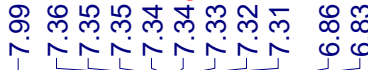

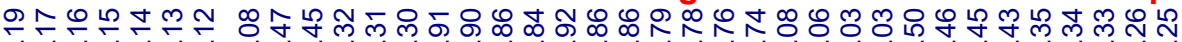

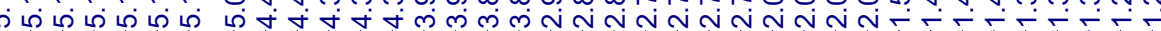

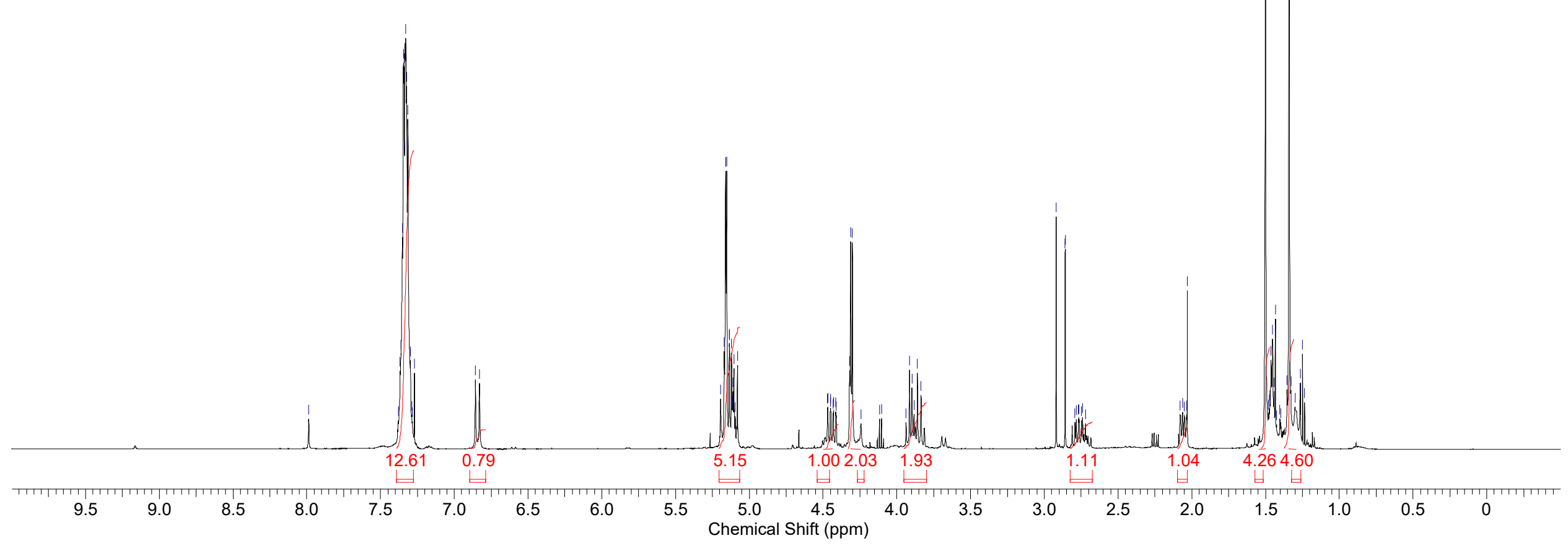


Page 104 of 127

This report was created by ACD/NMR Processor Academic Edition. For more information go to www.acdlabs.com/nmrproc/

702602.esp

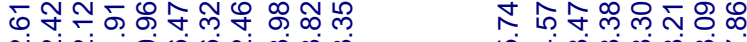

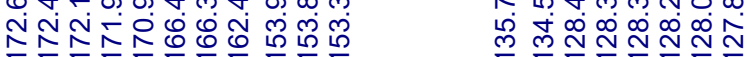

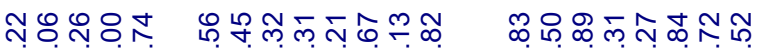

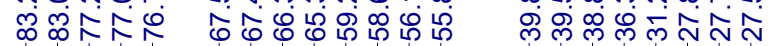

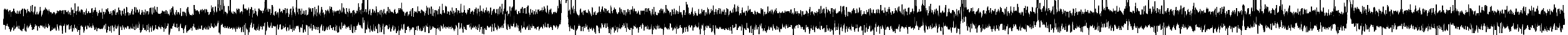

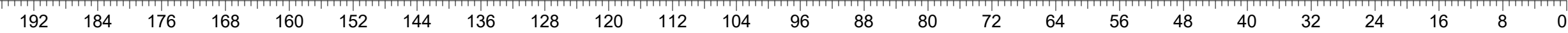

Chemical Shift (ppm) 
Page 105 of 127

This report was created by ACD/NMR Processor Academic Edition. For more information go to www.acdlabs.com/nmrproc/

704801.esp

穴

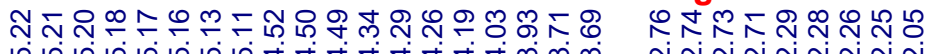

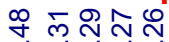

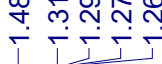

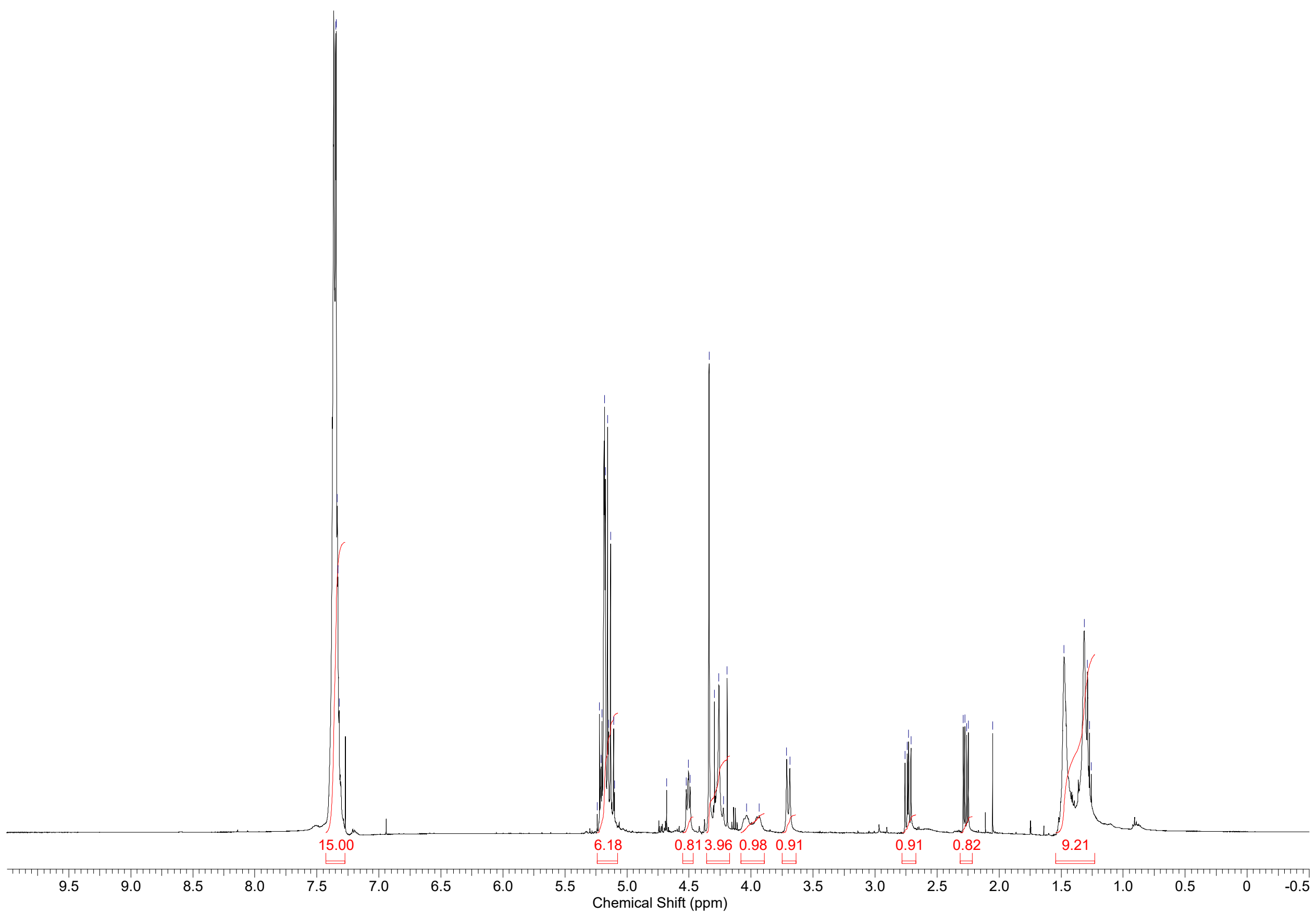


Page 106 of 127

This report was created by ACD/NMR Processor Academic Edition. For more information go to www.acdlabs.com/nmrproc/

704802.esp
テㅇำ ำ

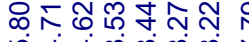

लं

ํㅗㄴ

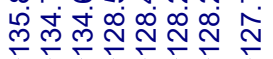

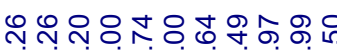

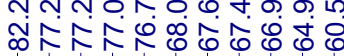

운

员吉

I

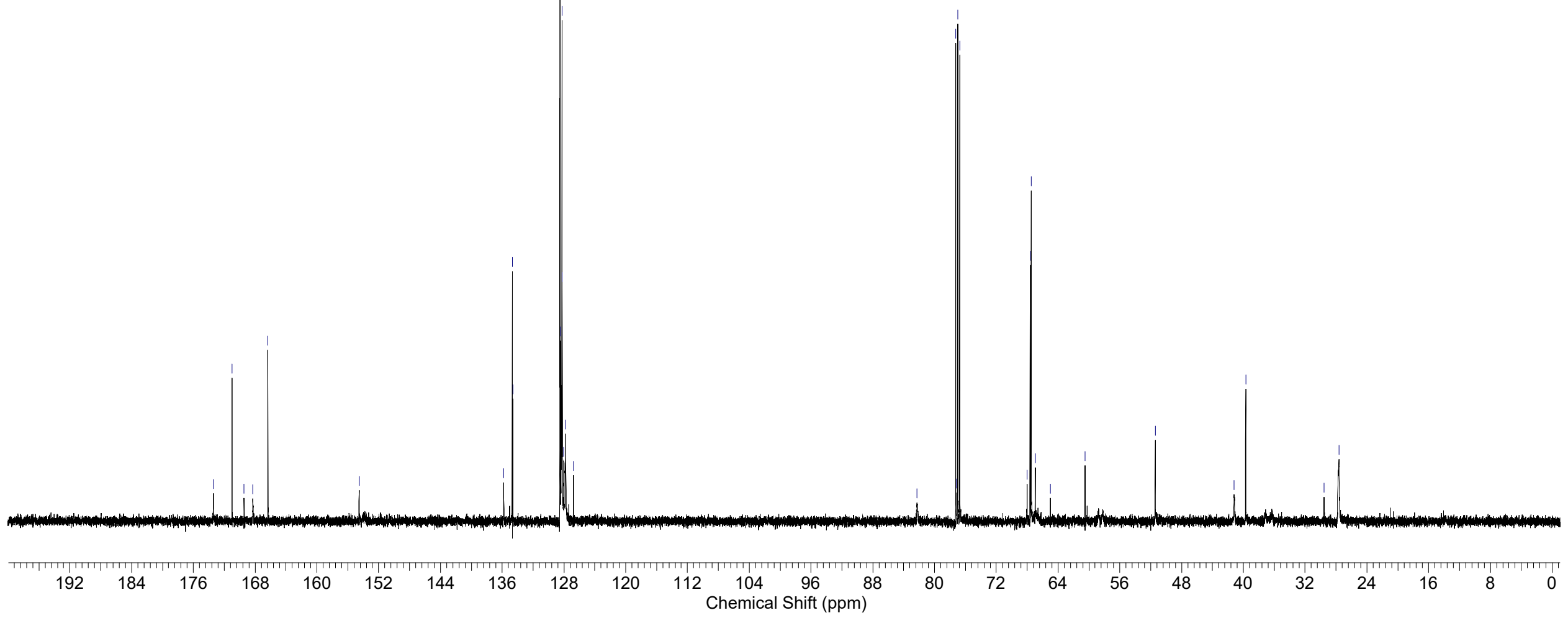


Page 107 of 127

This report was created by ACD/NMR Processor Academic Edition. For more information go to www.acdlabs.com/nmrproc/ 616401.esp

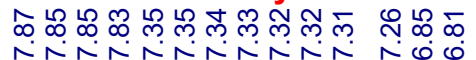

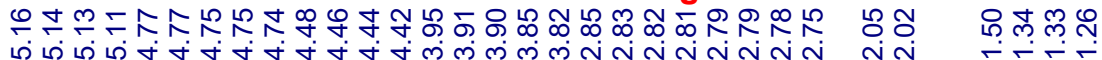

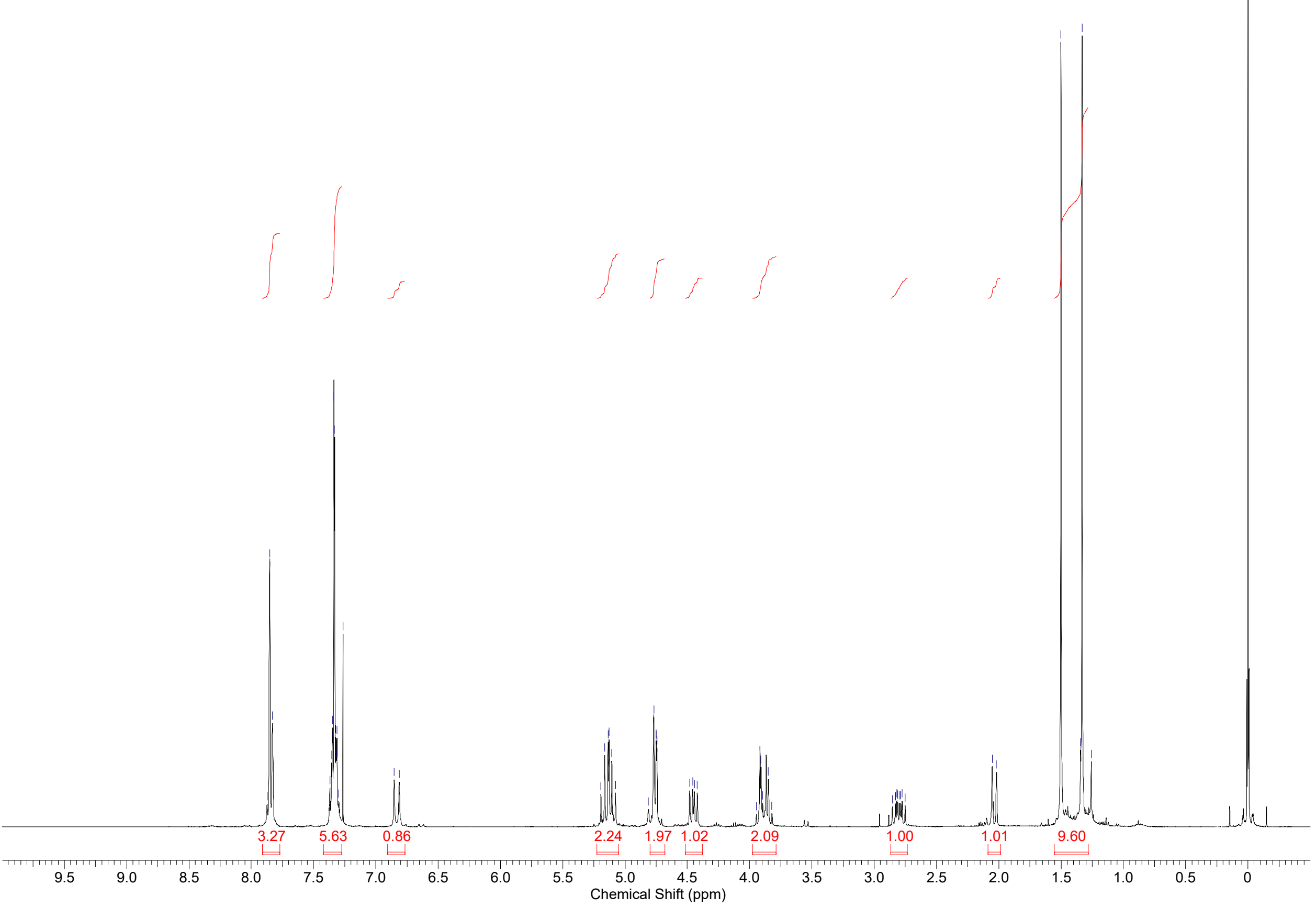


Page 108 of 127

This report was created by ACD/NMR Processor Academic Edition. For more information go to www.acdlabs.com/nmrproc/

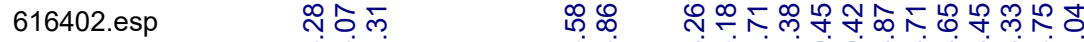

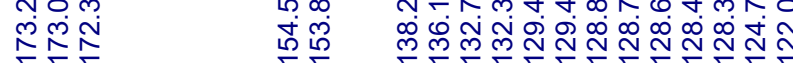

\&্ণ

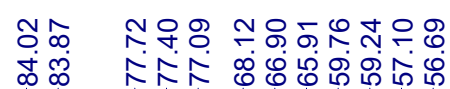

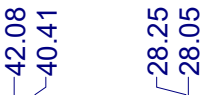

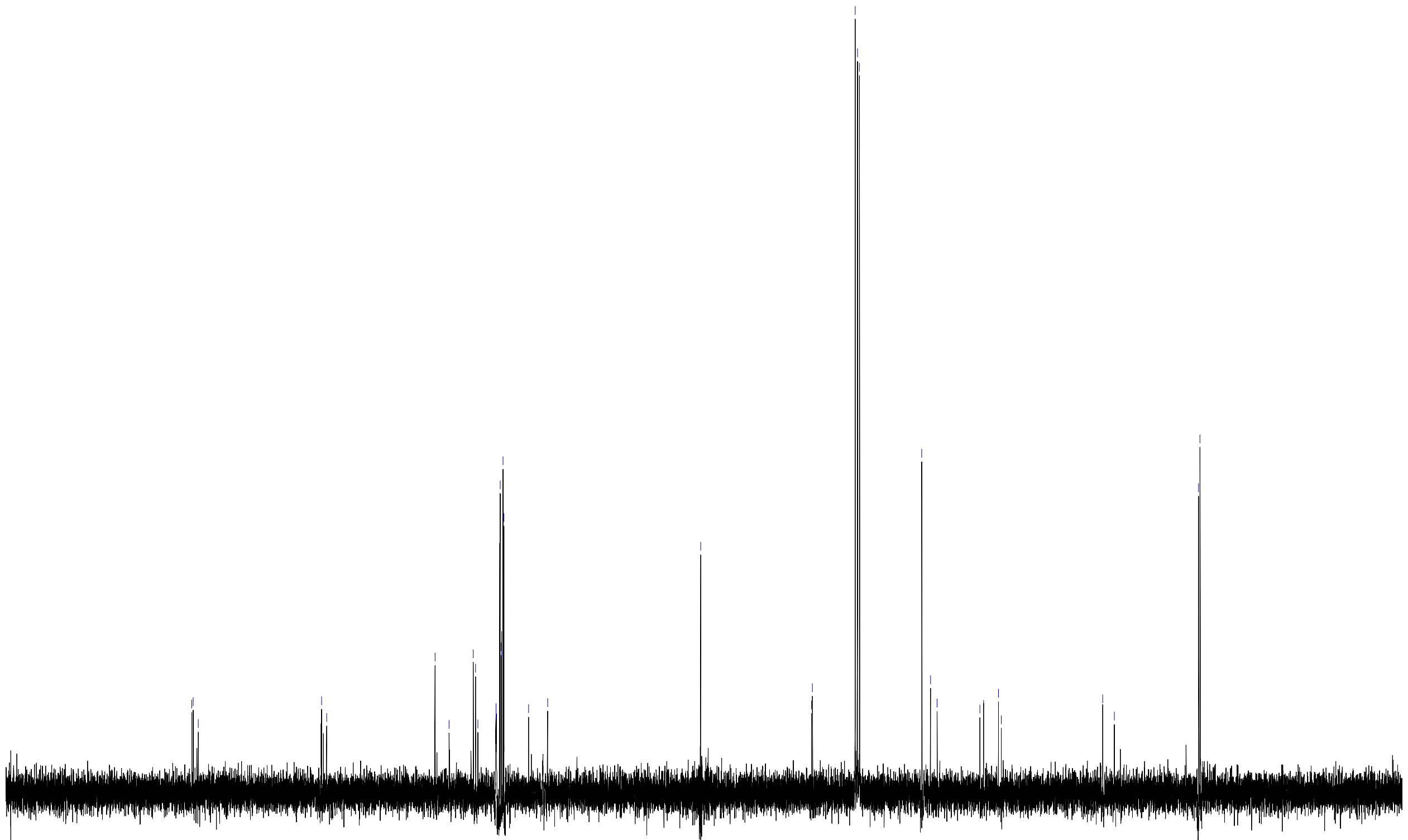


Page 109 of 127

This report was created by ACD/NMR Processor Academic Edition. For more information go to www.acdlabs.com/nmrproc/ 616201.esp

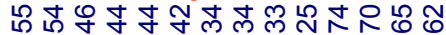

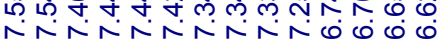

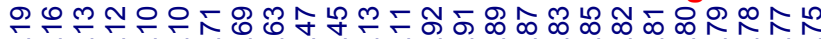

ம்

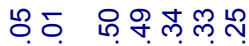

i i

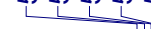

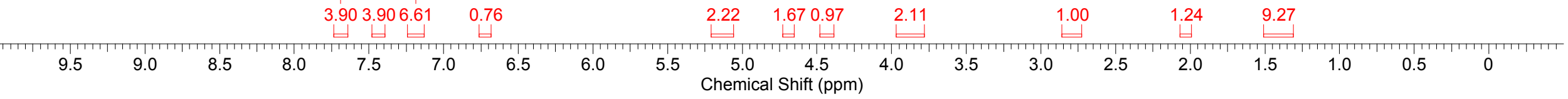


Page 110 of 127

This report was created by ACD/NMR Processor Academic Edition. For more information go to www.acdlabs.com/nmrproc/

616202.esp

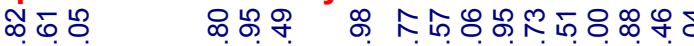

Nivi

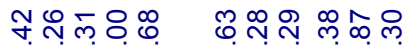

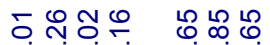

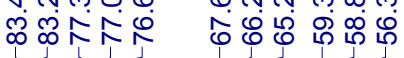

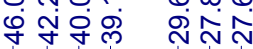

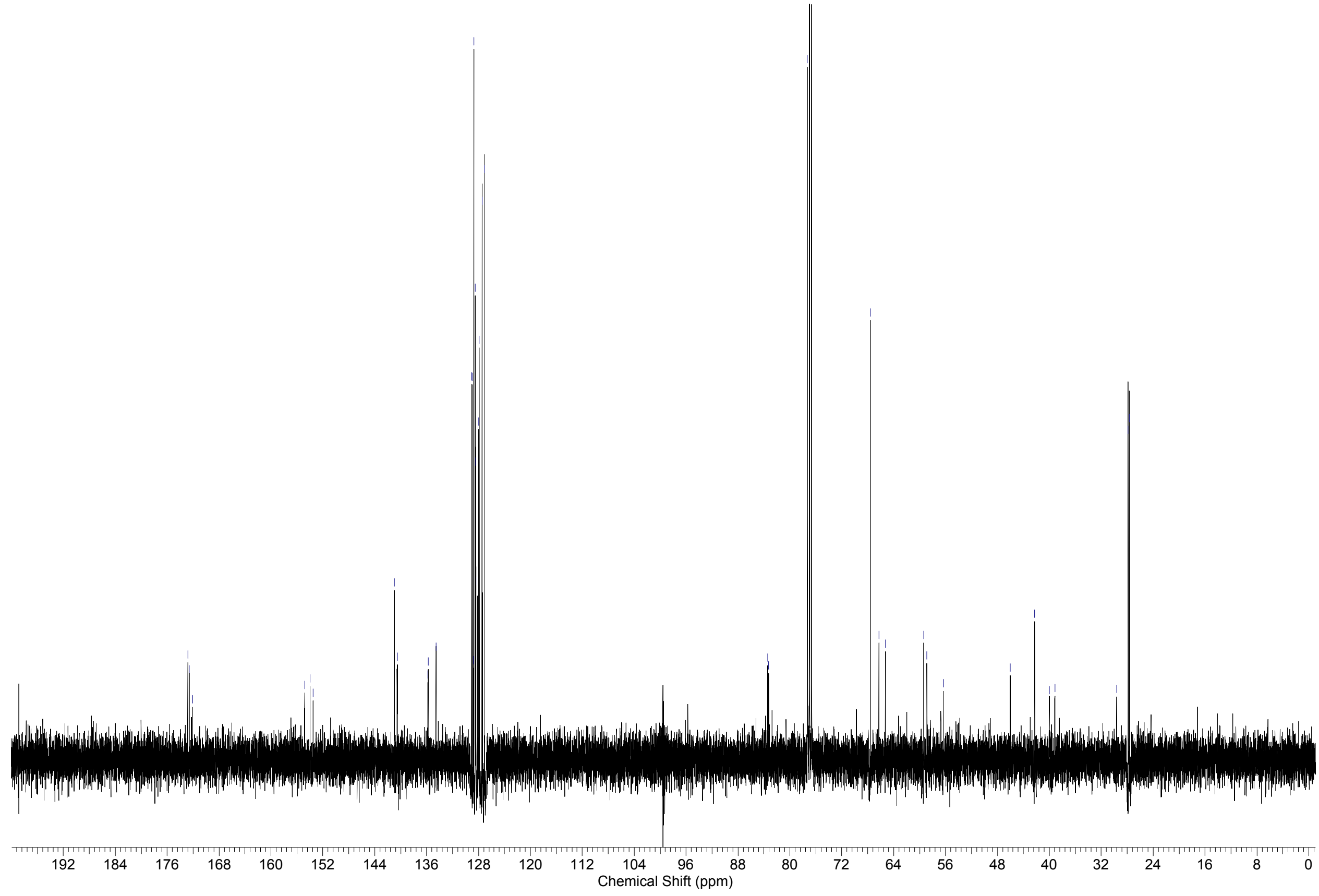


Page 111 of 127

This report was created by ACD/NMR Processor Academic Edition. For more information go to www.acdlabs.com/nmrproc/

703901.esp

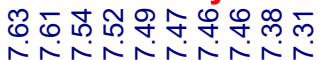

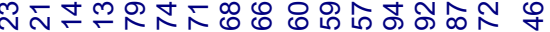

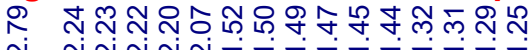

மம

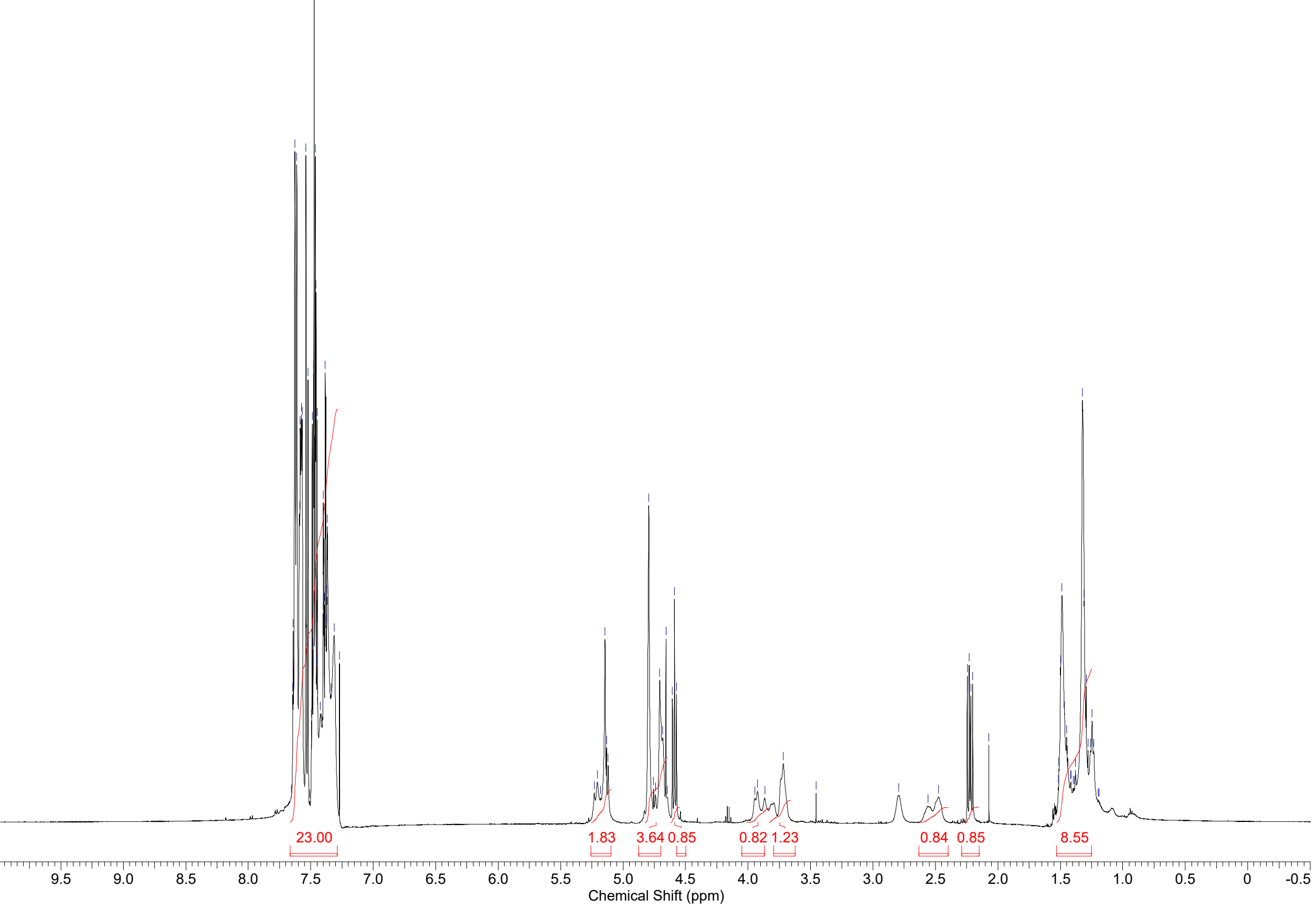


Page 112 of 127

G_039_002.esp

This report was created by ACD/NMR Processor Academic Edition. For more information go to www.acdlabs.com/nmrproc/

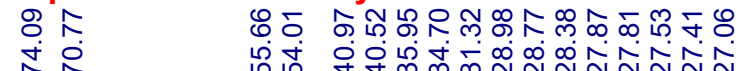

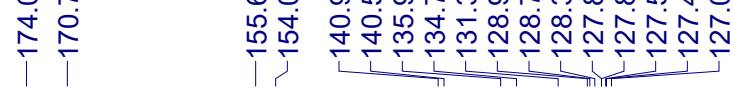

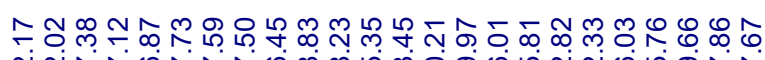

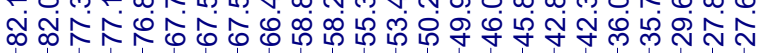

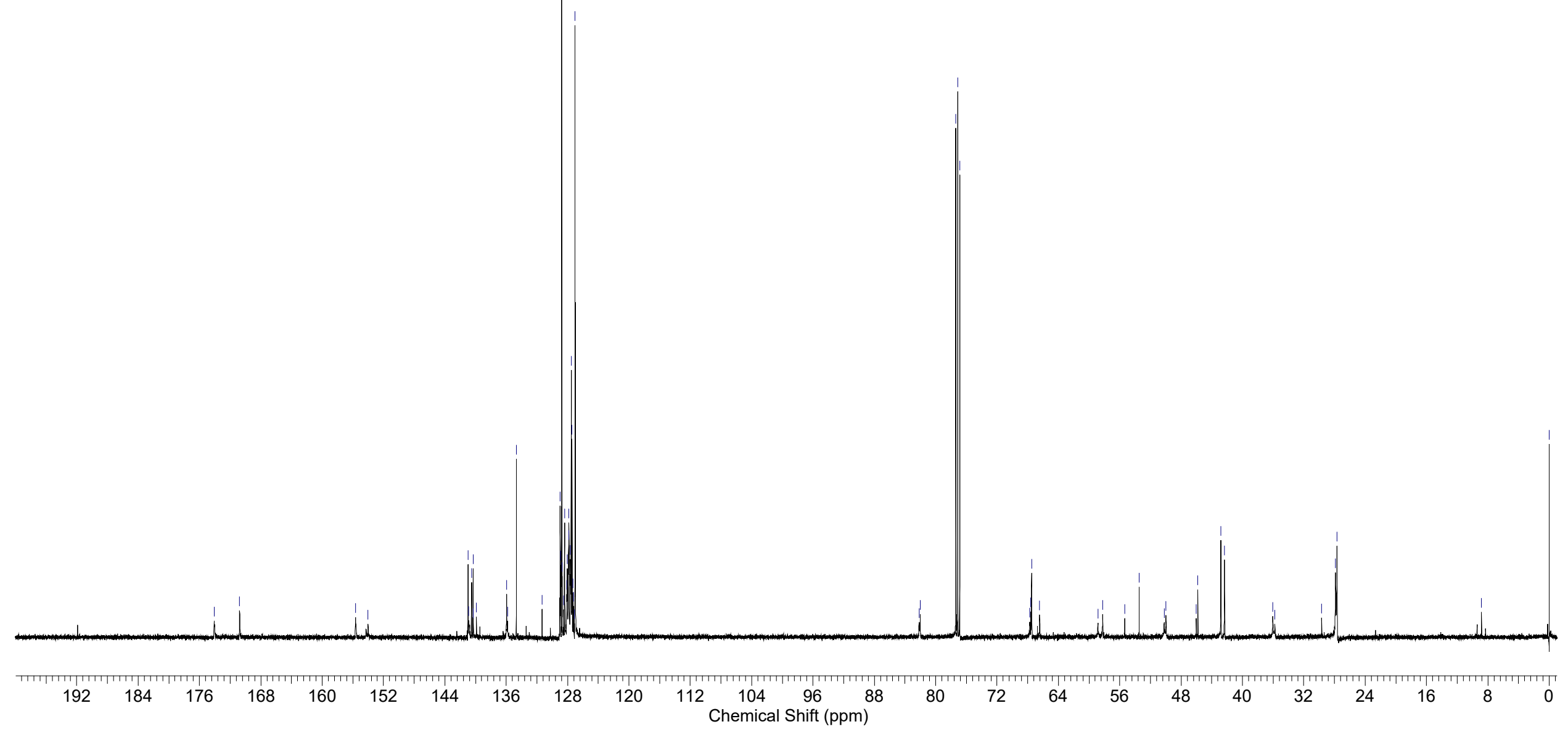


Page 113 of 127

This report was created by ACD/NMR Processor Academic Edition. For more information go to www.acdlabs.com/nmrproc/

612001.esp

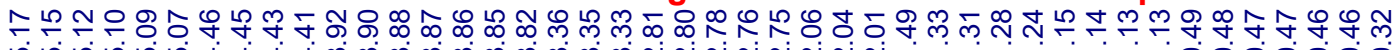

ம

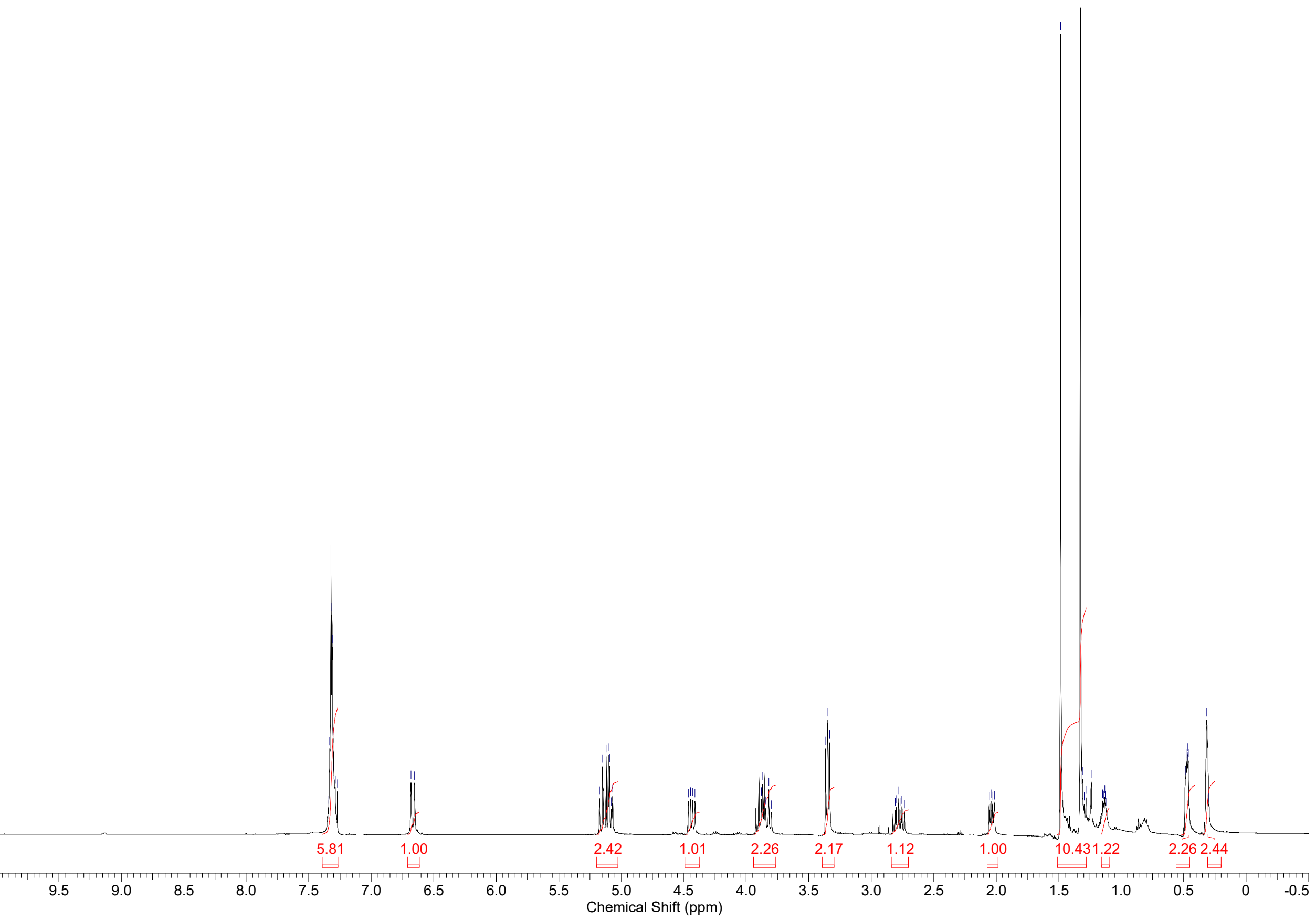


Page 114 of 127

This report was created by ACD/NMR Processor Academic Edition. For more information go to www.acdlabs.com/nmrproc/

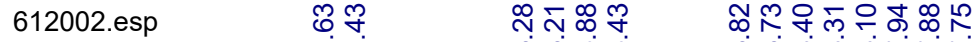

至

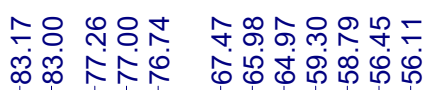

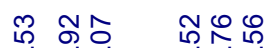

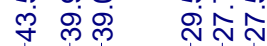

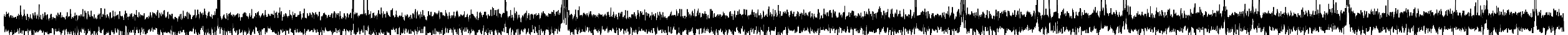

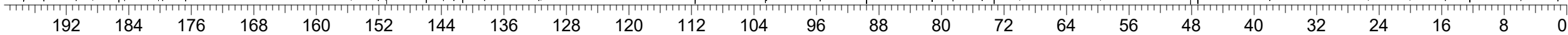

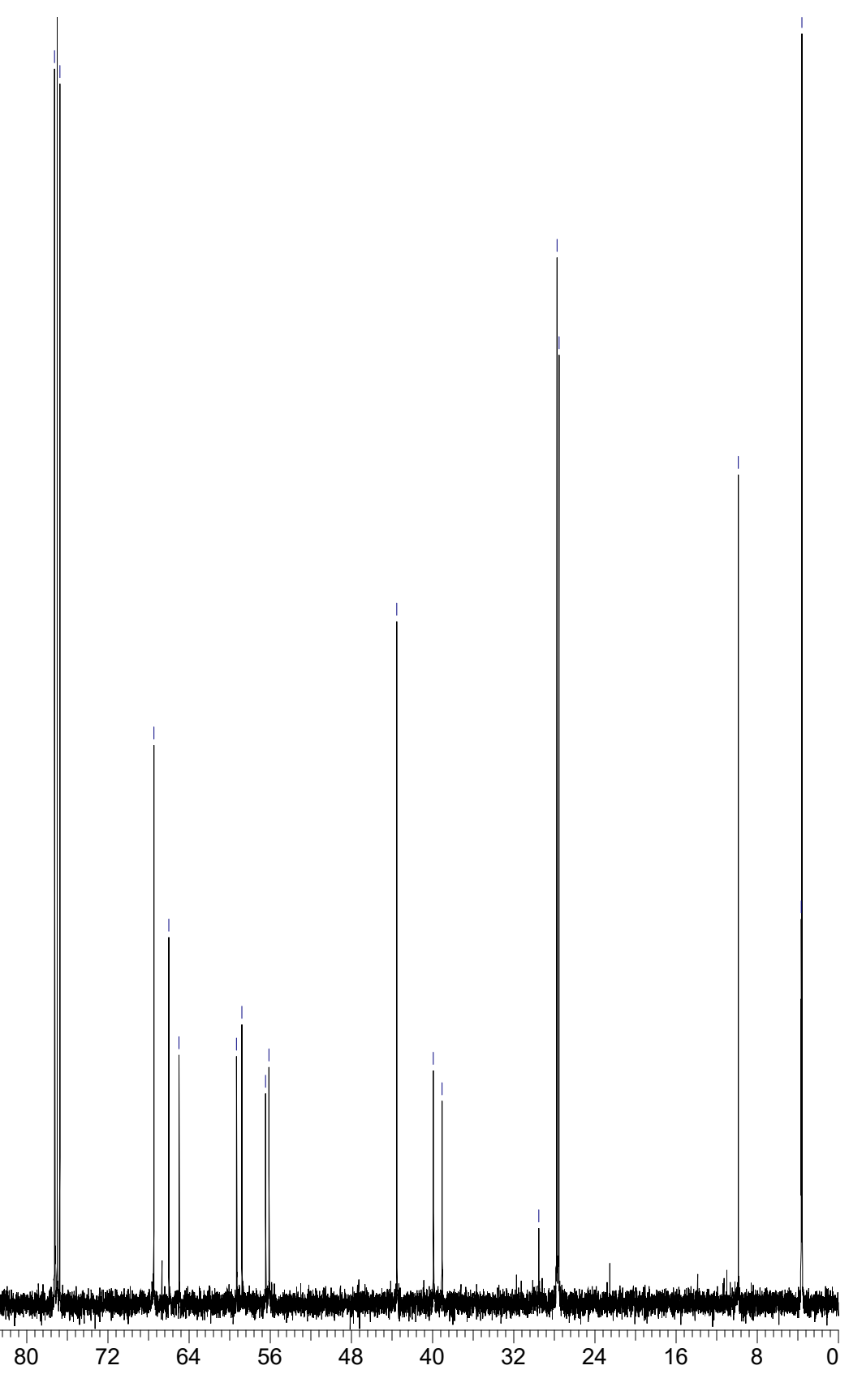


Page 115 of 127

This report was created by ACD/NMR Processor Academic Edition. For more information go to www.acdlabs.com/nmrproc/

612901.esp

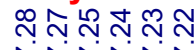

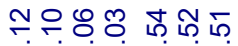

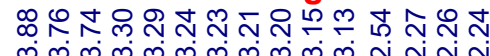

商昂 ம்

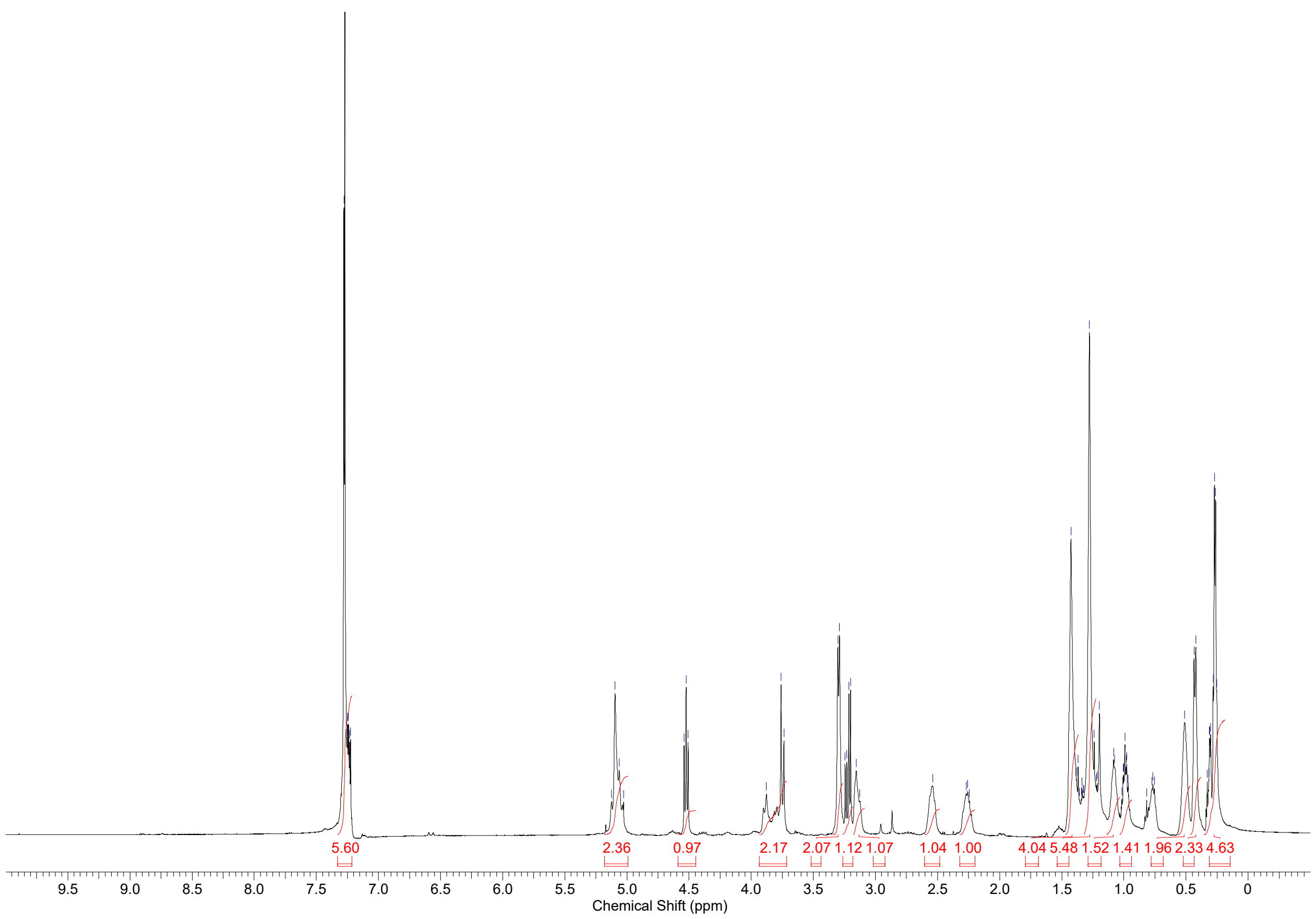


Page 116 of 127

This report was created by ACD/NMR Processor Academic Edition. For more information go to www.acdlabs.com/nmrproc/ 612902.esp

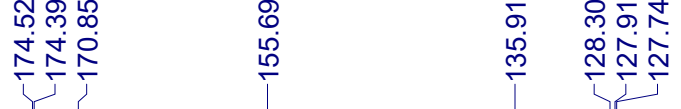

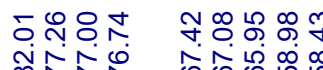

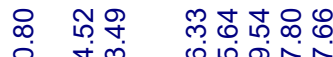

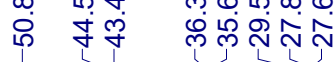

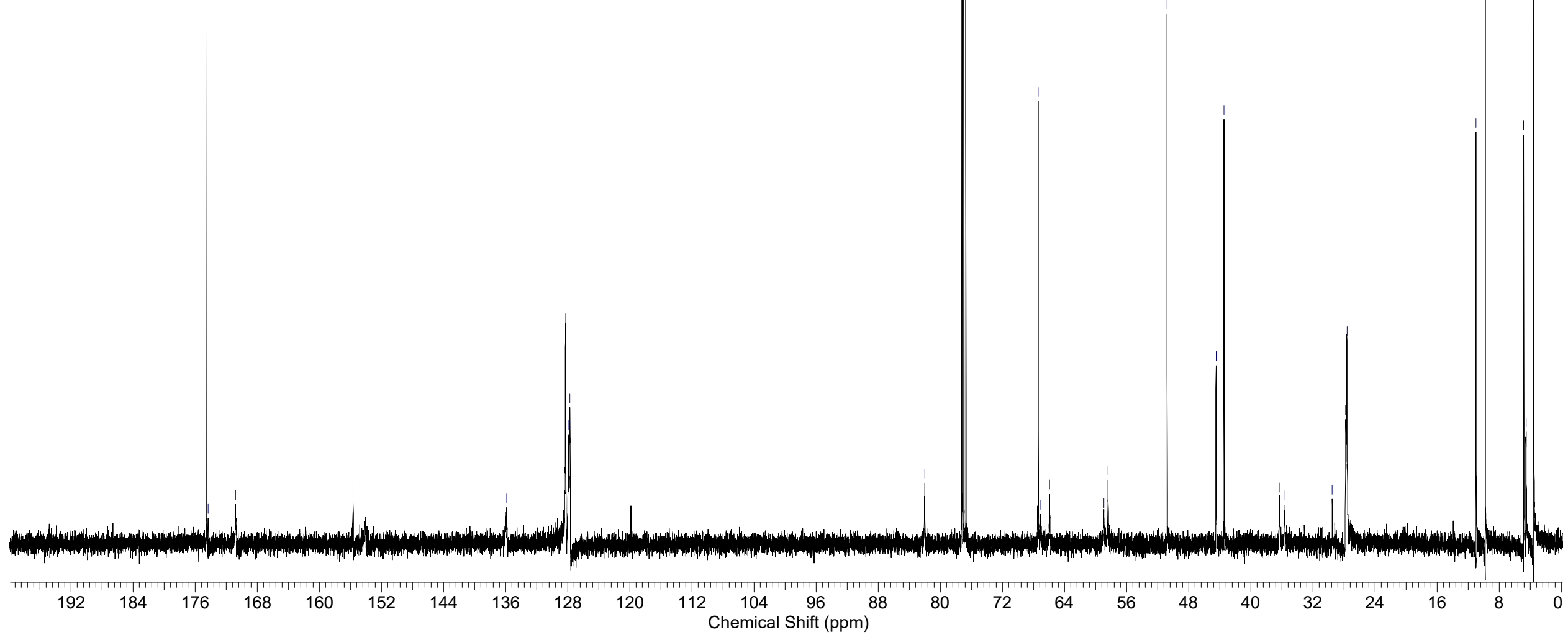


Page 117 of 127

This report was created by ACD/NMR Processor Academic Edition. For more information go to www.acdlabs.com/nmrproc/

612301.esp

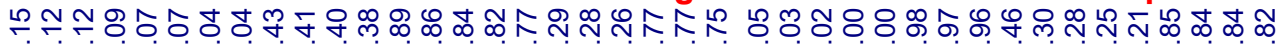

ம்

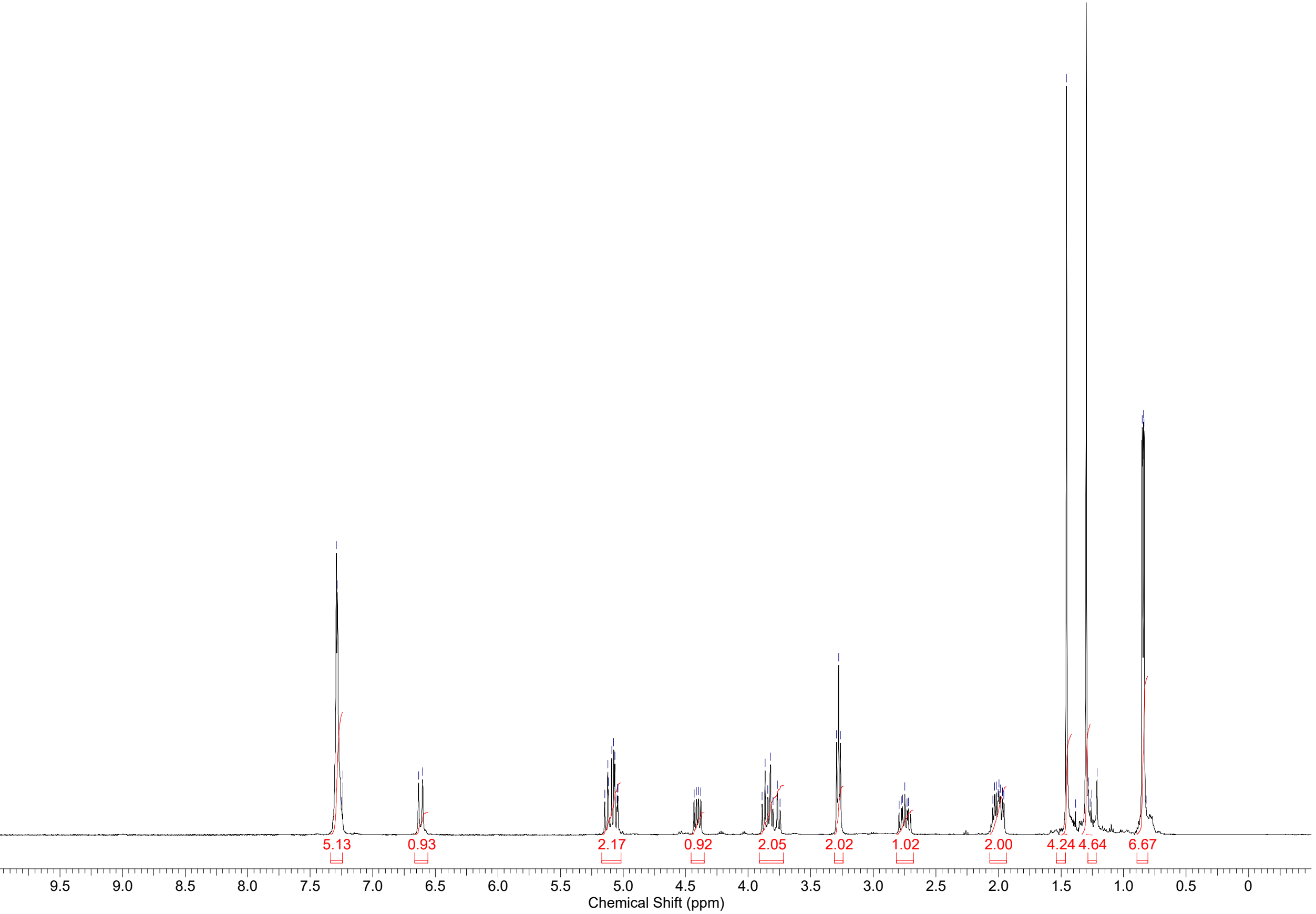


Page 118 of 127

This report was created by ACD/NMR Processor Academic Edition. For more information go to www.acdlabs.com/nmrproc/

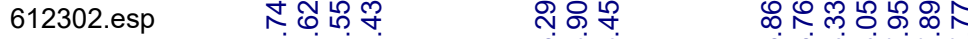

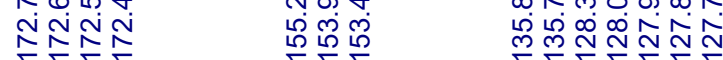

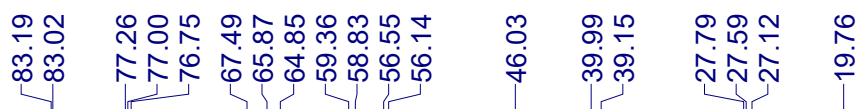

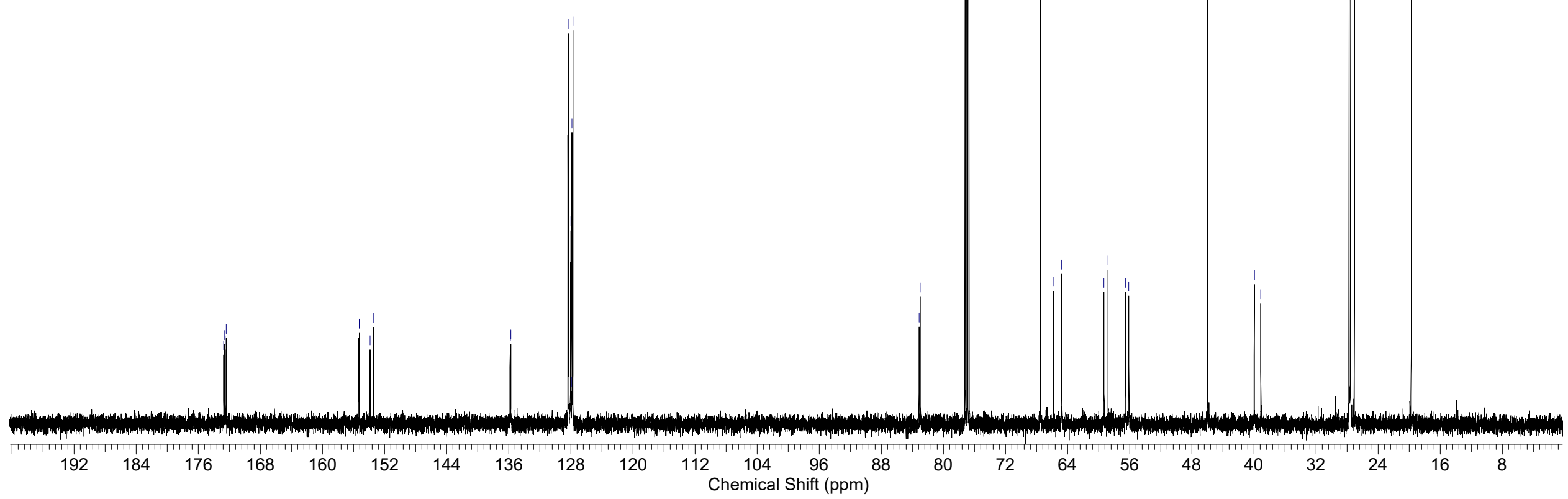


Page 119 of 127

This report was created by ACD/NMR Processor Academic Edition. For more information go to www.acdlabs.com/nmrproc/ 702101.esp 听

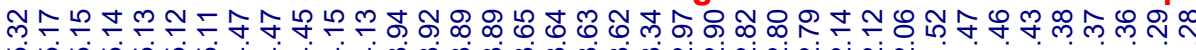

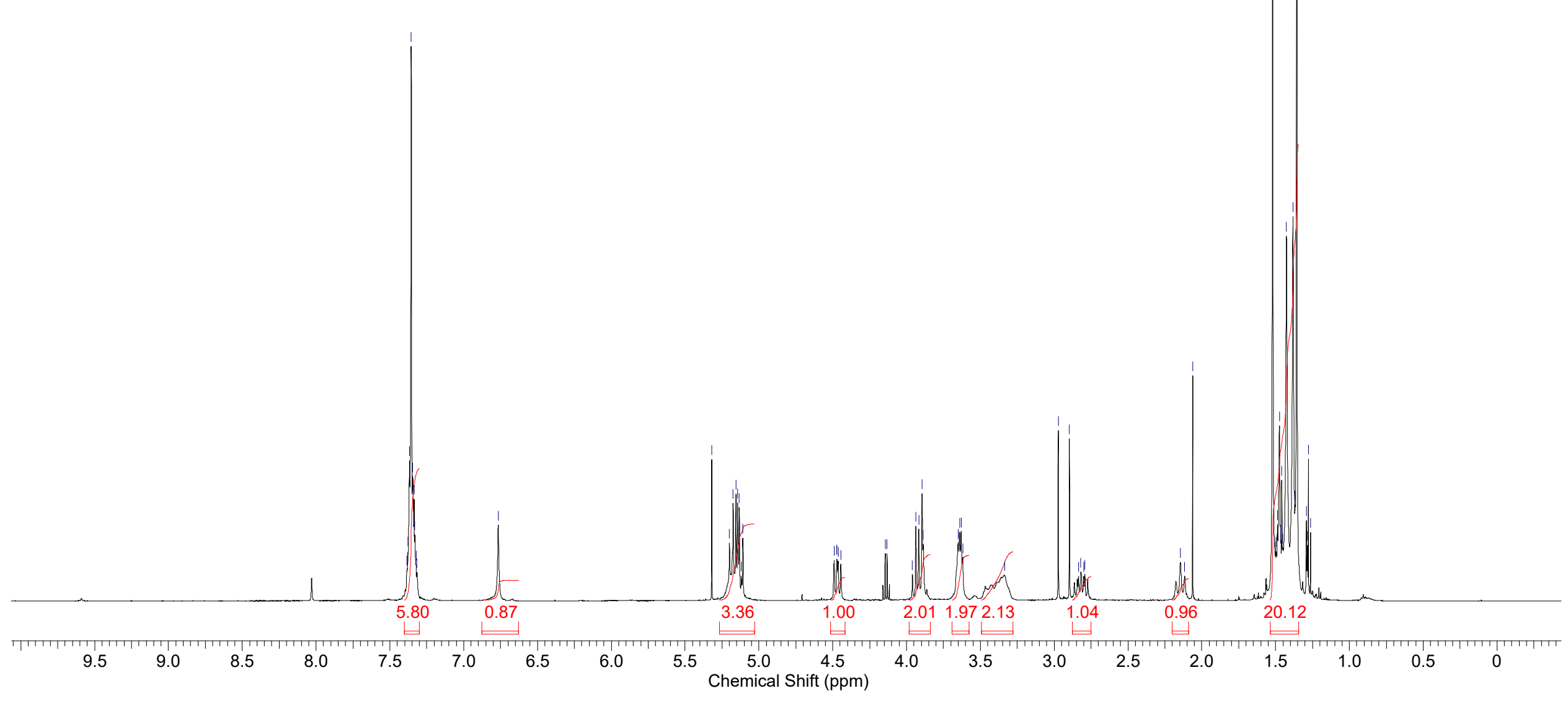


Page 120 of 127

This report was created by ACD/NMR Processor Academic Edition. For more information go to www.acdlabs.com/nmrproc/

702102.esp

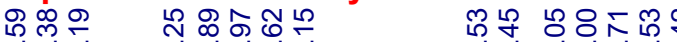

№n

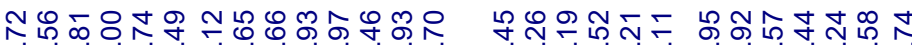

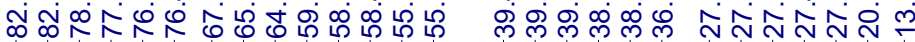

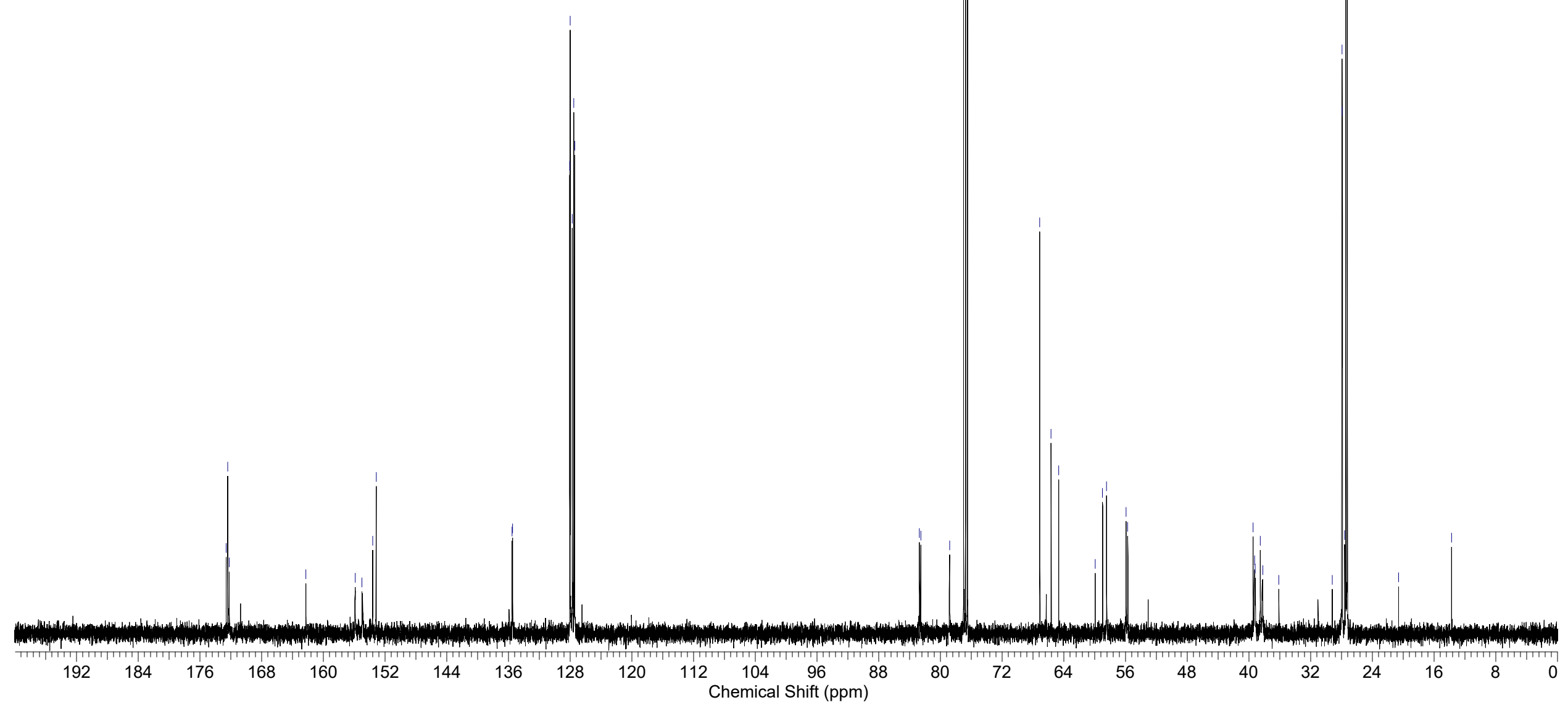



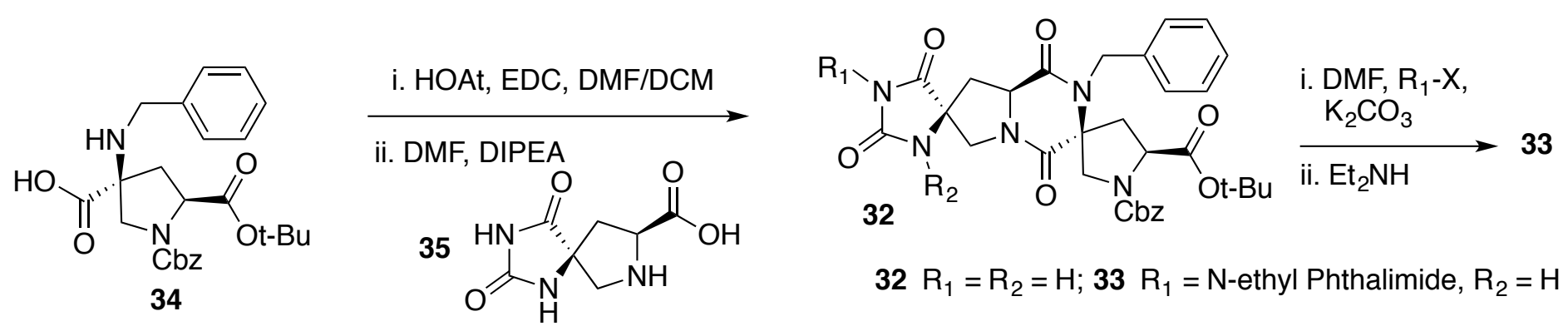

$32 \mathrm{R}_{1}=\mathrm{R}_{2}=\mathrm{H} ; 33 \mathrm{R}_{1}=\mathrm{N}$-ethyl Phthalimide, $\mathrm{R}_{2}=\mathrm{H}$

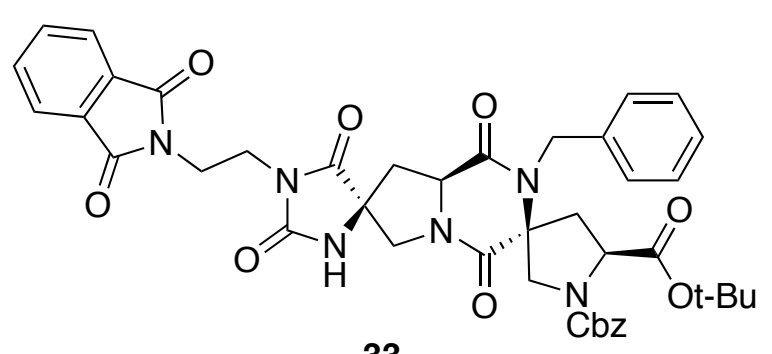


Page 122 of 127
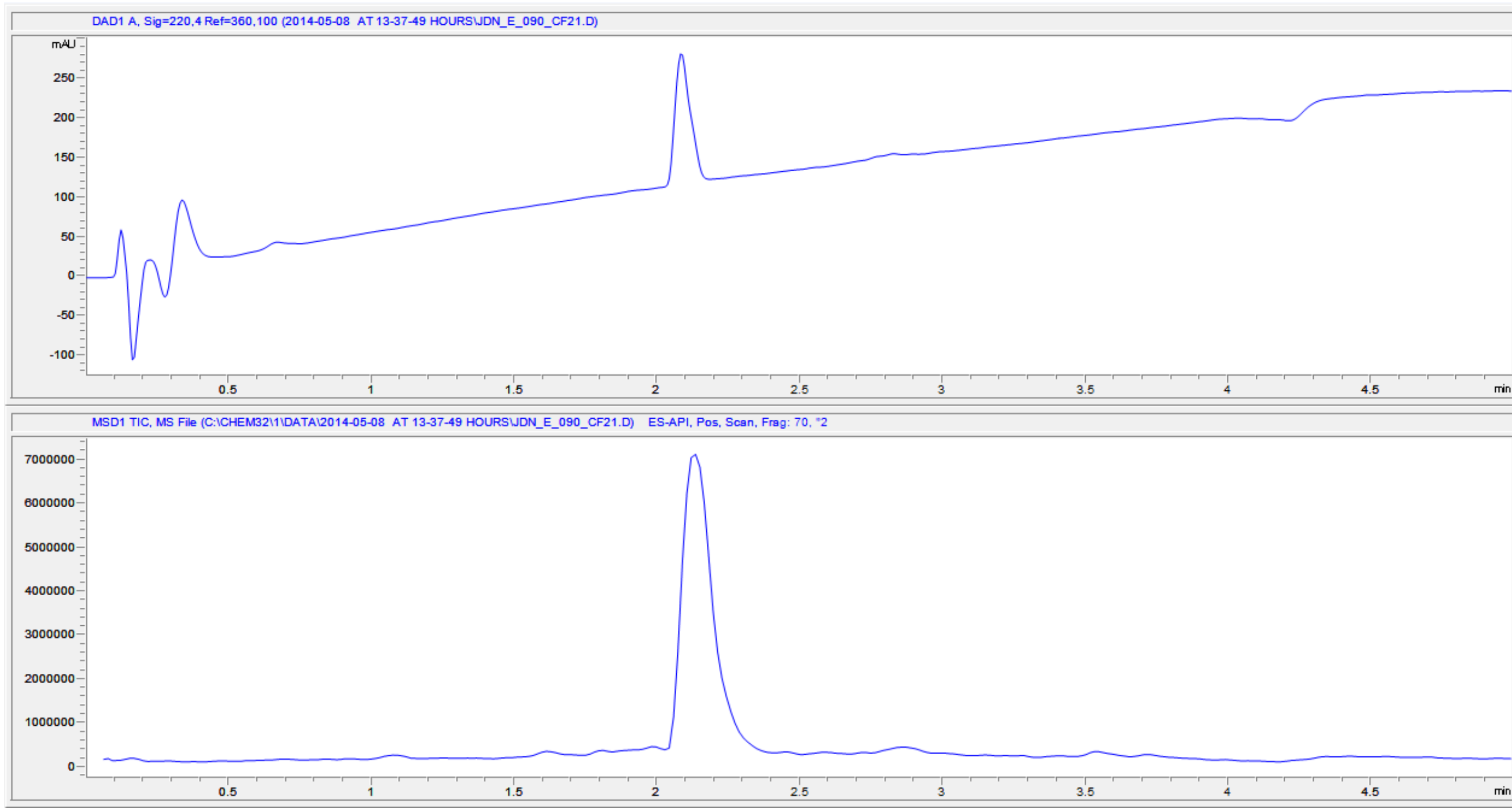
Page 123 of 127

This report was created by ACD/NMR Processor Academic Edition. For more information go to www.acdlabs.com/nmrproc/

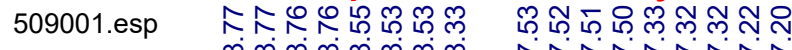

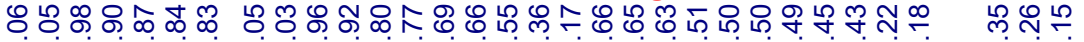

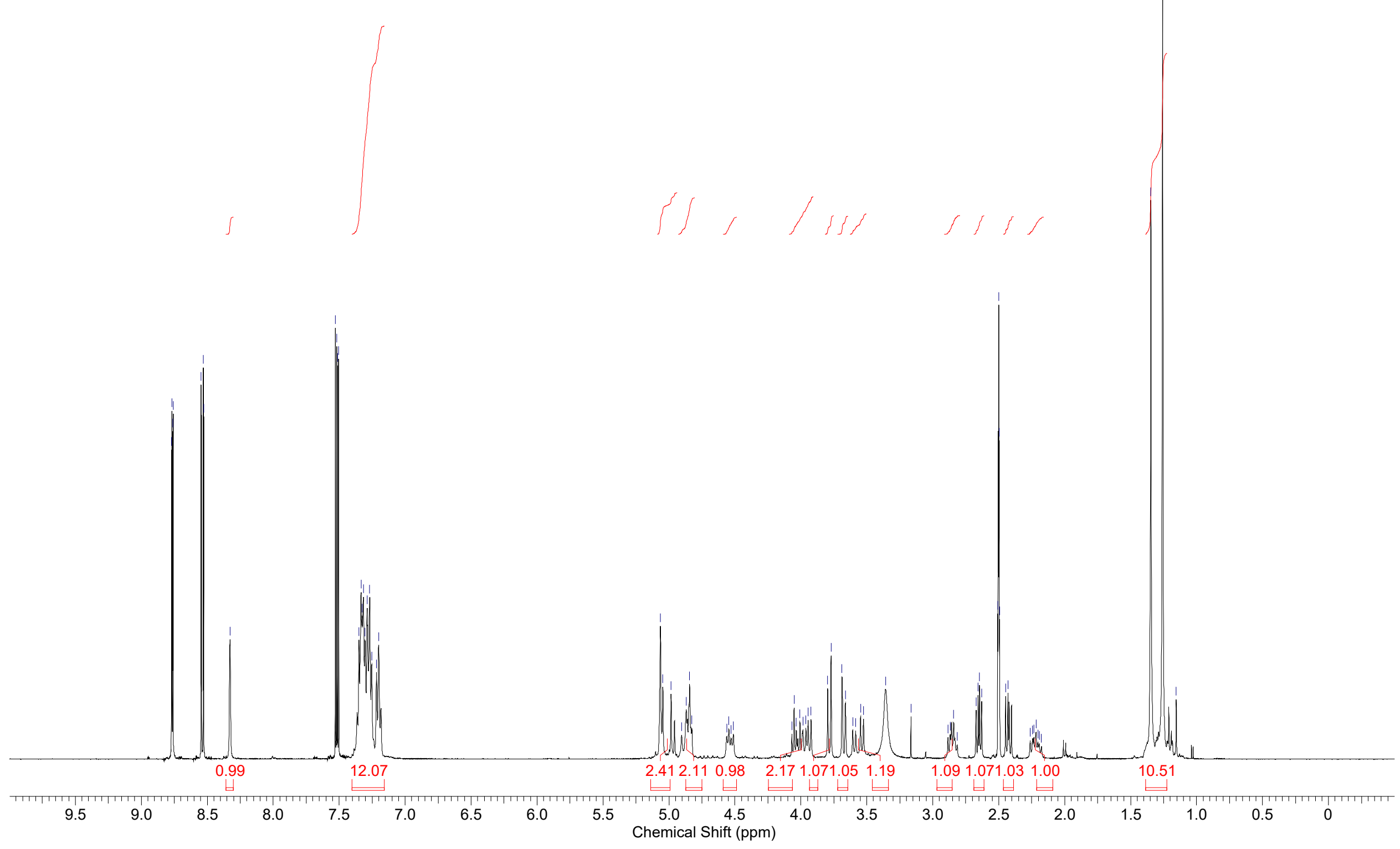


Page 124 of 127

This report was created by ACD/NMR Processor Academic Edition. For more information go to www.acdlabs.com/nmrproc/

E_090_4.esp

$\hat{f}$

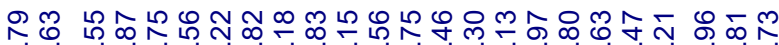
চॅ

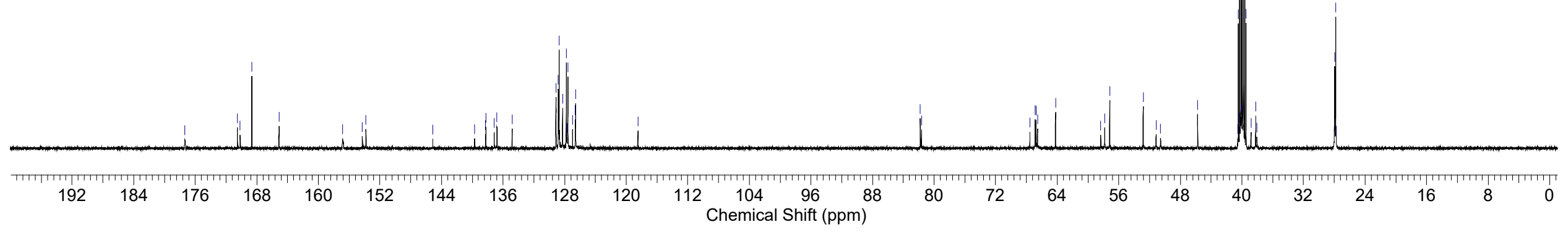


Page 125 of 127

DAD1 A, Sig $=220,4$ Ref $=360,100$ (2014-05-15 AT 12-35-33 HOURSUDN_E_091_P.D)

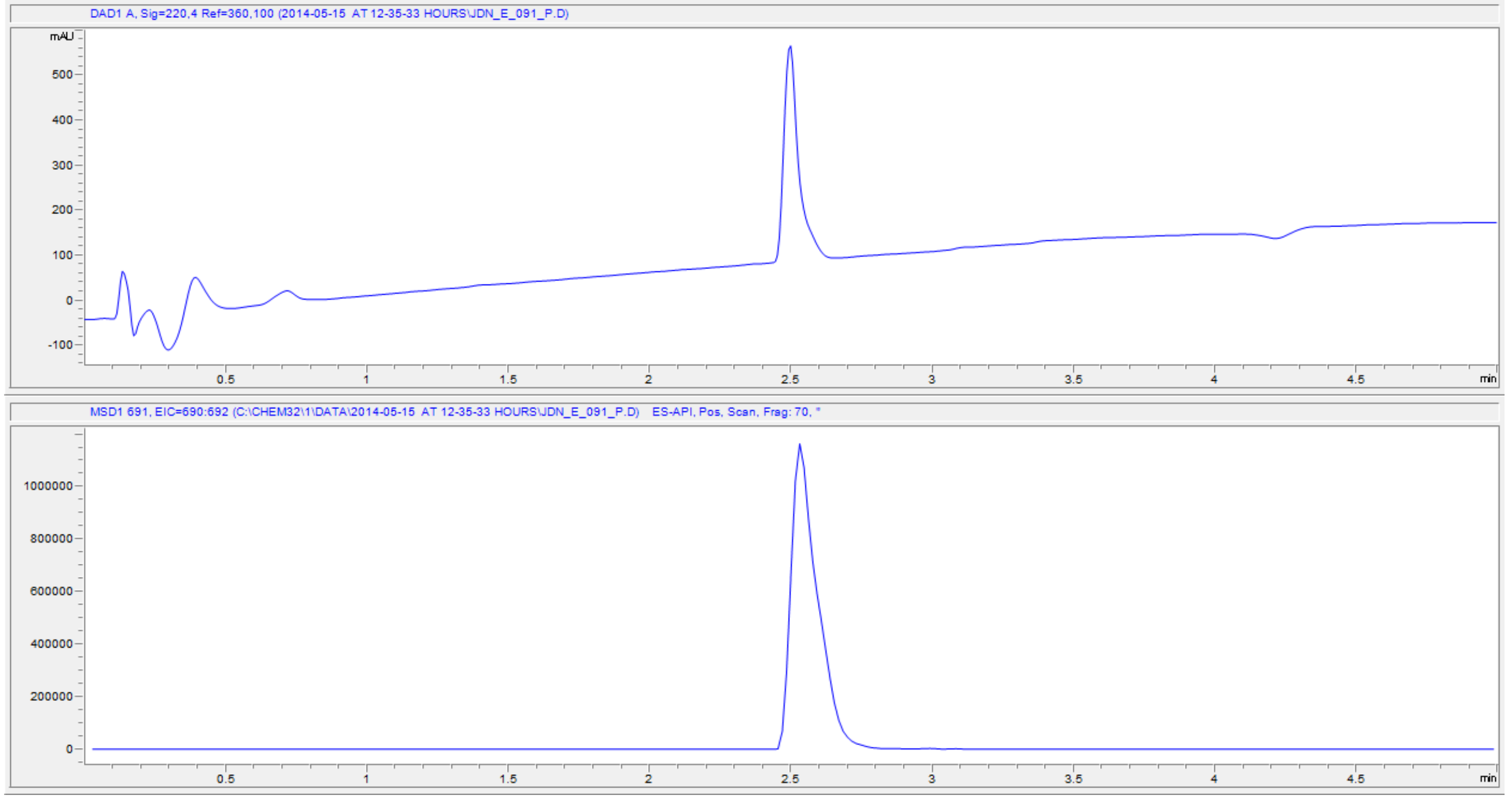


Page 126 of 127

This report was created by ACD/NMR Processor Academic Edition. For more information go to www.acdlabs.com/nmrproc/ 509101.esp

$\stackrel{\infty}{i} \quad \infty \infty \hat{\infty}$

i

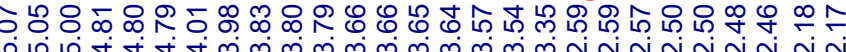

ल्ले స్

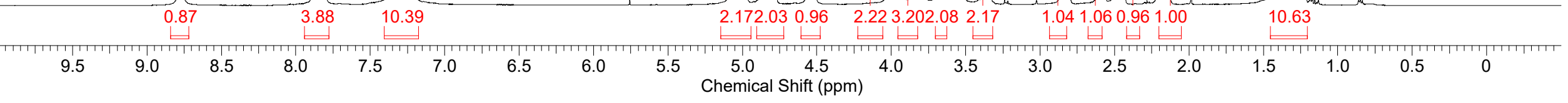


Page 127 of 127

This report was created by ACD/NMR Processor Academic Edition. For more information go to www.acdlabs.com/nmrproc/

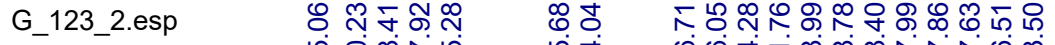

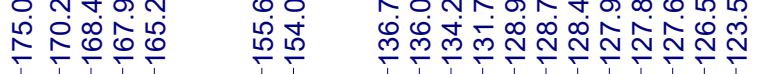

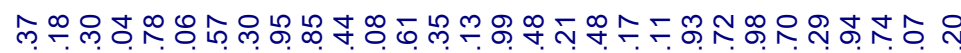

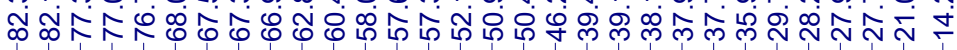

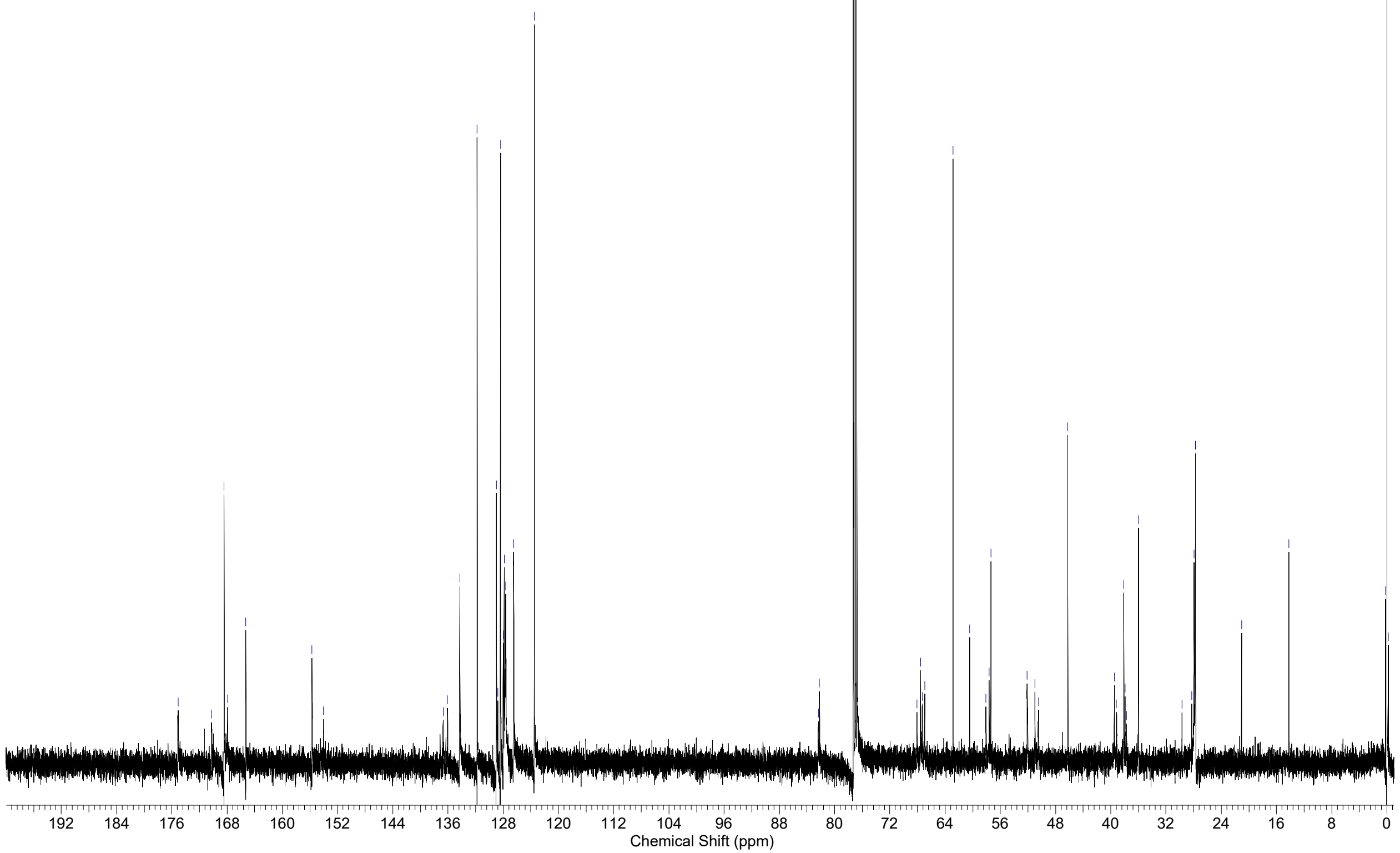

